Aus der Poliklinik für Zahnärztliche Prothetik

(Prof. Dr. med. dent. R. Bürgers)

im Zentrum Zahn-, Mund- und Kieferheilkunde

der Medizinischen Fakultät der Universität Göttingen

\title{
Funktionen von SMURF1 und SMURF2 in der Differenzierung von chondrogenen Progenitorzellen
}

\author{
INAUGURAL - DISSERTATION \\ zur Erlangung des Doktorgrades \\ der Medizinischen Fakultät der \\ Georg-August-Universität zu Göttingen \\ vorgelegt von \\ Manuel Altherr \\ aus Landstuhl
}

Göttingen 2017 
Dekan

Prof. Dr. rer. nat. H. K. Kroemer

Referent:

Prof. Dr. med. N. Miosge

Ko-Referent:

Prof. Dr. mult. T. Meyer

Drittreferent:

Prof. Dr. med. M. Oppermann

Datum der mündlichen Prüfung:

17.07.2018 


\section{Inhaltsverzeichnis}

Abkürzungsverzeichnis

VI

Abbildungsverzeichnis

VIII

Tabellenverzeichnis

IX

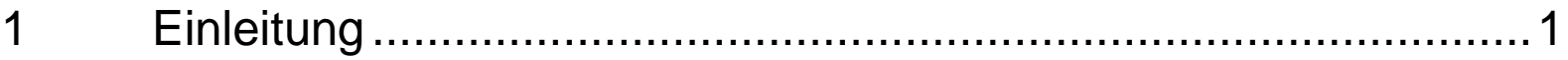

1.1 Aufbau und Funktion des Gelenkknorpels ........................................... 1

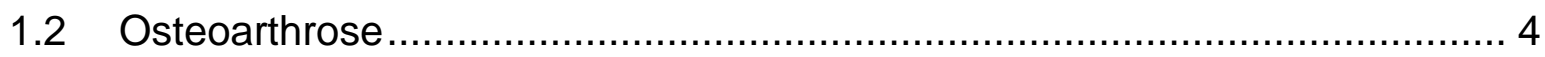

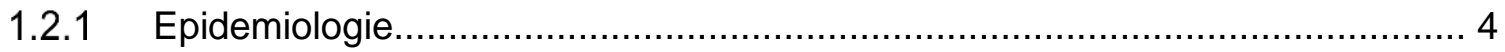

1.2.2 Ätiologie und Pathogenese...................................................................... 5

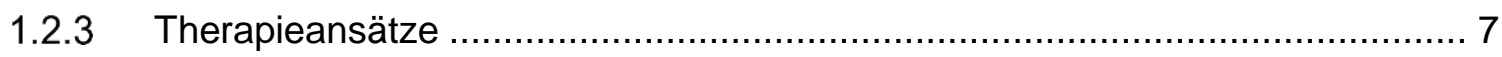

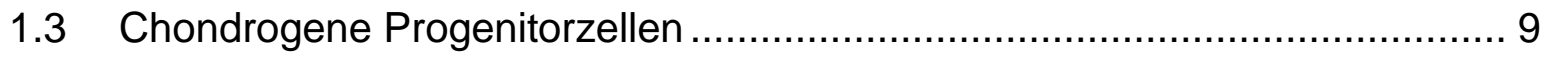

1.3.1 Funktionen von SOX9 und RUNX2 in der Regulation der Chondrogenese......11

1.4 Proteasomaler Abbau durch Ubiquitinierung …..................................... 12

1.5 SMAD-ubiquitination regulatory factor ............................................... 14

1.5.1 SMURF1/2 im BMP- und TGF- $\beta$-Signalweg..............................................15

1.5.2 SMURF1/2 in der Entwicklung der Osteoarthrose ........................................17

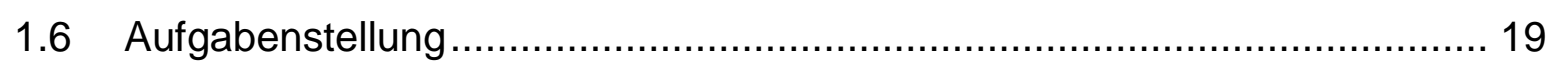

$2 \quad$ Material und Methoden ..................................................20

2.1 Gewebe- und zellbiologische Methoden .............................................. 20

2.1.1 Gewebeisolation und Präparation..............................................................20

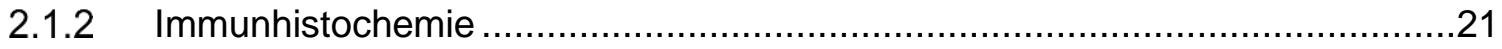

2.1.3 Zellisolierung und -anzucht der chondrogenen Progenitorzellen ....................23

2.1.4 Kultivieren und Passagieren der chondrogenen Progenitorzellen....................23

2.1.5 Immortalisierte chondrogene Progenitorzellen.............................................24 


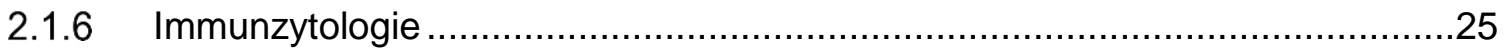

2.2 Quantitative Real-Time Polymerase Chain Reaction............................ 26

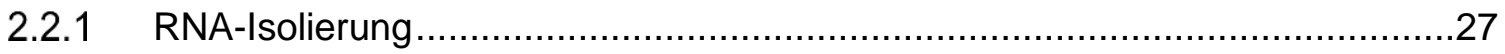

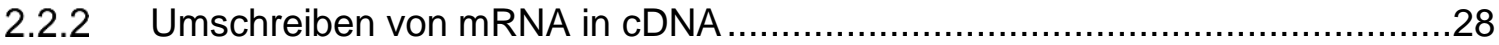

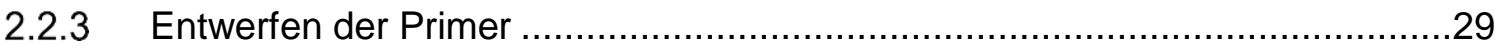

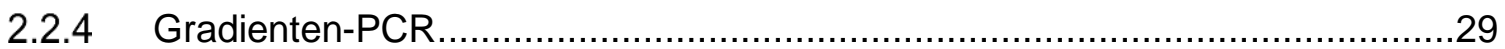

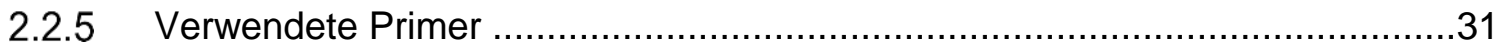

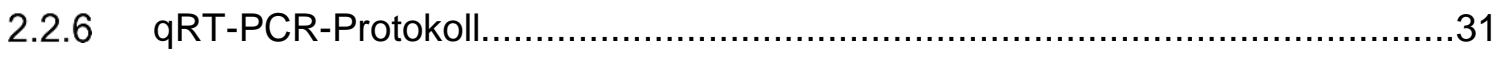

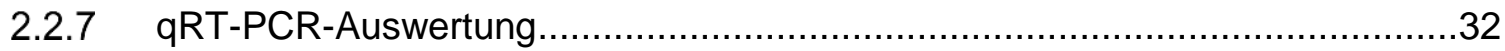

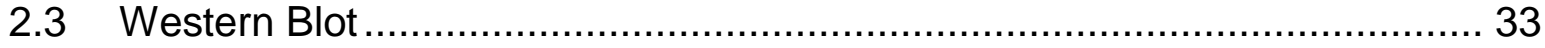

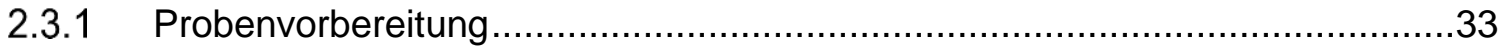

2.3.2 Natriumdodecylsulfat-Polyacrylamid-Gelelektrophorese ...............................34

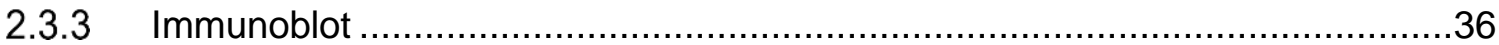

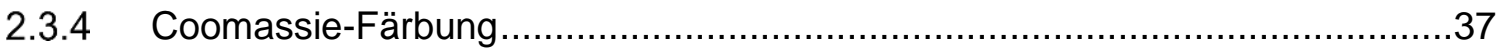

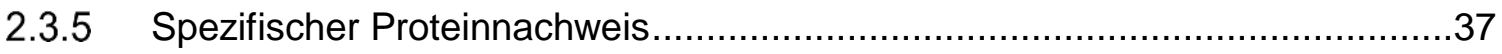

2.3.6 Quantitative Auswertung des Western Blots...............................................

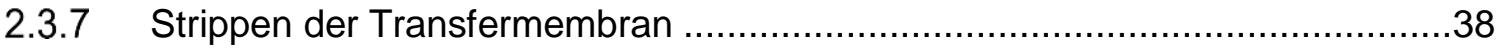

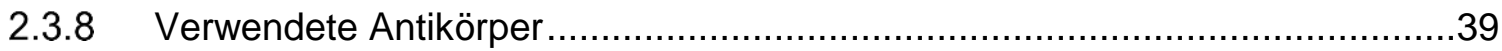

2.4 Transienter Knockdown von SMURF1 und SMURF2 ........................... 40

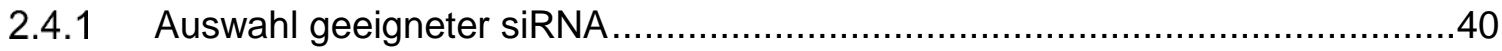

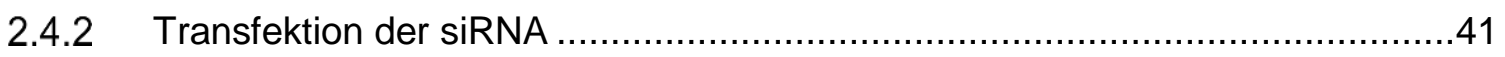

2.5 Überexpression von SMURF1 und SMURF2 ................................. 41

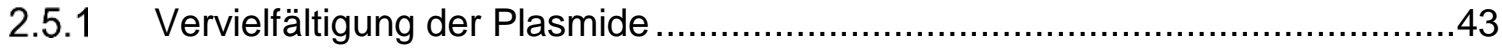

2.5.2 Isolierung der Plasmid-DNA aus DH5a-Escherichia coli ................................43

2.5.3 Restriktionsverdau der klonierten Plasmid-DNA …....................................44

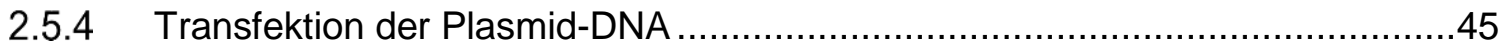




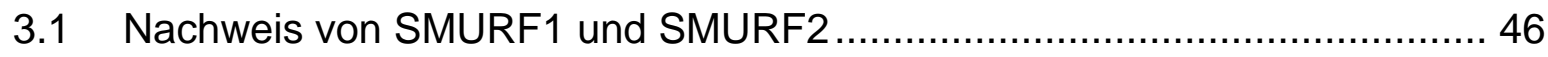

3.1.1 Immunhistologischer Nachweis in Kniegelenkknorpel ...............................46

3.1.2 Immunzytologischer Nachweis in CPCht ..............................................47

3.1.3 Proteinnachweis in CPCht und primären CPCs........................................48

3.2 Nachweis von SOX9, RUNX2, SMAD1 und SMAD2/3 .......................... 49

3.3 Knockdown von SMURF1 und SMURF2 in CPCht............................. 50

3.3.1 Nachweis des Knockdowns im Western Blot .........................................50

3.3.2 Auswirkungen des Knockdowns von SMURF1 .......................................53

3.3.3 Auswirkungen des Knockdowns von SMURF2 ..........................................

3.4 Überexpression von SMURF1 und SMURF2 in CPCht ......................... 56

3.4.1 Nachweis der Überexpression im Western Blot......................................56

3.4.2 Auswirkungen der Überexpression von SMURF1 auf Proteinebene .................59

3.4.3 Auswirkungen der Überexpression von SMURF2 auf Proteinebene ................61

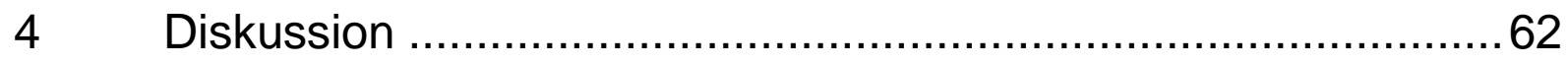

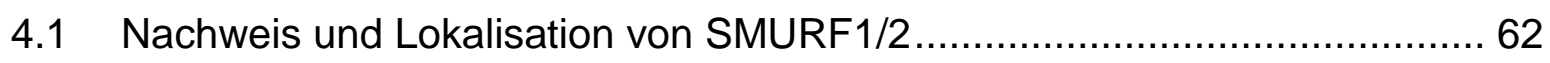

4.2 Auswirkungen des Knockdowns und der Überexpression von SMURF1 auf

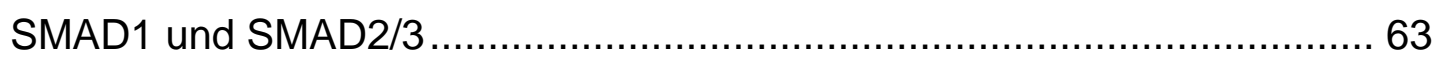

4.3 Auswirkungen des Knockdowns und der Überexpression von SMURF1 auf

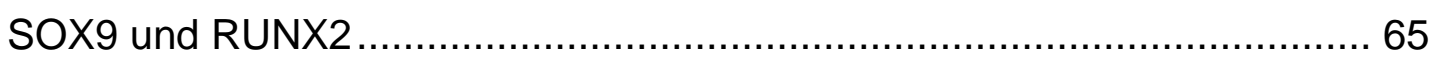

4.4 Auswirkungen des Knockdowns und der Überexpression von SMURF2 auf SOX9 und RUNX2.

4.5 SMURF1 und SMURF2 in der Differenzierung von CPCs ....................... 69

4.6 Funktionen von SMURF1 und SMURF2 in OA ................................ 71

$5 \quad$ Zusammenfassung......................................................... 74

$6 \quad$ Literaturverzeichnis ........................................................ 76 


\section{Abkürzungsverzeichnis}

$\begin{array}{ll}\text { AOT } & \text { autologe osteochondrale Transplantation } \\ \text { APS } & \text { Ammoniumperoxodisulfat } \\ \text { ATP } & \text { Adenosintriphosphat } \\ \text { BMPs } & \text { Bone morphogenetic proteins } \\ \text { BSA } & \text { bovines Serumalbumin } \\ \text { B2M } & \text { B2-Mikroglobulin } \\ \text { CDNA } & \text { complementary deoxyribonucleic acid } \\ \text { Co-SMADs } & \text { common-mediator-SMADs } \\ \text { CPCht } & \text { immortalisierte chondrogene Progenitorzellen } \\ \text { CPCht+SMURF1 } & \text { CPCht nach Plasmid-Überexpression von SMURF1 } \\ \text { CPCht+SMURF2 } & \text { CPCht nach Plasmid-Überexpression von SMURF2 } \\ \text { CPCht-SMURF1 } & \text { CPCht nach siRNA-Knockdown von SMURF1 } \\ \text { CPCht-SMURF2 } & \text { CPCht nach siRNA-Knockdown von SMURF2 } \\ \text { CPCs } & \text { chondrogene Progenitorzellen } \\ \text { Ct } & \text { cycle threshold } \\ \text { DAPI } & 4 \text { ',6-Diamidin-2-phenylindol } \\ \text { DG } & \text { Deckgläschen } \\ \text { DMEM } & \text { Dubecco's Modified Eagle's Medium } \\ \text { DNA } & \text { deoxyribonucleic acid } \\ \text { E. coli } & \text { Escherichia coli } \\ \text { E1 } & \text { spezifisch aktivierendes Enzym } \\ \text { E2 } & \text { Ubiquitin-Transport-Protein } \\ \text { E3 } & \text { Ubiquitin-Protein-Ligase } \\ \text { FCS } & \text { fetales Kälberserum } \\ \text { HECT } & \text { homologous to the E6-AP carboxyl terminus } \\ \text { HMG } & \text { high-mobility-group } \\ \text { hTERT } & \text { mothan telomerase reverse transcriptase } \\ \text { IL } & \text { matrixgekoppelte autologe Chondrozytentransplantation } \\ \text { I-SMADs } & \\ \text { MACT } & \text { mogainst decapentaplegic homology } \\ \text { MAD } & \text { MH }\end{array}$


$\mathrm{MHC}$

MMP

MPCs

mRNA

MSCs

$\mathrm{OA}$

PBS

PPXY

p-SMAD

qRT-PCR

RING

RISC

RNA

R-SMADs

RUNX2

SDS

SDS-PAGE

SiRNA

SMAD

SMURF

SOX9

Taq-Polymerase

TBS-T

TEMED

TGF

TNF

TRIS

UPS major histocompatibility complex

Matrix-Metalloproteasen

Meniskus-Progenitorzellen

messenger ribonucleic acid

mesenchymale Stammzellen

Osteoarthrose

Phosphate-buffered saline

proline-proline-x-tyrosine

phosphorylated mother against decapentaplegic homolog

quantitative real-time polymerase chain reaction

really interesting new gene

ribonucleic acid-induced silencing complex

ribonucleic acid

receptor-regulated-SMADs

run-related transcription factor 2

Natriumdodecylsulfat-Polyacrylamid

Natriumdodecylsulfat-Polyacrylamid-Gelelektrophorese

small-interfering ribonucleic acid

mother against decapentaplegic homolog

mother against decapentaplegic homolog ubiquitination regulatory factor

sex determining region $Y$ - (SRY-) box 9

thermostabile DNA-Polymerase des Bakteriums Thermus aquaticus

Tris(hydroxymethyl)-aminomethan-buffered saline with Tween20

Tetramethylethylendiamin

transforming growth factor

Tumornekrosefaktor

Tris(hydroxymethyl)-aminomethan

Ubiquitin-Proteasom-System 


\section{Abbildungsverzeichnis}

Abbildung 1.1: Schichtaufbau gesunden Gelenkknorpels .................................... 2

Abbildung 1.2: Morphologie einer fortgeschrittenen OA ....................................... 7

Abbildung 1.3: Chondrogene Progenitorzellen migrieren ................................... 10

Abbildung 1.4: Ubiquitinierung zum proteasomalen Abbau von Proteinen .............. 13

Abbildung 1.5: Struktur von SMADs und SMURF1/2 ...................................... 17

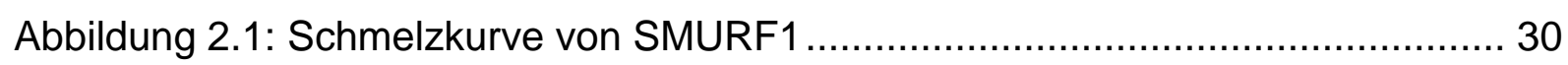

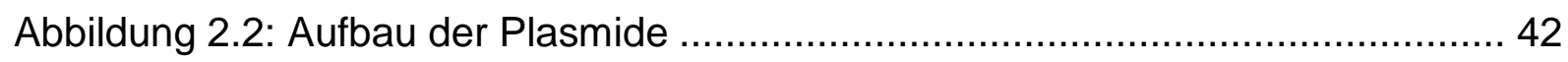

Abbildung 2.3: Gelelektrophorese-Agarose-Gel ............................................... 44

Abbildung 3.1: Immunhistologischer Nachweis von SMURF1 sowie SMURF2 ........ 46

Abbildung 3.2: Immunzytologischer Nachweis von SMURF1/2 in CPCht................ 47

Abbildung 3.3: Immunzytologie - Kontrolle ..................................................... 48

Abbildung 3.4: Nachweis von SMURF1/2 in CPCht und primären CPCs ................ 49

Abbildung 3.5: Nachweis von SOX9, RUNX2, SMAD1 sowie SMAD2/3 …............. 49

Abbildung 3.6: Nachweis des Knockdowns von SMURF1 in CPCht ...................... 51

Abbildung 3.7: Nachweis des Knockdowns von SMURF2 in CPCht ...................... 52

Abbildung 3.8: Auswirkungen des Knockdowns von SMURF1 auf SOX9, RUNX2,

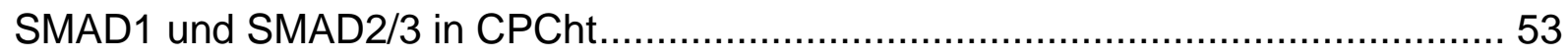

Abbildung 3.9: Auswirkungen des Knockdowns von SMURF1 auf SOX9, RUNX2, SMAD1 und SMAD2/3 in CPCht; statistische Auswertung ................................... 54 Abbildung 3.10: Auswirkungen des Knockdowns von SMURF2 auf SOX9 und RUNX2

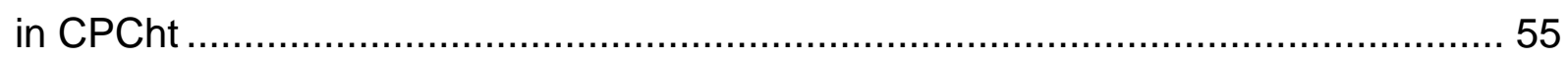

Abbildung 3.11: Nachweis der Überexpression von SMURF1 in CPCht ................. 57

Abbildung 3.12: Nachweis der Überexpression von SMURF2 in CPCht ................. 58

Abbildung 3.13: Auswirkungen der Überexpression von SMURF1 auf SOX9, RUNX2,

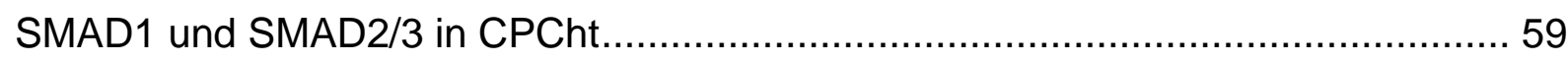

Abbildung 3.14: Auswirkungen der Überexpression von SMURF1 auf SOX9, RUNX2, SMAD1 und SMAD2/3 in CPCht; statistische Auswertung …................................. 60

Abbildung 3.15: Auswirkungen der Überexpression von SMURF2 auf SOX9 und

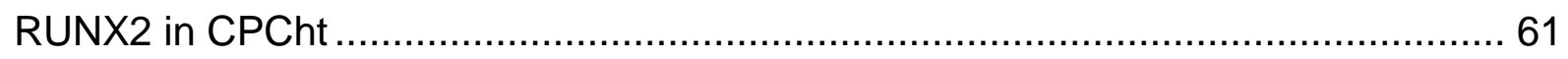




\section{Tabellenverzeichnis}

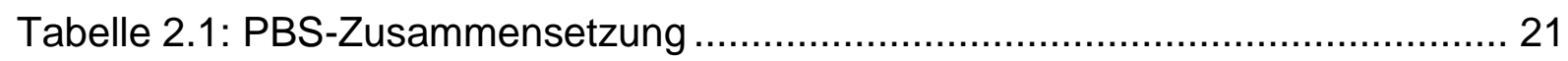

Tabelle 2.2: primären Antikörper zur immunhistologischen Untersuchung .............. 21

Tabelle 2.3: Protokoll des immunhistochemischen Nachweises von SMURF1/2 ..... 22

Tabelle 2.4: DMEM+/+-Zusammensetzung ...................................................... 23

Tabelle 2.5: Antikörper zur immunzytologischen Untersuchung ............................. 26

Tabelle 2.6: Pipettierschema der Gradienten-PCR ............................................ 30

Tabelle 2.7: Protokoll der Gradienten-PCR ..................................................... 31

Tabelle 2.8: Die verwendeten Primer ............................................................. 31

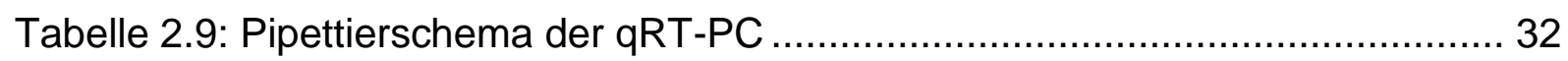

Tabelle 2.10: qRT-PCR-Protokoll - Konfiguration Thermocycler ............................. 32

Tabelle 2.11: Zusammensetzung der Probenpuffer................................................ 33

Tabelle 2.12: Sammelgel, Trenngel und Puffer - Zusammensetzung ....................... 34

Tabelle 2.13: SDS-Laufpuffer 5x - Zusammensetzung ........................................ 35

Tabelle 2.14: Transferpuffer - Zusammensetzung ............................................... 36

Tabelle 2.15: Färbelösung, Entfärbelösung, TBS-T - Zusammensetzung ……….... 37

Tabelle 2.16: Stripping-Puffer - Zusammensetzung ............................................... 39

Tabelle 2.17: Liste der verwendeten Antikörper im Western Blot ............................ 39

Tabelle 2.18: Verwendete siRNA ................................................................. 41 


\section{Einleitung}

\subsection{Aufbau und Funktion des Gelenkknorpels}

Gelenkknorpel wird von hyalinem Knorpel gebildet, der knöcherne, artikulierende Gelenkflächen überzieht und somit die Reibflächen aller Diarthrosen im menschlichen Körper bildet. Durch seine Oberflächenbeschaffenheit besitzt er einen geringen Reibungskoeffizienten, wodurch die Reibungskräfte zwischen den artikulierenden Gelenkflächen minimiert werden (McMahon et al. 2008). Synovia, die sich intrakapsulär im Gelenkspalt befindet, versorgt gemeinsam mit Gefäßen im subchondralen Knochengewebe den bradytrophen Gelenkknorpel mittels Diffusion (Houard et al. 2013) und sorgt ebenfalls für eine Verringerung der Reibungskräfte zwischen den artikulierenden Gelenkflächen (Huber et al. 2000). Zudem kann Gelenkknorpel Druckkräfte über seine Reibfläche aufnehmen und damit eine zeitlich verzögerte Kraftweiterleitung realisieren, wodurch eine räumliche Verteilung der wirkenden Kräfte auf den darunter liegenden Knochen sowie eine Dämpfung ermöglicht werden (Buckwalter et al. 2005).

Verantwortlich für die genannten biomechanischen Eigenschaften ist der molekulare Aufbau des hyalinen Knorpels. Dieser besteht aus spezialisierten Zellen, den Chondrozyten, sowie einer dichten extrazellulären Matrix. Die Hauptbestandteile der extrazellulären Matrix sind Wasser, Kollagen und Proteoglykane (Buckwalter und Mankin 1998). Etwa $90 \%$ des Kollagens in hyalinem Knorpel entfallen auf Kollagen II. Zudem sind Kollagen VI, IX, X und XI vertreten (Kuettner 1992). Weiterhin befinden sich in der extrazellulären Matrix nichtkollagene Proteine sowie Glykoproteine und Proteoglykane (Buckwalter und Mankin 1998). Aggrecan stellt den überwiegenden Teil der Gesamtmasse an Proteoglykanen und besteht aus einem Proteinkern sowie Glykosaminoglykanen, die in Kettenform an den Proteinkern gebunden sind. Negativ geladene Carboxyl- und Sulfatgruppen der Glykosaminoglykane ziehen Kationen an, die wiederum Wasser sowie Hyaluronan binden. Über Hyaluronan, welches das Rückgrat dieses beschriebenen Komplexes bildet, können mithilfe von Linker- 
Proteinen weitere Aggrecanmoleküle vernetzt werden (Hardmeier et al. 2010). Damit ermöglicht Aggrecan das Entstehen eines Quelldrucks, der in einem Gleichgewicht mit der aktuellen Druckbelastung steht. Bei Belastung des Gelenks kann Wasser aus der extrazellulären Matrix des Gelenkknorpels in die Synovia fließen. Bei Entlastung kann Wasser erneut im Gelenkknorpel an den Komplex aus Aggrecan und Kationen binden. Dieser Mechanismus beschreibt die molekulare Basis für die biomechanisch druckelastischen Eigenschaften des Gelenkknorpels in Diarthrosen (Huber et al. 2000).

Chondrozyten sind in Chondronen organisiert. Dabei handelt es sich um isogene Zellgruppen, die eine morphologische, funktionale und metabolische Einheit bilden (Poole et al. 1987). Eine perizelluläre Matrix umgibt die Chondrozyten eines Chondrons. Diese besteht hauptsächlich aus Proteoglykanen, Glykoproteinen, Kollagen IV sowie weiteren nichtkollagenen Proteinen (Guilak et al. 2006) und interagiert mit Rezeptoren der chondrozytären Zellmembran (Heinegård und Saxne 2011). Diese perizelluläre Matrix wird von einer territorialen Matrix umgeben, die überwiegend aus Kollagenfibrillen besteht, die ein geflechtartiges Netzwerk um die Chondrozyten bilden und sie damit vom Interterritorium abgrenzen. Das Interterritorium bildet die Matrix zwischen den Chondronen, nimmt das größte Volumen innerhalb des Gelenkknorpels ein und besteht aus Kollagenfibrillen und Proteoglykanen (Sophia Fox et al. 2009).

Lichtmikroskopisch sind im hyalinen Gelenkknorpel drei Schichten voneinander zu unterscheiden. Abbildung 1.1 stellt diese Schichtung schematisch und anhand eines histologischen Schnitts dar.
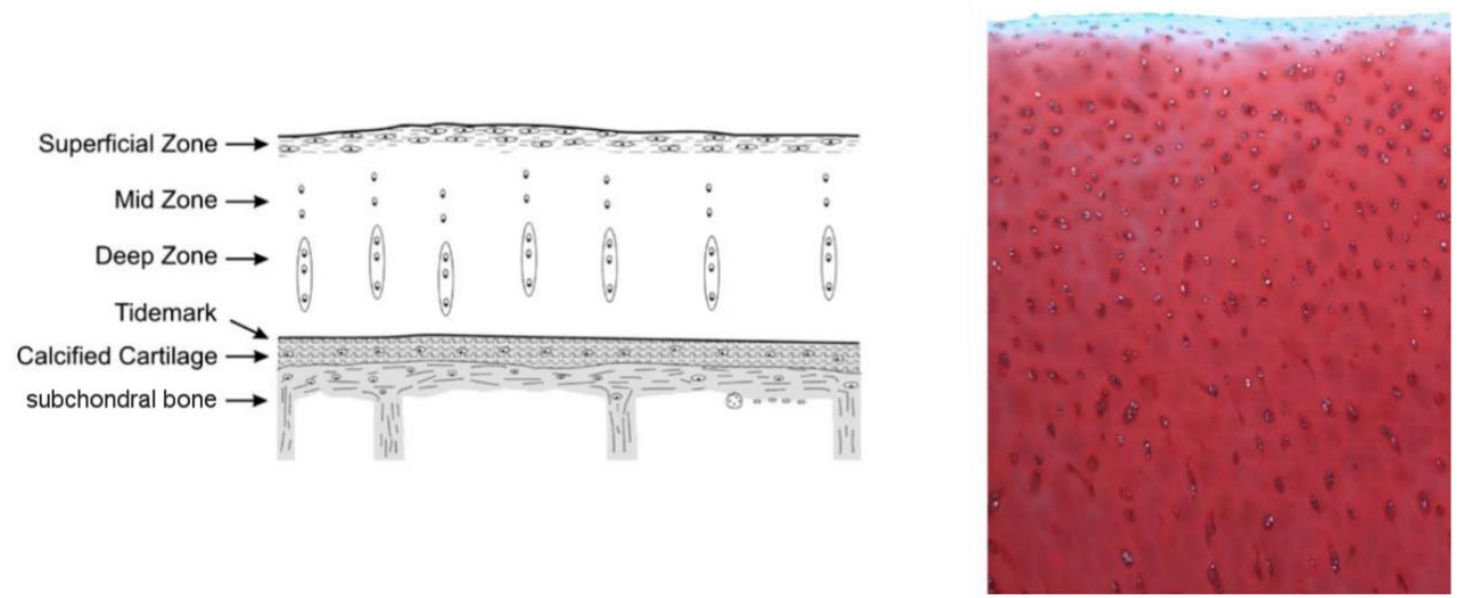

Abbildung 1.1: Schichtaufbau gesunden Gelenkknorpels; Safranin-O-Färbung, Vergrößerung: 5x, bearbeitet (Pritzker et al. 2006). Der Abdruck erfolgt mit freundlicher Genehmigung der Autoren. 
Eine dünne superfizielle, dem Gelenkspalt zugewandte Schicht bildet etwa 10 - $20 \%$ der Gesamtdicke des Gelenkknorpels (Sophia Fox et al. 2009). Hierin verlaufen zwei Lagen Kollagenfasern, wobei die obere parallel zur Oberfläche verläuft und die darunterliegende senkrecht dazu. Diese räumliche Organisation verleiht der superfiziellen Schicht ihre biomechanische Funktion, tiefer liegende Schichten vor Scherspannungen zu schützen. Die Chondrozyten in der superfiziellen Schicht sind dicht gepackt und weisen eine flache Morphologie auf (Huber et al. 2000; Heinegård und Saxne 2011).

Die mittlere Schicht repräsentiert etwa 40 - 60 \% der Schichtdicke des Gelenkknorpels (Sophia Fox et al. 2009) und beinhaltet hauptsächlich Proteoglykane und Kollagenfibrillen, die ohne einheitliche Orientierung zur Oberfläche ausgerichtet sind. Chondrozyten dieser Schicht werden als sphärisch beschrieben (He et al. 2014).

Die tiefe Schicht bildet etwa $30 \%$ der Gesamtschichtdicke des Gelenkknorpels und schließt mit einer mikroskopisch identifizierbaren, unregelmäßigen Linie zum kalzifizierten Knorpel ab (Sophia Fox et al. 2009). Diese als Tidemark bezeichnete Linie bildet den Abschluss der Mineralisationsfront des kalzifizierten Knorpels. Die Kollagenfibrillen der tiefen Schicht durchdringen die Tidemark und schließen sich kontinuierlich an jene der kalzifizierten Schicht an (Madry et al. 2010). Die tiefe Schicht bedingt durch eine hohe Konzentration von Proteoglykanen und eine geringe Konzentration Wasser gemeinsam mit der mittleren Schicht den druckelastischen Charakter des Gelenkknorpels (Huber et al. 2000). Die Chondrozyten dieser Schicht liegen in Säulen orientiert und damit parallel zu den vorhandenen Kollagenfasern vor, die senkrecht zur Gelenksoberfläche ausgerichtet sind (Madry et al. 2010).

Die Schicht des kalzifizierten Knorpels verankert den nichtkalzifizierten Gelenkknorpel im subchondralen Knochen über Kollagenfibrillen aus der tiefen Schicht. Hier zeigen sich wenige, hypertrophe Chondrozyten mit runden Zellkörpern, die in nicht kalzifizierten Lakunen liegen (Oegema et al. 1997). 


\subsection{Osteoarthrose}

Osteoarthrose $(\mathrm{OA})$ ist eine degenerative Gelenkerkrankung, die sich durch einen zunehmenden Verlust des Gelenkknorpels sowie durch eine Zunahme der Knochendichte des subchondralen Knochens auszeichnet (Goldring und Goldring 2010). Loeser et al. (2012) sehen in dem pathologischen Prozess der OA eine acitve response to inury, womit biomechanische Ursachen der Erkrankung priorisiert benannt werden. Im Rahmen dieser muskuloskelettalen Erkrankung ist nicht ausschließlich der Gelenkknorpel von pathologischen Veränderungen betroffen, vielmehr beschreibt $O A$ die Erkrankung eines gesamten Organsystems (Loeser et al. 2012).

\subsubsection{Epidemiologie}

Aufgrund unterschiedlich angewandter Kriterien zur Definition der OA variieren verfügbare epidemiologische Daten. Weiterhin sind die in den Studien berücksichtigten Gelenke sowie die untersuchte Population für die beobachteten Unterschiede der Ergebnisse entscheidend. 2010 litten etwa 250 Millionen Menschen an einer Gonarthrose, womit 3,6\% der Weltbevölkerung betroffen war (Vos et al. 2012). 2020 wird die $O A$ voraussichtlich eine der vier Hauptursachen für krankheitsbedingte körperliche Beeinträchtigungen weltweit darstellen. Hierzu tragen eine verlängerte Lebenserwartung sowie eine alternde Bevölkerung bei (Woolf und Pfleger 2003). Es besteht eine signifikante Abhängigkeit zwischen steigendem Alter und der Prävalenz der OA (Johnson und Hunter 2014).

Das Robert Koch-Institut ermittelte im Rahmen des Gesundheitsberichts des Bundes 2013 in Deutschland im Jahr 2010 eine Lebenszeitprävalenz für OA von 27,1\% bei Frauen und $17,9 \%$ bei Männern. Hierbei wurde die Diagnose mithilfe von radiologischen, klinischen sowie anamnestischen Daten gestellt (Rabenberg 2013).

Durch die hohe Zahl an Betroffenen sind die aus der Erkrankung resultierenden negativen wirtschaftlichen Folgen zu beachten, welche durch direkte Kosten im Gesundheitssystem zur Behandlung der OA entstehen. Zudem kommt es durch eine mit der Erkrankung einhergehende verminderte Produktivität zu indirekten Kosten (Woolf et al. 2012). 


\subsection{2 Ätiologie und Pathogenese}

Die möglichen Ursachen für die Entstehung der OA sind vielfältig. Mechanische, zelluläre sowie biomechanische Einflussfaktoren führen in einem komplexen Zusammenhang zum Endstadium der OA. Lokale und systemische Risikofaktoren sowie nichtveränderliche Risikofaktoren wie Alter, Geschlecht, Ethnie sowie genetische Faktoren spielen bei der Entstehung der Erkrankung eine entscheidende Rolle (Johnson und Hunter 2014). Zu den Hauptrisikofaktoren der Gonarthrose werden vorausgegangene Knietraumata, ein erhöhter Body-Mass-Index sowie eine bereits bestehende $O A$ in den Händen gezählt. Weiterhin werden das weibliche Geschlecht, erhöhtes Alter, arbeitsbedingte Mehrbelastung durch kniende Tätigkeiten und intensive sportliche Belastungen als Risikofaktoren aufgeführt (Blagojevic et al. 2010).

Die Pathogenese der OA ist an verschiedenen gelenkbildenden Strukturen zu beobachten (Cucchiarini et al. 2016). Die dabei auftretenden Veränderungen im Gelenkknorpel folgen einem konstanten Muster (Goldring und Goldring 2010). In frühen Stadien der OA werden Zellaggregate, die als Cluster bezeichnet werden, mikroskopisch sichtbar. Im fortgeschrittenen Zustand zeigen sich besonders eindrücklich diskontinuierliche, ausgefranste Oberflächen (Pritzker et al. 2006). Cluster bestehen aus Chondrozyten, die wahrscheinlich aufgrund eines verstärkten Zellwachstums und einer allgemein erhöhten Syntheseleistung gebildet werden, wodurch verstärkt extrazelluläre Matrixproteine produziert werden. Im weiteren Verlauf kann eine erhöhte katabolische Aktivität nachgewiesen werden, die mit einer erhöhten Produktion von Proteinasen einhergeht, womit der Verlust von Proteoglykanen und Kollagen Il erklärt wird (Goldring und Goldring 2010). Zu diesen Proteinasen zählen Aggrecanasen und Kollagenasen, die den Matrix-Metalloproteasen (MMP) zugeordnet werden. Wenn dieses Stadium, in dem Kollagene der extrazellulären Matrix abgebaut werden, erreicht ist, kann von einer irreversiblen Schädigung des Gelenkknorpels ausgegangen werden (Loeser et al. 2012). Miosge et al. (2004) zeigten, dass in osteoarthrotischem Knorpelgewebe Kollagen I vermehrt nachzuweisen ist. Weiterhin ist eine Hypertrophie der Chondrozyten (Kerkhofs et al. 2016) sowie eine verstärkte Expression von immunmodulatorischen Proteinen, Matrixproteinen, Apoptosemarkern und Transkriptionsfaktoren zu beobachten (Goldring und Goldring 2010). Mit diesen zellulären Veränderungen werden eine beginnende Fibrillation sowie die lokale Synthese von Faserknorpel assoziiert, wodurch die biomechanischen Eigenschaften 
des hyalinen Gelenkknorpels verändert werden (Pritzker et al. 2006). Zudem wird die Entwicklung der OA von einem entzündlichen Prozess in der Synovia gefördert, der von Interleukinen (IL) und Tumornekrosefaktor (TNF) getragen wird. So induziert IL$1 \beta$ die Expression von MMP, welche die Synthese der extrazellulären Matrix inhibieren (Gari et al. 2016).

Menisci und Bänder des betrachteten osteoarthrotischen Gelenks unterliegen ebenfalls pathologischen Veränderungen (Loeser et al. 2012). Vorausgegangene Traumata dieser Strukturen fördern die Entstehung von OA (Felson et al. 2000). So wurde ein Meniskusschaden bei $63 \%$ der Erwachsenen mit einer symptomatischen Gonarthrose diagnostiziert (Englund et al. 2008). Ein Abriss des vorderen Kreuzbandes ist ebenfalls gehäuft bei Erwachsenen mit Gonarthrose zu finden (Loeser et al. 2012). In diesem Zusammenhang ergab eine MRT-gestützte Studie, dass 22,8 \% der Patienten mit einer symptomatischen Gonarthrose einen Abriss des vorderen Kreuzbandes zu verzeichnen hatten. Dabei gaben nur 47,9\% dieser Patienten an, ein adäquates Trauma erlitten zu haben (Hill et al. 2005). Die pathologischen Veränderungen innerhalb der Menisci zeigen Ähnlichkeit zu jenen im Gelenkknorpel (Loeser et al. 2012). Auch hier sind mikroskopisch Fibrillationen, Clusterbildung sowie eine ausgefranste Oberfläche zu sehen (Pauli et al. 2011).

Das Wolff-Transformationsgesetz besagt, dass Knochen an Stellen dauerhafter Belastung aufgebaut und an Stellen dauerhafter Entlastung abgebaut werden. Somit wird die Struktur der knöchernen Anteile eines Gelenks maßgeblich durch die herrschende biomechanische Beanspruchung beeinflusst und ist durch eine kontinuierliche Adaptation gekennzeichnet (Wolff 1995). Zusätzlich spielen Pathomechanismen auf zellulärer Ebene im subchondralen Knochen bei der Entwicklung der OA eine Rolle. So bilden Osteoblasten in fortgeschrittenen Stadien der OA ein in seiner Struktur verändertes Kollagen, das weniger Calcium binden kann und somit zu einer verminderten Mineralisierung sowie Steifigkeit führt, trotz einer Zunahme der Knochendichte des subchondralen Knochens (Cucchiarini et al. 2016). Lahm et al. (2014) zeigten jedoch, dass die alleinige Betrachtung der subchondralen Knochendichte keine verlässliche Aussage über die zeitliche Entwicklung einer $O A$ ermöglicht. Weiterhin sind Veränderungen der Tidemark zu beobachten. Umbauprozesse im subchondralen Knochengewebe sowie Änderungen der zellulären Zusammensetzung im kalzifizierten Knorpel unterhalb der Tidemark bedingen eine 
Verdickung und Vaskularisierung des kalzifizierten Knorpels. Im weiteren Verlauf der Erkrankung kommt es zur vaskulären Infiltration des nicht kalzifizierten Gelenkknorpels, womit morphologisch Duplikationen der Tidemark assoziiert sind (Goldring und Goldring 2010; Loeser et al. 2012).

Abbildung 1.2 zeigt am Beispiel einer fortgeschrittenen OA die beschriebenen charakteristischen morphologischen Änderungen auf mikroskopischer Ebene im Gelenkknorpel.

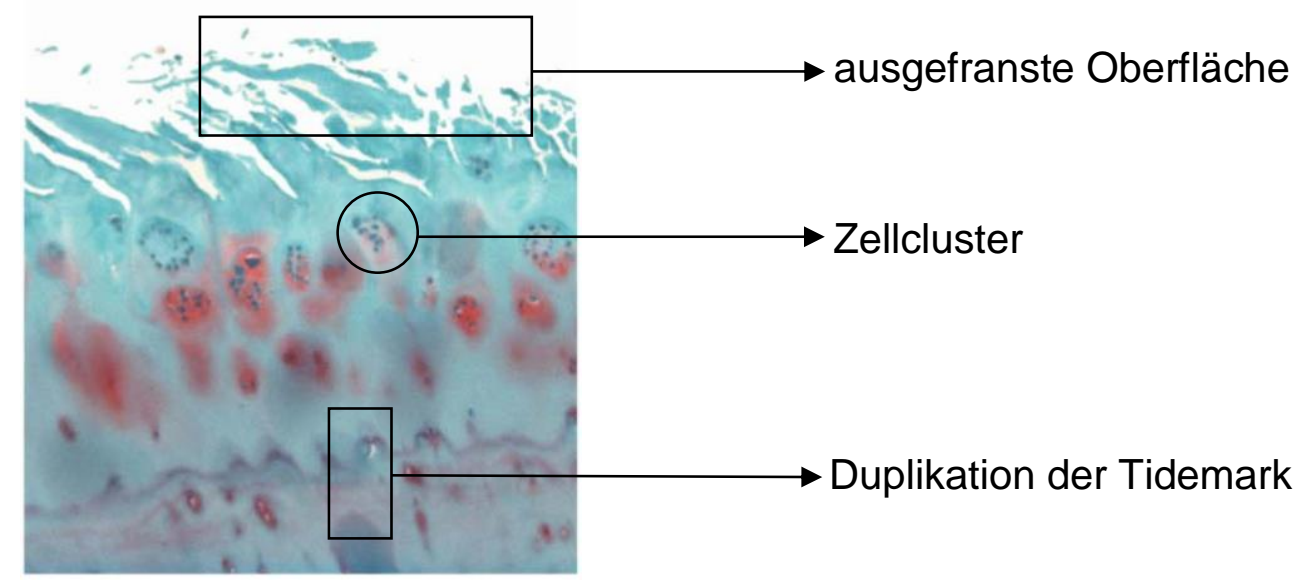

Abbildung 1.2: Morphologie einer fortgeschrittenen OA, Safranin-O-Färbung, Vergrößerung: 5x bearbeitet (Pritzker et al. 2006). Der Abdruck erfolgt mit freundlicher Genehmigung der Autoren.

\subsubsection{Therapieansätze}

Nach heutigem Kenntnisstand ist das Krankheitsbild der OA nicht heilbar. Die angewendeten Therapien dienen vor allem der Schmerzreduktion sowie der Erhaltung der Funktion des erkrankten Gelenks (Michael et al. 2010). Innerhalb der konservativen Behandlungsstrategie werden im Rahmen der nichtmedikamentösen Therapie Physiotherapie, physikalische Therapie sowie Ergotherapie und orthopädische Hilfsmittel eingesetzt. Die medikamentöse Therapie hat die Linderung von Schmerzen und Entzündungsprozessen als Ziel, womit die Voraussetzung für eine mechanische Belastung der betroffenen Gelenke geschaffen werden kann (Rabenberg 2013).

Bei therapierefraktären Symptomen nach Ausschöpfung aller konservativer Methoden kann eine operative Therapie angezeigt sein (Mancuso et al. 1996). Die Wahl der expliziten Operation ist zudem abhängig vom Schweregrad der vorliegenden OA, dem klinischen Bild des Patienten sowie dessen Leidensdruck (Rabenberg 2013). 
$\mathrm{Zu}$ den gelenkerhaltenden Operationen zählen die Arthroskopie, mit deren Hilfe intraartikulär störende Strukturen sowie Unebenheiten entfernt und geglättet werden (Débridement sowie Shaving) und eine Spülung des Gelenks möglich ist (Lavage) (Spahn 2007). Zu den knochenmarkstimulierenden Techniken zählen PridieBohrungen, Mikrofrakturierung sowie Abrasionsarthroplastiken, welche ebenfalls mithilfe der Arthroskopie durchgeführt werden. Bei Anwendung dieser Methoden wird die Grenzlamelle zwischen Knorpel und Knochen punktuell durchbrochen, womit Stammzellen aus dem Knochen angeregt werden, in den Knorpel einzuwandern, um einen Regenerationsprozess im Knorpel zu induzieren (Rabenberg 2013). Das hierdurch entstehende fibrokartilaginäre Ersatzgewebe stellt jedoch weder in seiner molekularen Struktur noch in seinen mechanischen Eigenschaften einen adäquaten Ersatz für hyalinen Gelenkknorpel dar (Kreuz et al. 2006). Weiterhin zählen die Gelenkflächenwiederherstellung, wie die autologe osteochondrale Transplantation (AOT) sowie die matrixgekoppelte autologe Chondrozytentransplantation (MACT), zu den gelenkerhaltenden Operationsverfahren. Im Rahmen der AOT werden aus intakten, wenig belasteten Bereichen des artikulierenden Knorpels Knorpel-KnochenZylinder entnommen und in osteoarthrotische Bereiche transplantiert. Sowohl die begrenzte Anzahl an Transplantaten als auch die potentielle Degeneration der Entnahmestellten sind limitierende Faktoren dieses Verfahrens (Muller et al. 2010). Zur Durchführung der MACT wird mithilfe einer Arthroskopie Knorpelgewebe von einem gesunden, wenig belasteten Areal entnommen und die darin enthaltenen Chondrozyten in vitro isoliert. Anschließend werden in einer offenen Operation die dadurch gewonnenen Chondrozyten im defekten Knorpelareal reimplantiert (Peterson et al. 2002).

Die Endoprothetik findet im Rahmen gelenksersetzender Operationen Anwendung. Dieses operative Verfahren ist bei klinisch sowie radiologisch nachgewiesener fortgeschrittener $\mathrm{OA}$ indiziert, bei der eine gelenkerhaltene Operation nicht mehr möglich ist (Jordan et al. 2003; Lohmander und Roos 2007). Ein künstlicher Gelenkersatz ist somit in der Behandlung der OA als Ultima Ratio einzustufen.

Arthrodesen, also Gelenkversteifungen, die den gelenklimitierenden Operationsverfahren zugeordnet werden, sind meist bei kleinen Gelenken oder bei Versagen der Endoprothetik indiziert und sollen Schmerzfreiheit ermöglichen (Rabenberg 2013). 
Die hier dargestellten Therapieansätze haben gemeinsam, dass mit deren Hilfe eine Wiederherstellung der physiologischen Gelenkfunktion sowie -struktur nicht in vollem Umfang möglich ist, da inadäquate Ersatzgewebe gebildet oder ganze Gelenke ersetzt werden. Das Tissue Engineering hat zum Ziel, ein adäquates Gewebe zu transplantieren, das zuvor auf Grundlage von menschlichen Zellen in vitro unter speziellen Wachstumsbedingungen hergestellt wurde und welches dem ursprünglich physiologischen Gewebe gleicht. Hierfür werden Chondrozyten sowie differenzierungsfähige Zellen wie mesenchymale Stammzellen (MSCs) aus Knochenmarkspunktaten verwendet. Zur Erzeugung der Wachstumsbedingungen werden dreidimensionale Gerüste (scaffolds), Wachstumsfaktoren sowie mechanische Reize eingesetzt und genetische Manipulationen angewendet (Johnstone et al. 2013; Madry und Cucchiarini 2014). In bisherigen Untersuchungen zur Entwicklung einer Therapie der OA konnte mithilfe des Tissue Engineering jedoch ebenfalls kein adäquates Ersatzgewebe generiert werden. Es entsteht fibrokartilaginäres Ersatzgewebe, das kein adäquater Ersatz für hyalinen Gelenkknorpel darstellt (Cucchiarini et al. 2014).

Weiterhin werden stammzellbasierte Therapieverfahren zur Behandlung der OA erforscht. Hierbei ist es Ziel, pluri- oder multipotente Stammzellen so zu modulieren, dass sie sich zu Zellen differenzieren, welche in der Lage sind, die Integrität des hyalinen Gelenkknorpels wiederherzustellen und zu erhalten. Bisher ist es mit diesem Ansatz jedoch nicht gelungen, einen adäquaten Knorpelersatz bei $\mathrm{OA}$ in vivo zu erzeugen (Muhammad et al. 2013).

\subsection{Chondrogene Progenitorzellen}

Da Gelenkknorpel ein nerven- sowie gefäßfreies Gewebe darstellt, das einem anaeroben Metabolismus unterliegt, ist das Potential zur Regeneration limitiert. Zudem besitzen die Chondrozyten des Gelenkknorpels keine ausreichende Migrationsfähigkeit, da sie in einer dichten kollagenen extrazellulären Matrix eingebettet sind. Weiterhin ist der Gelenkknorpel einer näherungsweise kontinuierlich biomechanischen Belastung ausgesetzt, die schlechte Voraussetzungen für Regenerationsmechanismen bietet (Perera et al. 2012). Chondrogene Progenitorzellen hingegen besitzen Migrationsfähigkeit und sind in osteoarthrotischem Gelenkknorpel präsent, siehe Abbildung 1.3 (Koelling et al. 2009). 


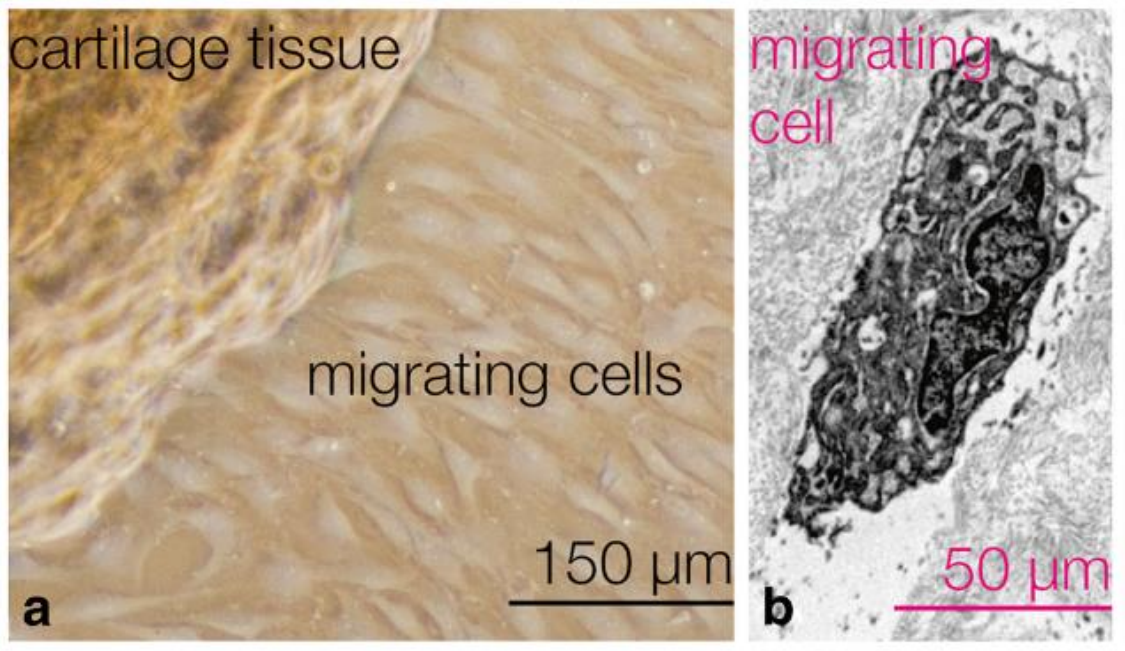

Abbildung 1.3: Chondrogene Progenitorzellen migrieren aus osteoarthrotischem Knorpelgewebe (Schminke und Miosge 2014). Der Abdruck erfolgt mit freundlicher Genehmigung der Autoren.

Neben kontinuierlich degenerierenden gesunden Chondrozyten sowie degenerierten Chondrozyten, die kontinuierlich abgebaut werden, finden sich in osteoarthrotischem Gewebe fibroblastenartige Chondrozyten, deren Zahl in fortgeschrittenen Stadien der OA steigt. Fibroblastenartige Chondrozyten produzieren überwiegend Kollagen I und nicht Kollagen II, welches für gesunden hyalinen Gelenkknorpel charakteristisch ist (Tesche und Miosge 2005). Tesche und Miosge (2005) konnten zeigen, dass fibroblastenartige Chondrozyten zudem die Proteoglykane Decorin sowie Biglycan in erhöhtem Maße produzieren. Gemeinsam mit Perlecan sind Decorin und Biglycan physiologischerweise mit der Synthese von Kollagen II verknüpft (Tesche und Miosge 2005). Koelling et al. (2009) zeigten weiterhin, dass fibroblastenartige Chondrozyten Stammzelleigenschaften aufweisen. So konnten Stammzellmarker, Migrationspotential sowie Multipotenz nachgewiesen werden, wobei eine mögliche Differenzierung in Abhängigkeit von den Wachstumsbedingungen in Adipozyten, Osteozyten und Chondrozyten gezeigt werden konnte. Die somit charakterisierten Zellen wurden chondrogene Progenitorzellen (CPCs) benannt (Koelling et al. 2009).

Die Fähigkeit der CPCs zur Synthese extrazellulärer Matrixkomponenten des hyalinen Gelenkknorpels wie Kollagen II kann als chondrogenes Potential der CPCs bezeichnet werden. Es konnte eine Abhängigkeit dieses chondrogenen Potentials von der Expression der Transkriptionsfaktoren sex determining region Y- (SRY-) box 9 (SOX9) sowie run-related transcription factor 2 (RUNX2) nachgewiesen werden. Durch den Knockdown von RUNX2 in CPCs wurde eine erhöhte Expression von SOX9 
beobachtet sowie eine damit einhergehende verstärkte Synthese von Kollagen II (Schminke und Miosge 2014). Aufgrund ihrer migratorischen Eigenschaft, die das Einwandern in osteoarthrotischen Knorpel ex vivo ermöglicht, und aufgrund ihres chondrogenen Regenerationspotentials könnten CPCs als Ansatzpunkt für eine regenerative Therapie der OA geeignet sein (Koelling et al. 2009).

\subsubsection{Funktionen von SOX9 und RUNX2 in der Regulation der Chondrogenese}

Der überwiegende Anteil des Skeletts, mit Ausnahme der flachen Knochen, wird durch den Prozess der enchondralen Ossifikation gebildet. Hierbei dient zunächst ein Knorpelskelett als Vorlage für die darauffolgende Knochenbildung (Wuelling und Vortkamp 2010). Zu Beginn der Bildung des Knorpelskeletts steht die Differenzierung von MSCs zu Knorpel. Dieser Prozess wird als Chondrogenese bezeichnet. Die Chondrogenese umfasst die Kondensation von Mesenchym sowie die Differenzierung zu Chondroblasten und Chondrozyten.

Die strenge Regulation dieser Prozesse wird durch extrazelluläre sowie intrazelluläre Signalwege realisiert. Intrazellulär spielt SOX9 hierbei eine Schlüsselrolle. So ist SOX9 an der mesenchymalen Kondensation, der Differenzierung der MSCs sowie an der Initiierung der Osteogenese maßgeblich beteiligt (Kawakami et al. 2006). Ein Defekt von SOX9 führt hingegen zum Krankheitsbild der kampomelen Dysplasie, die mit dramatischen skelettalen Fehlbildungen einhergeht (Wunderle et al. 1998). SOXProteine gehören zur high-mobility-group-(HMG-) Box-family, die eine hohe Ähnlichkeit mit der deoxyribonucleic acid (DNA) -bindenden Domäne der chromosomalen Nichthistonproteine (HMG-Domäne) von SRY aufweist. Diese HMG-Domäne wird als SRY-Box bezeichnet, worin die Namensgebung der SOX-Proteine ihren Ursprung findet. SOX9 hat eine molekulare Masse von 56 kDa (Wegner 1999).

RUNX2 gehört zur Gruppe der core binding factors, die eine Gruppe von Transkriptionsfaktoren darstellen. Ein Defekt von RUNX2 führt zum Krankheitsbild der cleidocranialen Dysplasie, die mit Fehlbildungen der Clavicula sowie einer verzögerten Ossifikation des knöchernen Schädels einhergeht. Die molekulare Masse von RUNX2 beträgt 57 kDa (Mundlos et al. 1997; Otto et al. 1997; Wuelling und Vortkamp 2010). Die Expression von RUNX2 während der mesenchymalen Kondensation bewirkt eine 
Differenzierung von Osteochondroprogenitorzellen zu Osteoblasten. Osteochondroprogenitorzellen sind Stammzellen, die sich im Rahmen der mesenchymalen Kondensation bilden und sowohl zu Knochen- als auch zu Knorpelzellen differenzieren können (Kawakami et al. 2006). Eames et al. (2004) beschreiben einen „binary molecular code" bestehend aus SOX9 sowie RUNX2 in Hühnchenembryos, der die Differenzierung der Osteochondroprogenitorzellen bestimmt, wobei ein erhöhte Expression von SOX9 zu einer chondrogenen und eine erhöhte Expression von RUNX2 zu einer osteogenen Differenzierung führen. RUNX2 wird somit als Osteogenese-spezifischer Transkriptionsfaktor bewertet (Xu et al. 2015).

SOX9 sowie RUNX2 spielen demnach sowohl in der Differenzierung von CPCs und damit in jenen Zellen eine wichtige Rolle, die zur Regeneration des hyalinen Gelenkknorpels prinzipiell fähig sind, als auch in der Chondro- sowie Osteogenese. Damit stellen sie sinnvolle Kandidaten für eine Untersuchung dar, die es zum Ziel hat, eine Modulation dieser Schlüsselfaktoren zur Behandlung der OA einzusetzen.

\subsection{Proteasomaler Abbau durch Ubiquitinierung}

Lysosomen und Proteasomen bilden die zellulären Systeme zum Abbau von Proteinen durch Proteolyse. Die Hauptfunktion der Proteasomen besteht im Abbau von intrazellulären Proteinen (Huang und Chen 2009). So sind Proteasomen für den Abbau von fehlgefalteten und in ihrer Funktion eingeschränkten Proteinen zuständig. Weiterhin bauen Proteasomen Proteine ab, die Signaltransduktionsprozesse, Zellzyklus, Apoptose, Antigenpräsentation sowie Transkription beeinflussen, wodurch sie an der Regulation dieser Prozesse beteiligt sind (Lecker et al. 2006; Tramutola et al. 2016). Lysosomen sind vor allem für den Abbau von endozytierten Proteinen zuständig (Huang und Chen 2009).

Proteasomen erkennen abzubauende Porteine an einer Markierung durch Ubiquitin (Suresh et al. 2016). Zudem können einige Proteine auch ohne eine vorhergehende Ubiquitinierung durch Proteasomen abgebaut werden (Lecker et al. 2006). Da der proteasomale Abbau meist abhängig von der Ubiquitinierung der Zielproteine stattfindet, werden die an diesen Prozessen beteiligten Strukturen als UbiquitinProteasom-System (UPS) zusammengefasst (Gong et al. 2016). 
Ubiquitin ist ein Protein mit einer Masse von $8,5 \mathrm{kDa}$, welches aus 76 Aminosäuren besteht. Der Prozess der Ubiquitinierung bildet eine reversible posttranslationale Modifikation und wird mithilfe von drei Enzymen realisiert. (Suresh et al. 2016). Abbildung 1.4 stellt den im Folgenden beschriebenen chemischen Prozess zur Ubiquitinierung eines Zielproteins (in Abbildung 1.4 als "Substrate" bezeichnet) schematisch dar.

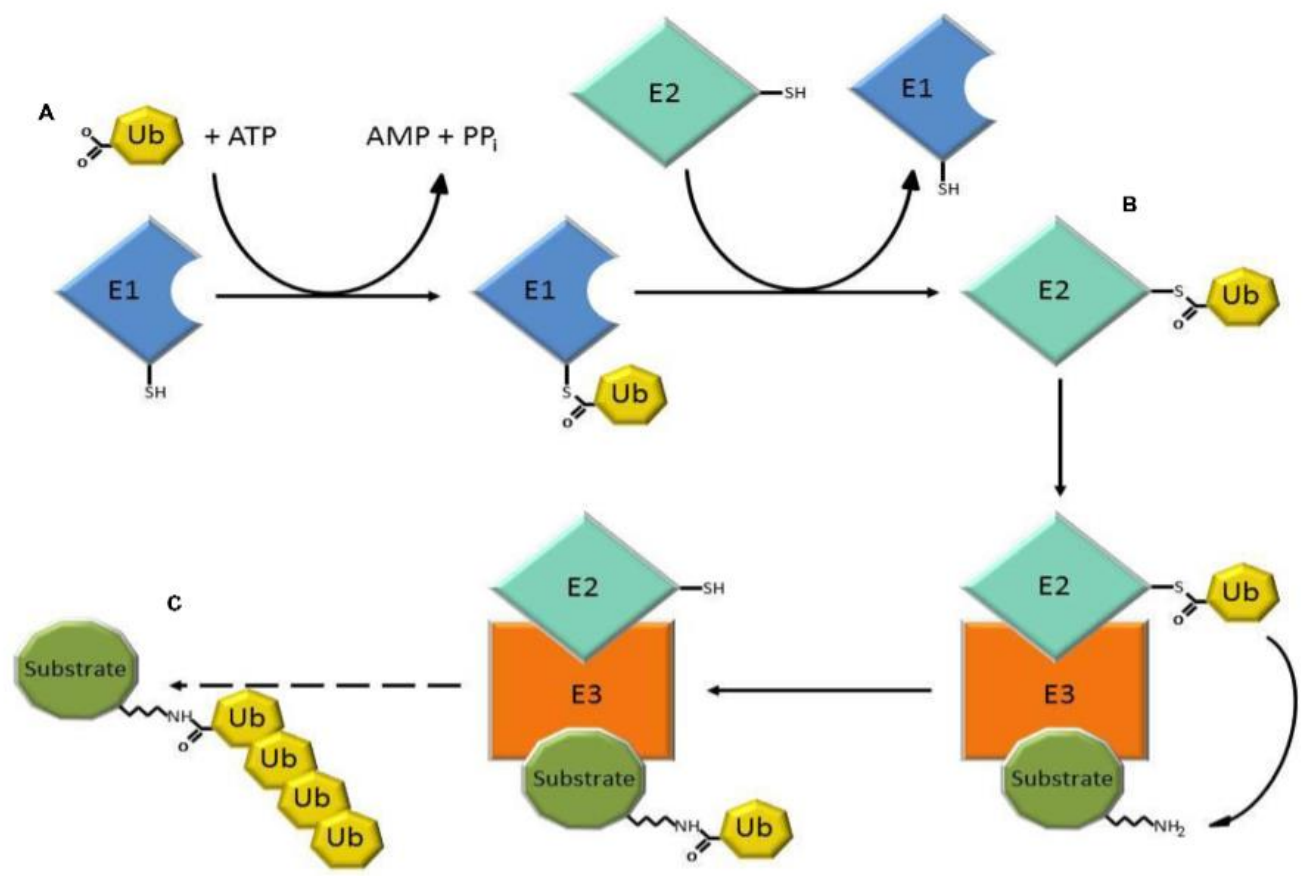

Abbildung 1.4: Ubiquitinierung zum proteasomalen Abbau von Proteinen (Gong et al. 2016). Der Abdruck erfolgt mit freundlicher Genehmigung der Autoren sowie des Frontiers Media SA-Verlags.

Initial wird das carboxyterminale Glycin des Ubiquitins Adenosintriphosphat (ATP) abhängig von einem spezifisch aktivierendem Enzym (E1) aktiviert. Dabei entsteht eine Thioesterbindung zwischen dem terminalen Kohlenstoff des Ubiquitins und dem Cystein des aktiven Zentrums von E1. Das somit aktivierte Ubiquitin wird nun über eine Thioesterbindung an das Cystein des aktiven Zentrums des Ubiquitin-TransportProteins (E2) gebunden (Hershko und Ciechanover 1998). In einem dritten Schritt wird nun das Ubiquitin auf das Zielprotein übertragen. Hierbei katalysiert die UbiquitinProtein-Ligase (E3) die Verbindung zwischen der $\varepsilon$-Aminogruppe eines Lysinrests des Zielproteins und dem carboxyterminalen Gylcin des Ubiquitins (Homrich et al. 2015).

Der Ablauf dieser Reaktion ist abhängig von der Struktur der beteiligten E3-Ligase. Besitzt E3 eine homologous to the E6-AP carboxyl terminus- (HECT-) Domäne wird 
das aktivierte Ubiquitin von E2 auf ein Cystein im aktiven Zentrum des E3 übertragen und darauf folgend an das Zielprotein gebunden (Tramutola et al. 2016). Really interesting new gene-(RING-) sowie RING-assoziierte E3-Ligasen katalysieren eine direkte Übertragung des Ubiquitins von E2 auf das Zielprotein (Metzger et al. 2012).

Ubiquitin besitzt sieben Lysinreste, welche jeweils eine Ubiquitin-Ubiquitin-Verbindung ermöglichen, womit eine Polyubiquitinierung des Zielproteins erreicht werden kann. Die Länge der Ubiquitinkette sowie der spezifische Lysinrest determinieren die Funktion der Ubiquitinierung des Zielproteins (Suresh et al. 2016). So wird eine Polyubiquitinierung mit dem Proteinabbau durch Proteasomen assoziiert, wohingegen eine Monoubiquitinierung mit Endozytosen, DNA-Reparaturprozessen sowie Signaltransduktionen in Verbindung steht (Tramutola et al. 2016).

\subsection{SMAD-ubiquitination regulatory factor}

Mother against decapentaplegic homolog-(SMAD-) ubiquitination regulatory factor 1 (SMURF1) und SMURF2 sind intrazelluläre Enzyme mit einer molekulare Masse von $86 \mathrm{kDa}$, welche den E3-Ligasen vom HECT-Typ zugeordnet sind. Damit bilden sie einen funktionellen Teil des UPS (Inoue und Imamura 2008). SMURF1 sowie SMURF2 sind an der Regulation von Zellsignalwegen beteiligt, die Bestandteil von Zellentwicklung, -wachstum sowie von Zelldifferenzierung, Ausbildung von Zellpolarität, Tumorentwicklung und immunologischen Prozessen sind (Fukunaga et al. 2008; Cao und Zhang 2013; David et al. 2013). Weiterhin besitzen SMURF1 sowie SMURF2 E3Ligase-unabhängige regulatorische Funktionen, die durch ihre räumliche Struktur bedingt sind ( $\mathrm{Nie}$ et al. 2010). So ist beispielsweise SMURF1 an der selektiven Autophagie von Mitochondrien durch einen E3-Ligase-unabhängigen Vermittlungsprozess beteiligt (Orvedahl et al. 2011).

Im Rahmen dieser Arbeit werden SMURF1 und SMURF2 hinsichtlich ihrer Funktionen in der Zelldifferenzierung untersucht. Ihre Beteiligung an den hierbei betrachteten Signalkaskaden wird im folgenden Kapitel dargestellt. 


\subsubsection{SMURF1/2 im BMP- und TGF- $\beta$-Signalweg}

Transforming growth factor $\beta$ (TGF- $\beta$ ) family bezeichnet eine Gruppe von Wachstumsfaktoren, die an vielen biologischen Prozesse wie Entzündung, Wundheilung und Zellproliferation sowie -differenzierung beteiligt sind. Menschen besitzen drei Isoformen des TGF- $\beta$, welche strukturelle Ähnlichkeiten aufweisen, sich jedoch in ihrer Expressionsregulation unterscheiden (van der Kraan et al. 2009). Bone morphogenetic proteins (BMPs) sind ebenfalls Teil dieser TGF- $\beta$-Familie, deren Mitglieder eine Aktivierung von Typ 1- sowie Typ 2- Serin-/Threonin-KinaseRezeptoren zur Signaltransduktion nutzen (Miyazono et al. 2010). Hierzu binden die Liganden TGF- $\beta$ sowie BMP an für sie spezifische Kombinationen aus Typ 1- und Typ 2- homodimeren Rezeptoren, wodurch ein hetero-tetramerer Komplex entsteht und eine Phosphorylierung des Typ 1 Rezeptors durch die Kinasefunktion des Typ 2Rezeptors ausgelöst wird (Inoue und Imamura 2008). Der dadurch aktivierte Typ 1Rezeptor phosphoryliert wiederum receptor-regulated-SMADs (R-SMADs), die als intrazelluläre Mediatoren dienen (Shen et al. 2014).

SMADs, die aus 400 bis 500 Aminosäuren bestehen, können funktionell in drei Gruppen unterteilt werden. SMAD1/2/3/5/8 werden als R-SMADS bezeichnet, SMAD4 als common-mediator-SMADs (Co-SMADs) und SMAD6/8 als inhibitory-SMADs (ISMADs) (Attisano und Lee-Hoeflich 2001).

R-SMADs sind Substrate der Serin- / Threonin-Kinase-Rezeptoren und werden zur Aktivierung an einem für R-SMADs spezifischem SSXS-Motiv phosphoryliert. SMAD4 bildet mit aktivierten R-SMADs einen heteromeren Komplex, der sich in den Zellkern verlagert und dort durch Bindung an DNA den Prozess der Transkription beeinflusst (Wrana und Attisano 2000). I-SMADs sind Teil einer auto-inhibitorischen Rückkopplung des BMP- und TGF- $\beta$-Signalwegs. Die Synthese der I-SMADs wird entscheidend durch extrazelluläre Signale reguliert. So führt eine erhöhte Aktivierung der BMP- und TGF- $\beta$-Rezeptoren zu einer verstärken Synthese von SMAD6/7. Diese binden kompetitiv an Typ 1-Rezeptoren und verhindern so die Aktivierung von RSMADs. Zudem verhindert SMAD6 durch Bindung an SMAD4 eine Komplexbildung zwischen SMAD4 und R-SMADs (Derynck und Zhang 2003). SMAD7 ist weiterhin an der Rekrutierung von SMURF1 sowie SMURF2 zu Typ 1-TGF- $\beta$-Rezeptoren beteiligt, womit eine Ubiquitinierung und ein darauf folgender Abbau dieser Rezeptoren verbunden ist (Kavsak et al. 2000; Ebisawa et al. 2001). 
R- sowie Co-SMADs besitzen sowohl eine MAD homology (MH)1-Domäne als auch eine MH2-Domäne, die durch eine Linker-Region miteinander verbunden sind. ISMADs unterscheiden sich hiervon, da sie eine von der MH1-Domäne abweichende Struktur aufweisen. Die MH1-Domäne ist für eine Bindung mit DNA sowie weiteren DNA-bindenden Proteinen verantwortlich und für den Transport in den Zellkern notwendig. Die MH2-Domäne ermöglicht eine Interaktion mit den Serin- / ThreoninKinase-Rezeptoren, weiteren SMADs sowie DNA-bindenden Proteinen (Miyazono et al. 2010). Die Linker-Region weist potentielle Phosphorylierungsstellen auf, die eine Interaktion mit weiteren Signalkaskaden ermöglicht. So können beispielsweise Mitogen-aktivierte Protein-Kinasen durch Phosphorylierung die Translokation von SMADs verhindern und somit die BMP- und TGF- $\beta$-Signalkaskade beeinflussen (Burch et al. 2011).

SMURF1 sowie SMURF2 sind an der Regulation der BMP- und TGF- $\beta$-Signalkaskade beteiligt. So werden R-SMADs durch SMURF1/2 und TGF- $\beta$-Rezeptoren mithilfe von I-SMADS ubiquitiniert und somit für den proteasomalen Abbau markiert (Arora und Warrior 2001). SMURF1/2 interagieren dabei mithilfe von WW-Domänen mit prolineproline-x-tyrosine (PY) -Motiven innerhalb der Linker-Region (Chong et al. 2010). Weiterhin besitzen SMURF1/2 eine C2-Domäne, die eine Bindung des SMURF1/2SMAD7-Komplexes an der Zellmembran zur Ubiquitinierung des TGF- $\beta$-Rezeptors ermöglicht (Kavsak et al. 2000; Suzuki et al. 2002). Zudem wurde eine Wechselwirkung zwischen SMURF1 und SMURF2 beschrieben. So wiesen Fukunaga et al. (2008) den Abbau von SMURF1 durch SMURF2 in Brustkrebszellen nach.

Funktionelle Disparitäten zwischen SMURF1 und SMURF2 sind auf Unterschiede in der Struktur zurückzuführen. So unterliegt SMURF2 einer Autoinhibition, die bisher nicht für SMURF1 nachgewiesen wurde. Dennoch stimmen $74 \%$ der Aminosäuresequenz von SMURF1 und SMURF2 überein (Lu et al. 2011). Abbildung 1.5 stellt die Strukturen der beiden Proteine vergleichend dar. Weiterhin sind Funktionen von SMURF1/2 von ihrer subzellulären Lokalisation abhängig. SMURF1/2 halten sich vorwiegend im Zellkern auf, wobei jedoch keine statische Verteilung zu beobachten ist. Interaktionen zwischen SMURF1/2 und deren Substraten sowie das $\mathrm{N}$-terminale Ende der C2-Domäne und Rev-like nuclear export signal sequence im C-terminalen Ende von SMURF1/2 sind an der Regulation des Transports zwischen Zellkern und Zytoplasma beteiligt (David et al. 2013). 
(a)

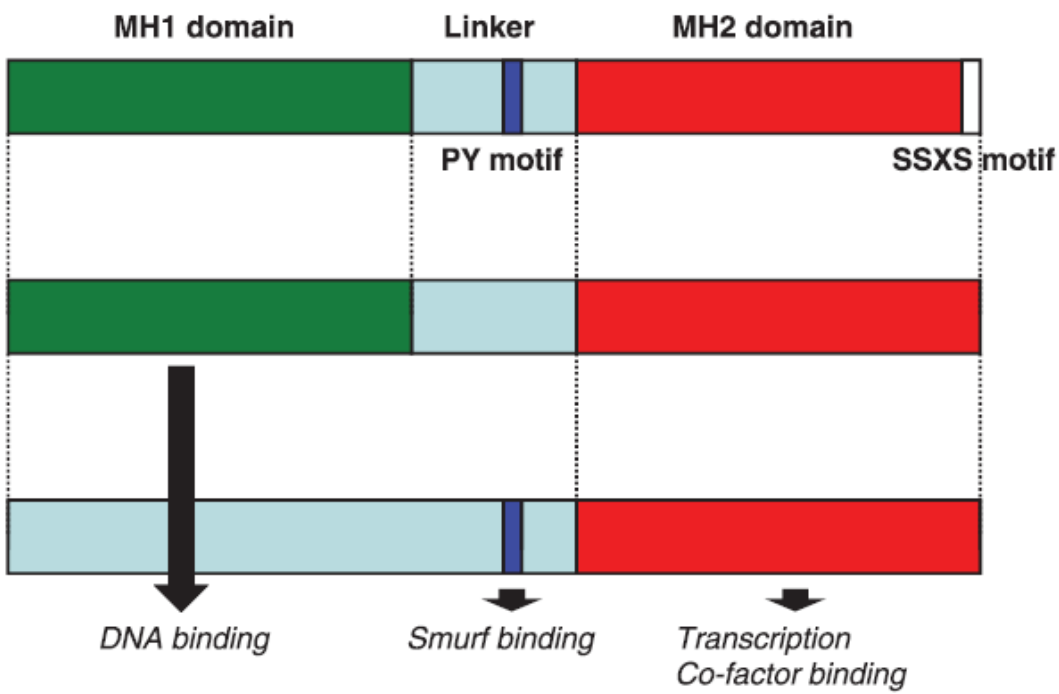

(b)

C2 domain WW domain

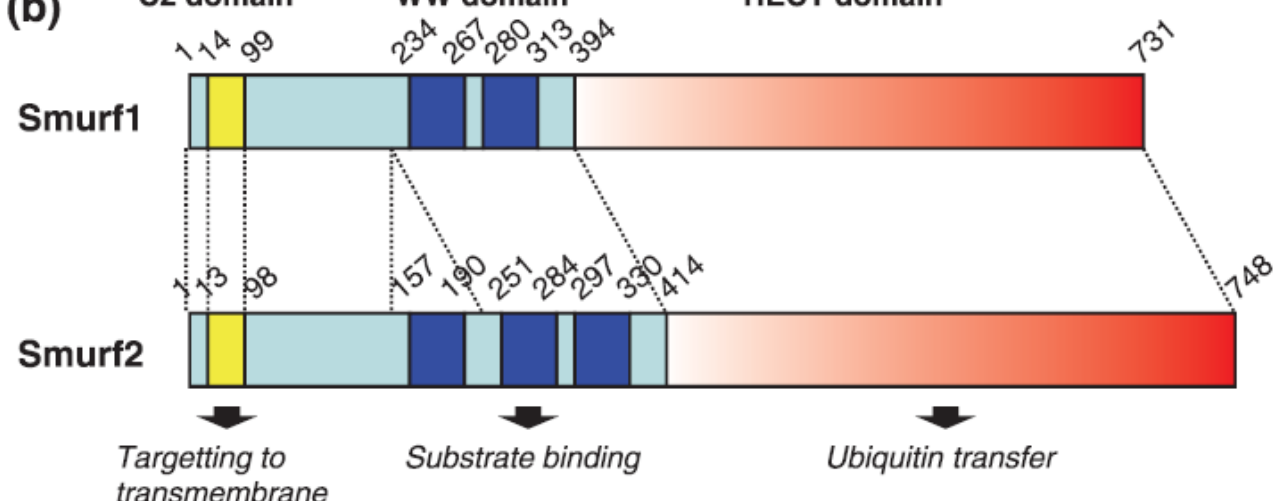

Abbildung 1.5: Struktur von SMADs und SMURF1/2 sowie Interaktion zwischen SMADs und SMURF1/2; R- sowie Co-SMAD mit MH1-Domäne, MH2-Domäne und Linker-Region; I-SMAD ohne MH1-Domäne; PY-Motiv als Stelle der Interaktion zwischen SMURF1/2 und SMADs; R-SMAD mit SSXS-Motiv zur Phosphorylierung durch membranständige Serin-/Threonin-Kinase-Rezeptoren; SMURF1/2 mit C2-, WW- sowie HECT-Domäne (Inoue und Imamura 2008). Der Abdruck erfolgt mit freundlicher Genehmigung des Wiley-Blackwell-Verlags.

\subsubsection{SMURF1/2 in der Entwicklung der Osteoarthrose}

SMURF1 und SMURF2 beeinflussen die intrazelluläre Antwort von Zellen nach Stimulation von BMP und TGF- $\beta$, indem sie Strukturen, die an diesen Signalkaskaden beteiligt sind, in ihrer Funktion beeinflussen oder dem UPS zuführen (Nie et al. 2010; David et al. 2013).

Eine Dysregulation von Chondrozyten steht in direkter Verbindung mit Knorpeldegenerationen im Rahmen einer OA (Shen et al. 2014). TGF- $\beta$ ist in allen Stadien der Chondrogenese sowie der Homöostase der Chondroyzten beteiligt (van der Kraan et al. 2012). Zudem nehmen BMP, SMADs sowie RUNX2 und SOX9 
Einfluss auf die Differenzierung von Chondrozyten (Green et al. 2015). Zhao et al. (2003) zeigten, dass SMURF1 einen Abbau von RUNX2 vermittelt.

Wu et al. (2008) konnten in einem Mausmodell zeigen, dass eine induzierte Überexpression von SMURF2 mit einem vermehrten Abbau von aktiviertem SMAD3 und der Entwicklung eines osteoarthrotischen Phänotyps assoziiert ist. Die eingesetzten transgenen Mäuse entwickelten Defekte im Kniegelenkknorpel, Fibrillationen, subchondrale Sklerosen und Osteophyten. Auf molekularer Ebene konnte eine erhöhte Synthese von Kollagen X und MMP-13 beobachtet werden.

In Meniskus-Progenitorzellen (MPCs), die gegenüber der Regulation durch RUNX2 und SOX9 Ähnlichkeiten zu CPCs aufweisen, konnte eine Verbindung zwischen den BMP- sowie TGF- $\beta$-Signalwegen und dem chondrogenen Potential von MPCs nachgewiesen werden. Hierbei führte eine Stimulation von MPCs durch TGF- $\beta$ zu einer erhöhten Expression von SMAD2/3 und SOX9 sowie einem verringertem Nachweis von RUNX2 (Muhammad et al. 2014).

Diese Untersuchungen deuten darauf hin, dass SMURF1/2 die Entwicklung einer OA sowie die Regenerationsfähigkeit der daran beteiligten Strukturen beeinflussen, weshalb eine genauere Betrachtung ihrer Funktionen in den dargestellten Signalkaskaden innerhalb von CPCs untersucht werden sollte. 


\subsection{Aufgabenstellung}

Im Rahmen dieser Dissertation soll SMURF1 bezüglich seiner Funktionen in der chondrogenen Differenzierung von CPCs untersucht werden. Hierfür sollen die Funktionen von SMURF1 innerhalb des TGF- $\beta$ - sowie BMP-Signalwegs betrachtet und mögliche Wechselwirkungen zwischen SMURF1 und den Transkriptionsfaktoren SOX9 sowie RUNX2 analysiert werden.

Zusätzlich sollen durch die Betrachtung möglicher Wechselwirkungen zwischen SMURF2 und SOX9 sowie RUNX2 die Funktionen von SMURF2 in der chondrogenen Differenzierung von CPCs untersucht werden.

Für einen immunhistochemischen Nachweis von SMURF1 sowie SMURF2 sollen Gewebeproben von resezierten Kniegelenksoberflächen gewonnen werden. Zudem sollen humane Zellen aus osteoarthrotischem Knorpel des Kniegelenks kultiviert werden, in denen SMURF1 und SMURF2 immunzytologisch nachgewiesen werden sollen. Durch Überexpression und Knockdown sollen die intrazelluläre Proteinkonzentration von SMURF1 und SMURF2 in immortalisierten CPCs moduliert und der daraus mögliche resultierende Einfluss auf den chondrogenen Charakter der CPCs auf Proteinebene mithilfe des Western Blots untersucht werden. Hierzu sollen die Proteine SOX9 und RUNX2 bei Überexpression und Knockdown von SMURF1 sowie SMURF2 betrachtet werden.

Zur Untersuchung der Funktionen von SMURF1 innerhalb des TGF- $\beta$ - sowie BMPSignalwegs sollen SMAD1 sowie SMAD2/3 bei Überexpression sowie Knockdown von SMURF1 auf Proteinebene untersucht werden.

Die Ergebnisse dieser Untersuchung sollen Erkenntnisse über Wechselwirkungen zwischen Mitspielern in den betrachteten Signalwegen der chondrogenen Differenzierung von CPCs liefern, um potentielle pharmakologische Zielstrukturen zur medikamentösen Behandlung der OA zu ermitteln. 


\section{Material und Methoden}

\subsection{Gewebe- und zellbiologische Methoden}

Die hier beschriebenen Methoden wurden zur Gewinnung der Gewebeproben und der zu untersuchenden Zellen eingesetzt. Es werden die Prozesskette vom intraoperativ erzeugten humanen Resektionsmaterial bis zur Kultivierung der CPCs sowie die Verarbeitung der Gewebeproben zu histologischen Präparaten dargestellt.

\subsubsection{Gewebeisolation und Präparation}

Das zu untersuchende Gewebe wurde aus Resektionsmaterial gewonnen, das im Rahmen von Kniearthroplastiken reseziert wird. Dabei handelt es sich um Tibiaplateaus und Femurkondylen von Erwachsenen im Alter von 65 - 75 Jahre. Die operativen Eingriffe wurden in der orthopädischen Abteilung des Akademischen Lehrkrankenhauses Neu-Mariahilf in Göttingen durchgeführt. Die behandelten Patienten erfüllten die Klassifikationskriterien des American College of Rheumatology für Gonarthrose (Altman et al. 1986) und gaben präoperativ ihre schriftliche Einwilligung zur Verwendung der Gewebeproben für wissenschaftliche Zwecke. Die vorliegende Dissertation, die auf Grundlage dieser Gewebeproben angefertigt wurde, wurde von der Ethikkommission der Medizinischen Fakultät der Georg-AugustUniversität Göttingen unter der Antragsnummer Dok 25/12/10 geprüft und genehmigt. Das Resektionsmaterial wurde intraoperativ in einen autoklavierten Transportbehälter gegeben und mit einer Nährlösung (50 ml Dubecco's-Modified-Eagle's Medium +GlutaMAX ${ }^{\mathrm{TM}}$ (DMEM+GlutaMAX ${ }^{\mathrm{TM}}$ ) + $50 \mathrm{ml}$ phosphate-buffered saline (PBS)) versetzt (Zusammensetzung PBS siehe Tabelle 2.1). Zudem wurden Alter, Geschlecht sowie Gewicht der operierten Patienten dokumentiert. Unter sterilen Bedingungen wurde der Inhalt der Transportbehälter im Labor makroskopisch inspiziert und durch Zugabe von PBS vor Austrocknung geschützt. Die histopathologische Untersuchung des Kniegelenkknorpels bestätigte die Diagnose einer hochgradigen OA (Pritzker et 
al. 2006). Die Gewebeproben wurden für immunhistochemische Untersuchungen sowie zur Zellisolierung verwendet.

\begin{tabular}{|lll|}
\hline PBS $\quad 81,8 \mathrm{~g}$ & $\mathrm{NaCl}$ \\
$16,0 \mathrm{~g}$ & $\mathrm{Na}_{2} \mathrm{HPO}_{4}$ (AppliChem, Darmstadt, D) \\
$2,0 \mathrm{~g}$ & $\mathrm{KCl}$ \\
$2,0 \mathrm{~g}$ & $\mathrm{KH}_{2} \mathrm{HPO}_{4}$ (Merck, Darmstadt, D) \\
& Auffüllen auf 1 I mit Aqua dest. \\
& $\mathrm{pH}=7,4$ einstellen \\
\hline Tabelle 2.1: PBS-Zusammensetzung
\end{tabular}

\subsubsection{Immunhistochemie}

Immunhistochemische Methoden ermöglichen den histologischen Nachweis von Proteinen sowie deren Lokalisation in einem Gewebeschnitt mittels Antikörperreaktion. In der vorliegenden Arbeit wurden mithilfe des HiDef Detection Alkalische Phosphatase PolymerSystem (Ca. No. 962D-12) von Cell Marque (Rocklin, USA) SMURF1 sowie SMURF2 in humanem osteoarthrotischem Knorpel des Kniegelenks nachgewiesen. Hierzu bindet zunächst der primäre Antikörper (siehe Tabelle 2.2) an das nachzuweisende Protein.

\begin{tabular}{|llll|}
\hline \multicolumn{4}{c|}{ primäre Antikörper } \\
Name & Anbieter / Produkt & Spezies & Verdünnung \\
SMURF1 & $\begin{array}{l}\text { Abnova } \\
\text { M01, clone 1D7 }\end{array}$ & $\begin{array}{l}\text { Maus } \\
\text { IgG, monoklonal }\end{array}$ & $1: 50$ \\
SMURF2 & $\begin{array}{l}\text { Santa Cruz } \\
\text { sc130878 }\end{array}$ & $\begin{array}{l}\text { Kaninchen } \\
\text { lgG, monoklonal }\end{array}$ & $1: 50$ \\
\hline
\end{tabular}

Tabelle 2.2: Liste der verwendeten primären Antikörper zur immunhistologischen Untersuchung

Ein an alkalische Phosphatase gekoppelter sekundärer Antikörper bindet daraufhin an den primären Antikörper. Dieses gekoppelte Enzym katalysiert eine Reaktion des Chromogen PermaRed, das hierdurch einen Farbumschlag erfährt und die immunologisch markierten Proteine bei lichtmikroskopischer Untersuchung in der Farbe Rot sichtbar werden lässt. Eine Gegenfärbung der umliegenden Strukturen ermöglicht eine Bewertung des histologischen Schnitts und die Lokalisation der immunologisch markierten Proteine. Für die vorliegende Arbeit wurde bereits von der Arbeitsgruppe präpariertes, in Paraffin eingebettetes Knorpelgewebe aus osteoarthrotischem 
Kniegelenkknorpel verwendet. Mit einem Mikrotom (Leica, Nussloch, DE) wurden hieraus histologische Schnitte mit einer Stärke von $4 \mu \mathrm{m}$ erzeugt. Darauffolgend wurden diese Schnitte mithilfe eines Pinsels in ein Wasserbad mit einer Temperatur von $37^{\circ} \mathrm{C}$ gelegt und anschließend auf einen Objektträger (Thermo Scientific, Braunschweig, DE) überführt. Das angewendete Protokoll der hiernach durchgeführten immunhistochemischen Färbung ist in Tabelle 2.3 dargestellt.

\begin{tabular}{|c|c|c|}
\hline Schritt & Substrat & Zeit \\
\hline Entparaffinieren & Xylol & $2 \times 10 \min$ \\
\hline absteigende Alkoholreihe & Ethanol $100 \%-50 \%$ & je $5 \mathrm{~min}$ \\
\hline Waschen & TBS-T & $10 \mathrm{~min}$ \\
\hline Blocken & Universalblock & $30 \mathrm{~min}$ \\
\hline Waschen & TBS-T & $3 \times 3 \mathrm{~min}$ \\
\hline Antigendemaskierung & Protaqs, $60^{\circ} \mathrm{C}$ & $20 \mathrm{~min}$ \\
\hline Waschen & TBS-T & $3 \times 3 \mathrm{~min}$ \\
\hline Vorverdau & Protease 24 & $2 \min$ \\
\hline Waschen & TBS-T & $3 \times 3 \min$ \\
\hline Blocken & $1 \% \mathrm{BSA} / \mathrm{TBS}$ & $10 \mathrm{~min}$ \\
\hline primärer Antikörper & SMURF $1 / 2$ & ca.16 h (über Nacht) \\
\hline Waschen & TBS-T & $3 \times 5 \min$ \\
\hline sekundärer Antikörper & HiDef Amplifier & $30 \mathrm{~min}$ \\
\hline Waschen & TBS-T & $3 \times 3 \mathrm{~min}$ \\
\hline Polymer & HiDef Polymer & $20 \min$ \\
\hline Waschen & TBS-T & $3 \times 3 \min$ \\
\hline Chromogenfärbung & PermaRed & $9 \min$ \\
\hline Waschen & TBS-T & $8 \min$ \\
\hline Gegenfärbung & Lichtgrün (1:4) & $90 \mathrm{sec}$ \\
\hline Waschen & Essigsäure $1 \%$ & wenige Sekunden \\
\hline \multirow[t]{2}{*}{ Dehydrieren } & Ethanol $50 \%-100 \%$ & je $1 \mathrm{~min}$ \\
\hline & Xylol & $2 \times 10 \min$ \\
\hline
\end{tabular}




\subsubsection{Zellisolierung und -anzucht der chondrogenen Progenitorzellen}

Zur Zellisolierung wurden aus dem Randbereich des makroskopisch ersichtlichen degenerativen Knorpelanteils des Resektionsmaterials Gewebequader entnommen. Hierfür wurde der beschriebene Bereich mit einem Skalpell eingekerbt und durch einen Schnitt im rechten Winkel zur Kerbe Gewebequader mit einer Kantenlänge von etwa $2 \mathrm{~mm}$ gewonnen. Diese wurden in $75 \mathrm{~cm}^{2}$ große Zellkulturflaschen (Sarstedt, Newton, USA), die zuvor mit $10 \mathrm{ml}$ Kulturmedium (DMEM+/+, siehe Tabelle 2.4) befüllt wurden, überführt. Die Zellkulturflaschen wurden $10-14$ Tage bei $37^{\circ} \mathrm{C}$, einer relativen Luftfeuchtigkeit von $95 \%$, bei atmosphärischem Druck und einer $\mathrm{CO}_{2}$-Konzentration von $5 \%$ in einem Brutschrank (Heraeus, Hanau, D) inkubiert. Der Prozess der Migration und Besiedelung der Kulturflaschen durch primäre CPCs aus den Gewebeproben wurde täglich mikroskopisch (Axiovert 40 CFL Zeiss, Göttingen, DE) geprüft.

\begin{tabular}{|ll|}
\hline DMEM +/+ & $500 \mathrm{ml}$ DMEM+GlutaMax \\
& $50 \mathrm{ml}$ fetales Kälberserum (FCS) (GIBCO, Paisley, UK) \\
& $500 \mu \mathrm{l}$ Gentamycin (PromoCell, Heidelberg, D)) \\
\hline
\end{tabular}

Tabelle 2.4: DMEM+/+-Zusammensetzung

\subsubsection{Kultivieren und Passagieren der chondrogenen Progenitorzellen}

Durch den bisher beschriebenen Prozess konnten humane primäre CPCs aus osteoarthrotischem Kniegelenkknorpel gewonnen werden. Das Kulturmedium DMEM+/+ wurde in einem Abstand von drei Tagen gewechselt.

Bei einer mikroskopisch (Axiovert $40 \mathrm{CFL}$ Zeiss, Göttingen, DE) beobachteten Konfluenz von etwa $60 \%$ wurden die Zellen passagiert, womit die Ausbildung von interzellulären Kontakten sowie eine Differenzierung der primären CPCs vermieden wurde. Hierzu wurde zunächst das Kulturmedium verworfen und der Boden der Zellkulturflaschen zweimal mit PBS gewaschen. Anschließend wurden $2 \mathrm{ml}$ Trypsin hinzugegeben und die Zellkulturflaschen ein bis zwei Minuten im Brutschrank inkubiert. Dabei erfolgte die Lagerung der Zellkulturflaschen in horizontaler Ausrichtung, wodurch eine flächendeckende Benetzung der Zellen am Boden der Zellkulturflaschen erreicht werden konnte. Nach Inkubation wurden die Zellen unter visueller mikroskopischer Kontrolle durch leichtes seitliches Klopfen gegen die Zellkulturflaschen gelöst. Die hierdurch abgelösten Zellen wurden in ein 50-ml-Röhrchen (Falcon Tube) 
überführt. Durch Zugabe von $2 \mathrm{ml}$ DMEM+/+ wurde die enzymatische Reaktion des Trypsin gestoppt. Anschließend wurden die Zellkulturflaschen zweimal mit 2,5 ml PBS gespült, um die restlichen Zellen aus den Flaschen zu entfernen. Diese wurden ebenfalls in das 50 -ml-Röhrchen überführt. Hiernach wurden die Zellen $10 \mathrm{~min}$ bei $300 \mathrm{~g}$ abzentrifugiert und der Überstand entfernt. Das Zellpellet wurde in $1 \mathrm{ml}$ PBS resuspendiert und die Lebendzellzahl mithilfe eines Zellzählautomaten (Cellometer Auto T4 Cell Counter Nexcelom Bioscience, Lawrence, USA) bestimmt.

Im Anschluss wurden die Zellen neu ausgesät. Hierfür wurden die Zellkulturflaschen mit $10 \mathrm{ml} \mathrm{DMEM+/+} \mathrm{befüllt} \mathrm{und} \mathrm{mit} 5 \cdot 10^{4}$ Zellen beimpft. Die überschüssigen Zellen wurden erneut $10 \mathrm{~min}$ bei $300 \mathrm{~g}$ zentrifugiert, der Überstand abpipettiert und das daraus gewonnene Zellpellet bei $-80^{\circ} \mathrm{C}$ eingelagert. Im Rahmen der Labordokumentation wurde jeweils eine Identifikationsnummer für die behandelte Zelllinie vergeben und die Passagenanzahl, die Zellzahl der eingefrorenen Zellpellets sowie das Datum der Passage notiert.

\subsubsection{Immortalisierte chondrogene Progenitorzellen}

Im Rahmen der vorliegenden Arbeit wurde eine immortalisierte Zelllinie chondrogener Progenitorzellen untersucht. Diese wurde durch einen lentiviralen Gentransfer mit dem Gen zur Ausbildung der human telomerase reverse transcriptase (hTERT) aus primären CPCs erzeugt und in Zellkulturfalschen von der Arbeitsgruppe zur Verfügung gestellt. Die dargestellte Methodik des Kultivierens sowie Passagierens wurde unverändert an dieser Zelllinie angewendet. Die untersuchte immortalisierte Zelllinie wird im Folgenden als CPCht bezeichnet. Die zu untersuchenden Proteine SMURF1 und SMURF2 wurden sowohl in primären als auch immortalisierten CPCs nachgewiesen, siehe Kapitel 3.1.3. 


\subsubsection{Immunzytologie}

Immunzytologische Methoden dienen dem Nachweis sowie der Lokalisation von Proteinen mittels Antikörperreaktion innerhalb einzelner Zellen. In der vorliegenden Arbeit wurde SMURF1 und SMURF2 in CPCht nachgewiesen.

CPCht wurden in einer 24-Well-Platte zu je 2,5 $10^{3}$ Zellen auf sterilen Deckgläschen (DG) ausgesät und 5 Tage in DMEM+/+ im Brutschrank inkubiert. Nach dieser Anwachsphase wurde das restliche $\mathrm{DMEM}+/+$ von den $D G$ mithilfe einer Wasserstrahlpumpe abgesaugt. Mithilfe einer Pinzette wurden die DG auf Parafilm gelegt und zweimal mit je $100 \mu$ l PBS gewaschen. Die Wasch- und Inkubationslösungen wurden hierbei jeweils mit der Wasserstrahlpumpe abgesaugt. Nach der Fixierung der Zellen mit $100 \mu$ pro DG für 15 min mit $2 \%$ Paraformaldehyd (Roth, Karlsruhe, DE) in PBS folgte ein Waschschritt mit $2 \times 100 \mu$ PBS pro DG. Zur Permeabilisierung der Zellmembran wurden die Zellen mit $100 \mu$ l pro DG 0,25 \% Triton-X100 (Sigma-Aldrich, Steinheim, DE) in PBS für 10 min inkubiert. Hierauf folgte ein weiterer Waschschritt mit $2 \times 100 \mu \mathrm{l}$ PBSproDG. Anschließend wurden die Proben mit $100 \mu \mathrm{l}$ pro DG $1 \%$ BSA in PBS geblockt, um unspezifische Bindungen des primären Antikörpers zu verhindern.

Der primäre Antikörper wurde mit 1\% BSA in PBS verdünnt und in einer feuchten Kammer bei $37^{\circ} \mathrm{C}$ für 60 min inkubiert. Nach einem weiteren Waschschritt mit $2 \times 100 \mu \mathrm{l}$ PBS pro DG wurde der enzymgekoppelte sekundäre Antikörper (gekoppelt mit Alexa 555 rot) zu 1:1000 mit 1\% BSA in PBS + 4',6-Diamidin-2-phenylindol (DAPI) verdünnt und mit $50 \mu \mathrm{l}$ pro DG aufgetragen. Die Inkubation fand für 60 min erneut in einer feuchten Kammer bei $37^{\circ} \mathrm{C}$ statt. Anschließend folgte ein Waschschritt mit $2 \mathrm{x}$ $100 \mu \mathrm{l}$ PBS pro DG. Zuletzt wurden die Proben mit etwa $10 \mu \mathrm{l}$ Mounting Medium (Mowiol 4-88) auf einem Objektträger eingedeckt und das überschüssige Eindeckmedium abgesaugt.

DAPI stellt Zellkerne durch Bindung an DNA bei Betrachtung mithilfe des Fluoreszenzmikroskops blau dar, womit eine räumliche Referenz zur Lokalisation der immunmarkierten Proteine erzeugt wird. Die eingedeckten Proben konnten für etwa zwei Wochen bei $4^{\circ} \mathrm{C}$ gelagert werden. Die in der Immunzytologie eingesetzten Antikörper sind in Tabelle 2.5 aufgelistet. 


\begin{tabular}{|c|c|c|c|}
\hline \multicolumn{4}{|c|}{ primäre Antikörper } \\
\hline Name & Anbieter / Produkt & Spezies & Verdünnung \\
\hline SMURF1 & $\begin{array}{l}\text { Abnova } \\
\text { M01, clone 1D7 }\end{array}$ & $\begin{array}{l}\text { Maus } \\
\text { lgG, monoklonal }\end{array}$ & $1: 10$ \\
\hline SMURF2 & $\begin{array}{l}\text { Santa Cruz } \\
\text { sc130878 }\end{array}$ & $\begin{array}{l}\text { Kaninchen } \\
\text { lgG, monoklonal }\end{array}$ & $1: 50$ \\
\hline \multicolumn{4}{|c|}{ sekundäre Antikörper, gekoppelt mit Alexa 555 rot } \\
\hline Name & Anbieter / Produkt & Spezies & Verdünnung \\
\hline Anti-Maus & $\begin{array}{l}\text { Abcam } \\
\text { ab150114 }\end{array}$ & $\begin{array}{l}\text { Ziege } \\
\text { lgG, polyklonal }\end{array}$ & $1: 1000$ \\
\hline Anti-Kaninchen & $\begin{array}{l}\text { Abcam } \\
\text { ab150074 }\end{array}$ & $\begin{array}{l}\text { Esel } \\
\text { lgG, polyklonal }\end{array}$ & $1: 1000$ \\
\hline
\end{tabular}

Tabelle 2.5: Liste der verwendeten Antikörper zur immunzytologischen Untersuchung

\subsection{Quantitative Real-Time Polymerase Chain Reaction}

Die quantitative real-time polymerase chain reaction (qRT-PCR) ist ein Verfahren zur Vervielfältigung spezifischer Nukleinsäuren, das gleichsam die Quantifizierung der Ausgangsmenge der vervielfältigten Nukleinsäure in einer Probe in Echtzeit ermöglicht. Mit der qRT-PCR ist demnach die Quantifizierung eines spezifischen messenger ribonucleic acid (mRNA) -Abschnitts einer Zelllinie realisierbar. Durch Normalisierung mithilfe von Housekeeping-Genen ist zudem ein Vergleich von Transkriptionsniveaus verschiedener Zelllinien möglich.

Das Grundprinzip der qRT-PCR beschreibt die Polymerase-Kettenreaktion (Polymerase Chain Reaction). Zur Durchführung einer PCR werden Nukleosidtriphosphate und eine thermostabile DNA-Polymerase (Taq-Polymerase des Bakteriums Thermus aquaticus), spezifische DNA-Primer sowie ein interkalierender fluoreszierender Farbstoff eingesetzt. Drei sich zyklisch wiederholende Phasen beschreiben den Ablauf einer PCR. Zunächst wird die vorliegende DNA durch Erhitzen auf $95^{\circ} \mathrm{C}$ denaturiert. In der zweiten Phase wird die Temperatur auf die Primerspezifische Annealing-Temperatur reduziert, sodass sich die Primer an die DNAEinzelstränge anlagern. In Phase drei synthetisiert die Taq-Polymerase die Komplementärstränge. Die dargestellten Phasen werden automatisiert in einem Thermocycler (Mastercycler, Eppendorf, Hamburg, DE) ausgeführt. Nach jedem Zyklus verdoppelt sich näherungsweise der zu vervielfältigende DNA-Abschnitt, der 
durch den Forward- und Reverse-Primer definiert ist. Der Fluoreszenzfarbstoff (SYBRGreen) bindet an der kleinen Furche der DNA. Damit besteht eine Korrelation zwischen der Anzahl vorhandener DNA-Stränge und der Fluoreszenzintensität. Diese wird in Echtzeit im Thermocycler nach jedem Zyklus gemessen und somit quantifiziert. Der ctWert (cycle threshold) beschreibt die Anzahl an Zyklen, die durchlaufen werden, bis ein definierter Schwellenwert der Fluoreszenzintensität erreicht wird. Damit ist der ct Wert ein reziprokes Maß für die Menge des zu quantifizierenden mRNA-Abschnitts.

\subsubsection{RNA-Isolierung}

Zur Isolierung der RNA aus zuvor erzeugten Zellpellets wurde das peqGOLD-TotalRNA-Kit (PEQLAB Biotechnologie, Order No. 12-6834-02) verwendet. Die Zellzahl betrug hierbei $10^{5}$ Zellen. Diese wurden in $400 \mu \mathrm{l} R N A-$ Lysis-Buffer-T lysiert. Das entstandene Lysat wurde anschließend auf eine DNA-Removing-Column pipettiert, deren Auslass in ein Sammelröhrchen mündete. Der Durchfluss wurde nach einer Zentrifugation von $1 \mathrm{~min}$ bei $12.000 \mathrm{~g}$ mit dem identischen Volumen von $70 \%$ Ethanol versetzt und mittels Pipette durchmischt. Diese Lösung wurde auf eine PerfectBindRNA-Column pipettiert, deren Auslass wiederum in ein Sammelröhrchen mündete. Nach Zentrifugation über $1 \mathrm{~min}$ bei $10.000 \mathrm{~g}$ wurde der Durchfluss verworfen. Nun folgten ein Waschschritt mit $500 \mu \mathrm{l}$ RNA-Wash-Buffer-1 sowie zweimaliges Waschen mit $600 \mu \mathrm{l}$ RNA-Wash-Buffer-2, wobei zwischen den Waschschritten jeweils eine Zentrifugation über $30 \mathrm{~s}$ bei $10.000 \mathrm{~g}$ erfolgte und der Durchfluss verworfen wurde. Hiernach schloss sich ein weiterer Zentrifugationsschritt für 2 min bei $10.000 \mathrm{~g}$ an. Zuletzt wurde die RNA mit 30 - $50 \mu \mathrm{l}$ RNAse-freiem Wasser aus der PerfectBind-RNAColumn gelöst. Dafür wurde die PerfectBind-RNA-Column auf ein Biopur-1,5 mlEppendorf-Cup gesteckt und nach Zugabe RNAse-freien Wassers über $1 \mathrm{~min}$ bei $5000 \mathrm{~g}$ zentrifugiert.

Die Konzentration der gewonnenen RNA wurde mithilfe des UV/VIS Nanodrop-1000Spectrometers (PeqLab Biotechnologie GmbH, Erlangen, DE) nach den Angaben des Herstellers bestimmt. Das Absorptionsmaximum von Nukleinsäuren liegt bei einer Wellenlänge von $260 \mathrm{~nm}$. Ein weiteres Absorptionsmaximum liegt bei $280 \mathrm{~nm}$. Hierfür sind phenylhaltige Gruppen verantwortlich, die Teil der aromatischen Aminosäuren sind. Hierzu zählen Tryptophan, Phenylalanin, Tyrosin sowie Histidin. Mithilfe des 
Lambert-Beerschen Gesetzes werden aus den Extinktionen bei $260 \mathrm{~nm}$ sowie $280 \mathrm{~nm}$ eine 260/280-Ratio als Maß für die Reinheit der extrahierten RNA errechnet. Hierbei sind laut Herstellerangaben Werte zwischen 1,8 und 2,1 akzeptabel. Zudem wird eine 260/230-Ratio als Maß für die Qualität der Probe bestimmt. Bei einer Wellenlänge von $230 \mathrm{~nm}$ besitzen organische Verbindungen ein Absorptionsmaximum. Hier soll laut Herstellerangaben eine 260/230-Ratio von >1,8 liegen, um eine zu starke Kontamination der Probe durch organische Verbindungen auszuschließen. Die ermittelten Werte für die durch dieses Verfahren isolierte mRNA von SMURF1 und SMURF2 lagen im geforderten Bereich.

\subsubsection{Umschreiben von mRNA in cDNA}

Zur Durchführung der qRT-PCR wird DNA benötigt, da die hierbei eingesetzte thermostabile Taq-Polymerase die Funktion einer DNA-Polymerase besitzt. Das Umschreiben der isolierten mRNA in DNA erfolgt mithilfe einer reversen Transkriptase, sodass das Endprodukt dieses Prozesses als complementary DNA (cDNA) bezeichnet wird.

Hierfür wurde das QuantiTect-Reverse-Transcription-Kit (Cat. No. 205313) der Firma Qiagen verwendet. Der gesamte Prozess wurde auf Eis durchgeführt, womit eine Degradierung der RNA verhindert werden sollte. Zunächst wurden zu $200 \mathrm{ng}$ mRNA $2 \mu \mathrm{l}$ genomic-DNA-Wipeout-Buffer gegeben und mit RNAse-freiem Wasser auf ein Volumen von $14 \mu$ l verdünnt. Eine Inkubation der Probe über 2 min bei $42^{\circ} \mathrm{C}$ sollte mögliche DNA-Anteile entfernen. Anschließend wurde ein Mastermix hinzugegeben. Hierzu gehörten ein Pimermix $(1 \mu \mathrm{l})$, ein Transkriptionspuffer $(4 \mu \mathrm{l}$ Quantiscript-RTBuffer 5x) sowie eine reverse Transkriptase (1 $\mu$ l Quantiscript-Reverse-Transcriptase). Hiernach folgten eine Inkubation für $15 \mathrm{~min}$ bei $42^{\circ} \mathrm{C}$ sowie eine weitere Inkubation über $3 \mathrm{~min}$ bei $95^{\circ} \mathrm{C}$, womit die reverse Transkription durchgeführt und sämtliche Enzyme deaktiviert wurden. Für die weitere Betrachtung der Konzentration der erhaltenen cDNA wird die Annahme getroffen, dass durch die reverse Transkription cDNA im gleichwertigen Verhältnis zur mRNA entstanden ist. Es folgte eine Verdünnung der Probe mittels RNAse-freien Wassers zu einer DNA-Konzentration von $1 \mathrm{ng} \cdot \mathrm{\mu l}^{-1}$ und eine Lagerung bei $-20^{\circ} \mathrm{C}$. 


\subsubsection{Entwerfen der Primer}

Primer zur quantitativen Bestimmung der mRNA von SMURF1 und SMURF2 wurden mithilfe der frei zugänglichen Software Primer3 Version 4.0.0 sowie dem Primer-Basic Local Alignment Search Tool (BLAST) entworfen. Dabei wurden die folgenden Parameter als Auswahlkriterien berücksichtigt:

- Primerlänge 18-23 Basenpaare

- Guanin / Cytosinanteil 40-60\%

Mittels BLAST wurden die entworfenen Sequenzen der Primer durch Abgleich mit der NCBI (National Center for Biotechnology Information) -Datenbank überprüft, sodass mögliche zusätzliche PCR-Produkte ausgeschlossen werden konnten. Somit wurde die Spezifität der Primer für die zu untersuchenden mRNA von SMURF1 sowie SMURF2 erreicht. Die ermittelten Primer wurden salzfrei bereinigt bei der Firma Eurofins Genomics in Bestellung gegeben und lyophilisiert geliefert. Bei Lieferung wurden die Primer durch Zugabe RNAse-freien Wassers auf eine Konzentration von $10 \mathrm{pmol} \cdot \mathrm{\mu l}^{-1}$ eingestellt und bei $-20^{\circ} \mathrm{C}$ eingelagert.

\subsubsection{Gradienten-PCR}

Eine Gradienten-PCR dient zur Bestimmung der spezifischen Annealing-Temperatur eines Primers und demnach der Temperatur, bei der eine optimale Bindungsfähigkeit des Primers an den zu kopierenden DNA-Strang erreicht wird. Hierfür wurden für die Primer zur quantitativen Bestimmung von SMURF1 und SMURF2 für 12 Kavitäten unterschiedliche Annealing-Temperaturen im Thermocycler eingestellt und die Schmelzkurven betrachtet. Deren Verlauf ist exemplarisch für SMURF1 für die Annealing-Temperaturen $60,7^{\circ} \mathrm{C}$ sowie $62,9^{\circ} \mathrm{C}$ in Abbildung 2.1 dargestellt. 

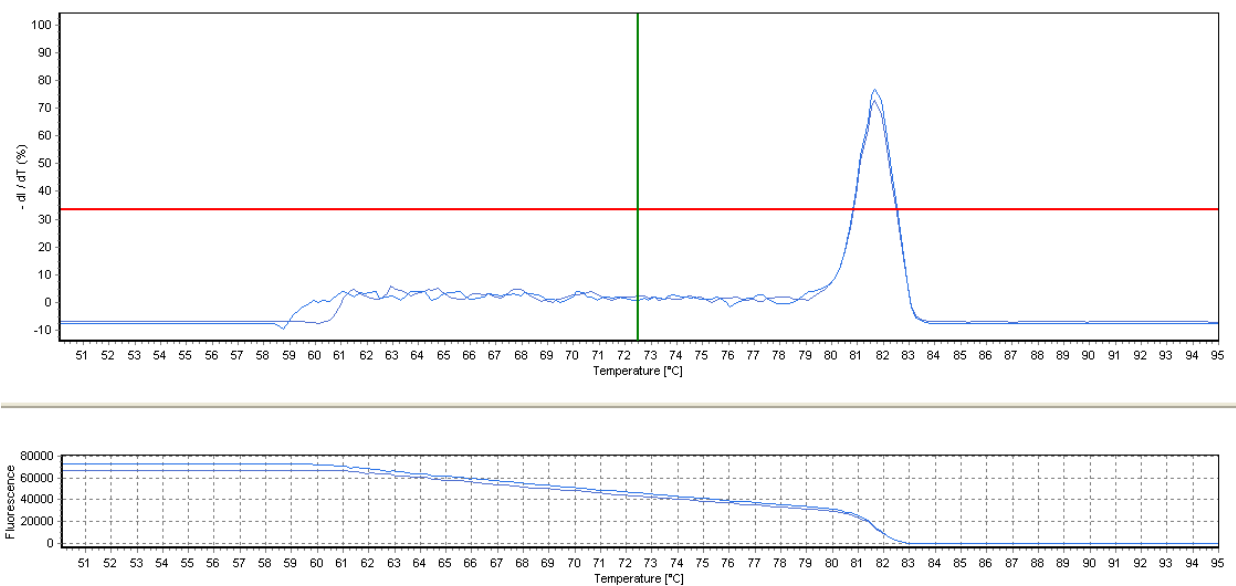

Abbildung 2.1: Schmelzkurve von SMURF1

Im zeitlichen Differential der relativen negativen Intensität der ausgestrahlten Fluoreszenz zeigt sich jeweils ein Maximum im Bereich von etwa $81,5^{\circ} \mathrm{C}$ woraus sich ergibt, dass ausschließlich ein einzelnes PCR-Produkt entstanden ist.

Die Produkte der PCR, die bei einer Annealing-Temperatur von $60,7^{\circ} \mathrm{C}$ sowie $62,9^{\circ} \mathrm{C}$ entstanden sind, wurden zur Kontrolle ihrer Spezifität von der Firma Seqlab, Göttingen sequenziert und die ermittelten Sequenzen mithilfe von BLAST eindeutig der mRNA von SMURF1 sowie SMURF2 zugeordnet. Somit wurde für SMURF1 und SMURF2 eine Annealing-Temperatur von $62^{\circ} \mathrm{C}$ festgelegt. Diese entspricht damit etwa dem Mittelwert der beiden ermittelten optimalen Temperaturen zur Anlagerung der Primer. Der Ansatz zur Durchführung der Gradienten-PCR setzte sich pro Kavität, wie in folgender Tabelle aufgelistet, zusammen:

\begin{tabular}{|lc|}
\hline SYBR-Green & $10 \mu \mathrm{l}$ \\
Primermix (Forward + Reverse) & $4 \mu \mathrm{l}$ \\
DEPC- $\mathrm{H}_{2} \mathrm{O}$ & $4 \mu \mathrm{l}$ \\
cDNA aus CPCht & $2 \mu \mathrm{l}$ \\
\hline Gesamtvolumen & $20 \mu \mathrm{l}$ \\
\hline
\end{tabular}

Tabelle 2.7 stellt das Protokoll zur Durchführung der Gradienten-PCR mittels Thermocycler dar. 


\begin{tabular}{|lll|}
\hline Phase & Temperatur & Zeit \\
Initiale Aktivierung & $95^{\circ} \mathrm{C}$ & $5 \mathrm{~min}$ \\
Denaturierung & $95^{\circ} \mathrm{C}$ & $15 \mathrm{~s}$ \\
Annealing & $52^{\circ} \mathrm{C}-68,5^{\circ} \mathrm{C}(12$ Kavitäten $)$ & $15 \mathrm{~s}, 45$ Zyklen \\
Elongation & $72^{\circ} \mathrm{C}$ & $20 \mathrm{~s}$ \\
Finale Extension & $72^{\circ} \mathrm{C}$ & $10 \mathrm{~min}$ \\
Schmelzkurve & Annealing-Temperatur des Primers $-1^{\circ} \mathrm{C}$ bis $95^{\circ} \mathrm{C}$ in & $15 \mathrm{~s}$ \\
& $0,2^{\circ} \mathrm{C}$ Schritten & je $8 \mathrm{~s}$ \\
\hline
\end{tabular}

Tabelle 2.7: Protokoll der Gradienten-PCR

\subsubsection{Verwendete Primer}

Die folgende Tabelle zeigt die verwendeten Forward- und Reverse-Primer sowie deren ermittelte optimale Annealing-Temperatur.

\begin{tabular}{|lll|}
\hline Zielgen & $\begin{array}{l}\text { Forward-Primer } 5^{\prime}-3^{\prime} \\
\text { Reverse-Primer } 5^{\circ}-3^{\prime}\end{array}$ & $\begin{array}{l}\text { Annealing- } \\
\text { Temperatur }\end{array}$ \\
SMURF1 & $\begin{array}{l}\text { TTGGCTTTGGTCACACAGGA } \\
\text { CAAACCCTCAATCAGCCACG }\end{array}$ & $62^{\circ} \mathrm{C}$ \\
SMURF2 & $\begin{array}{l}\text { GCCTGACAGTACTCTGTGCAAA } \\
\text { CCACTTTGGATCAAGC GTATTCTT }\end{array}$ & $62{ }^{\circ} \mathrm{C}$ \\
B2M & TGCTGTCTCCATGTTTGATGTATCT & $61^{\circ} \mathrm{C}$ \\
\hline
\end{tabular}

Tabelle 2.8: Die verwendeten Primer

\subsection{6 qRT-PCR-Protokoll}

Zur Durchführung der qRT-PCR wurde das HotStar-Taq-DNA-Polymerase-Kit der Firma Qiagen verwendet. Der hierfür notwendige Mastermix wurde pro Kavität, wie in Tabelle 2.9 gezeigt, hergestellt und in eine 96-Well-Platte (Biozym Scientific GmbH, Hessisch Oldendorf, DE) pipettiert. Die Well-Platte wurde anschließend mit OptivalFlap-Caps (Biozym Scientific GmbH, Hessisch Oldendorf, DE) verschlossen und anschließend für $10 \mathrm{~s}$ bei $200 \mathrm{~g}$ abzentrifugiert. Das Protokoll zur Konfiguration des Thermocyclers ist in Tabelle 2.10 dargestellt. Jede qRT-PCR zur Untersuchung der Zielgene wurde mit drei Ansätzen dreimal durchgeführt. 


\begin{tabular}{|lc|}
\hline SYBR-Green & $5 \mu \mathrm{l}$ \\
Primermix (Forward + Reverse) & $2 \mu \mathrm{l}$ \\
DEPC- $\mathrm{H}_{2} \mathrm{O}$ & $2 \mu \mathrm{l}$ \\
cDNA aus CPCht & $1 \mu \mathrm{l}$ \\
\hline Gesamtvolumen & $10 \mu \mathrm{l}$ \\
\hline
\end{tabular}

Tabelle 2.9: Pipettierschema der qRT-PC

\begin{tabular}{|lll|}
\hline Phase & Temperatur & Zeit \\
Initiale Aktivierung & $95^{\circ} \mathrm{C}$ & $5 \mathrm{~min}$ \\
Denaturierung & $95^{\circ} \mathrm{C}$ & $15 \mathrm{~s}$ \\
Annealing & abhängig vom Primer & $15 \mathrm{~s}, 45$ Zyklen \\
Elongation & $72^{\circ} \mathrm{C}$ & $20 \mathrm{~s}$ \\
Finale Extension & $72^{\circ} \mathrm{C}$ & $10 \mathrm{~min}$ \\
& Annealing-Temperatur des Primers $-1^{\circ} \mathrm{C}$ bis $95^{\circ} \mathrm{C}$ in & $15 \mathrm{~s}$ \\
Schmelzkurve & $0,2^{\circ} \mathrm{C}$ Schritten & je $8 \mathrm{~s}$ \\
\hline
\end{tabular}

Tabelle 2.10: qRT-PCR-Protokoll - Konfiguration Thermocycler

\subsection{7 qRT-PCR-Auswertung}

Die ct-Werte der qRT-PRC dienen als Grundlage für die Errechnung des relativen Verhältnisses der vorhandenen mRNA-Level in den betrachteten Zelllinien.

Die Normalisierung der Messwerte erfolgt nach der Methode von Pfaffl (Pfaffl 2001), wofür die Ermittlung des ct-Werts eines Housekeeping-Gens in allen betrachteten Zelllinien notwendig ist. In der vorliegenden Arbeit wurde $\beta 2-$ Mikroglobulin (B2M) als Housekeeping-Gen verwendet. Dieses kodiert für eine Proteinuntereinheit des Major Histocompatibility Complex (MHC) der Klasse 1, der sich auf der Oberfläche von kernhaltigen Zellen befindet und der Antigenpräsentation dient (Vandesompele et al. 2002). Näherungsweise ist das mRNA-Level dieses Gens in den betrachteten Zellinien als konstant anzunehmen und eignet sich demnach zur Normalisierung (Pombo-Suarez et al. 2008). Zudem wurden die ct-Werte aller untersuchter Zielgene in der Kontrollzelllinie CPCht bestimmt, um den Effekt des Knockdowns auf das mRNA-Level der betrachteten Zielgene zu erfassen und quantitativ zu beurteilen. Hierzu werden die normalisierten mRNA-Level der Proben in Relation zu den normalisierten mRNA-Level der Kontrollen gesetzt. 


\subsection{Western Blot}

Der Western Blot beschreibt ein Verfahren zum immunologischen Nachweis von antikörperspezifischen Proteinen auf einer Transfermembran mithilfe einer chemischen Lumineszenz-Reaktion. Im engeren Sinne beschreibt der Western Blot die Übertragung der zu untersuchenden Proteine von einem Gel, das zur elektrophoretischen Trennung von Proteinen verwendet wird, auf eine Membran, welche die Fähigkeit zur Bindung dieser Proteine besitzt, durch Anlegen eines elektrischen Feldes. In der vorliegenden Arbeit wurden ein Natriumdodecylsulfat-Polyacrylamid-Gel (SDS-Gel) sowie eine Polyvinylidenfluorid-Membran (PVDF -Membran) verwendet.

\subsubsection{Probenvorbereitung}

Zur Probenvorbereitung wurden Zellpellets, die nach dem in Kapitel 2.1.4 beschriebenen Prozess gewonnen wurden, in dem nach Tabelle 2.11 angesetzten Probenpuffer resuspendiert und mithilfe eines Vortexmischers durchmischt. Bei Zugabe des Probenpuffers wurde eine Zellkonzentration von $10^{4} Z_{\text {ellen }} \cdot \mathrm{ll}^{-1}$ eingestellt.

\begin{tabular}{|c|c|c|}
\hline Probenpuffer & $\begin{array}{l}900 \mu \mathrm{l} \\
100 \mu \mathrm{l}\end{array}$ & $\begin{array}{l}\text { SDS-Probenpuffer } 3 x \\
\beta \text {-Mercaptoethanol (Sigma-Aldrich, Steinheim, DE) }\end{array}$ \\
\hline SDS-Probenpuffer $3 x$ & $\begin{array}{r}3,6 \mathrm{~g} \\
9 \mathrm{~g} \\
22,5 \mathrm{~g}\end{array}$ & $\begin{array}{l}0,3 \mathrm{M} \text { TRIS (Roth, Karlsruhe, DE) } \\
9 \% \text { SDS (Roth, Karlsruhe, DE) } \\
22,5 \% \text { Glycerin (Roth, Karlsruhe, DE) } \\
\text { Spatelspitze Bromphenolblau } \\
\text { vor SDS-Zugabe mit } \mathrm{HCl} \text { auf } \mathrm{pH}=6,7 \text { einstellen } \\
\text { mit Aqua dest. auf } 100 \mathrm{ml} \text { auffüllen }\end{array}$ \\
\hline
\end{tabular}

Tabelle 2.11: Zusammensetzung der Probenpuffer

Anschließend wurden die Proben bei $95^{\circ} \mathrm{C}$ für 5 min inkubiert. Nach weiterem Durchmischen mittels Vortexmischer wurde die Probe erneut im Heizblock für 2 min bei $95^{\circ} \mathrm{C}$ inkubiert und darauffolgend in warmen Zustand auf das Gel zur Elektrophorese aufgetragen. 


\subsubsection{Natriumdodecylsulfat-Polyacrylamid-Gelelektrophorese}

Die Natriumdodecylsulfat-Polyacrylamid-Gelelektrophorese (SDS-PAGE) dient der räumlichen Trennung von Proteinen nach deren Masse. In der vorliegenden Arbeit wurde hierfür ein diskontinuierliches Gel nach Laemmli eingesetzt (Laemmli 1970), dessen Herstellung im Folgenden beschrieben wird.

Zunächst wurden zwei Glasplatten mit $100 \%$ Ethanol (AppliChem, Darmstadt, DE) gereinigt und Dichtungen entlang der aufliegenden Spacer eingelegt. Die zusammengelegten Glasplatten wurden durch Klammern miteinander fixiert und durch Befüllen des Plattenzwischenraums mit Aqua dest. auf Dichtheit überprüft. Mit einem wasserunlöslichen Stift wurde die Zielgrenze zwischen Sammel- und Trenngel bei $6 \mathrm{~cm}$ (gemessen vom unteren Rand) markiert, um eine reproduzierbare Höhe der Gele zu erreichen. Die Zusammensetzungen des Sammel- und Trenngels für jeweils zwei Gele sowie die dafür verwendeten Puffer sind in Tabelle 2.12 dargestellt.

\begin{tabular}{|c|c|c|}
\hline \multirow[t]{5}{*}{ Trenngel } & $2,8 \mathrm{ml}$ & Trenngelpuffer \\
\hline & $110 \mu \mathrm{l}$ & $10 \%$ SDS \\
\hline & $10 \mu \mathrm{l}$ & Tetramethylethylendiamin (TEMED) \\
\hline & $3,7 \mathrm{ml}$ & Acrylamid \\
\hline & $2,0 \mathrm{ml}$ & Aqua dest. \\
\hline \multirow[t]{5}{*}{ Sammelgel } & $1,25 \mathrm{ml}$ & Sammelgelpuffer \\
\hline & $50 \mu \mathrm{l}$ & $10 \%$ SDS \\
\hline & $5 \mu l$ & TEMED \\
\hline & $0,8 \mathrm{ml}$ & Acrylamid \\
\hline & $2,7 \mathrm{ml}$ & Aqua dest. \\
\hline \multirow[t]{3}{*}{ Trenngel - Puffer } & $45,4 \mathrm{~g}$ & TRIS (1,5 M) \\
\hline & $250 \mathrm{ml}$ & Aqua dest. \\
\hline & & mit $\mathrm{HCl}$ auf $\mathrm{pH}=8,9$ einstellen \\
\hline \multirow[t]{3}{*}{ Sammelgel - Puffer } & $15,1 \mathrm{~g}$ & TRIS (1,5 M) \\
\hline & $150 \mathrm{ml}$ & Aqua dest. \\
\hline & & mit $\mathrm{HCl}$ auf $\mathrm{pH}=6,8$ einstellen \\
\hline
\end{tabular}

Tabelle 2.12: Sammelgel, Trenngel und Puffer - Zusammensetzung

Bevor das Trenngel zwischen die vorbereiteten Glasplatten geschüttet werden konnte, wurde die Polymerisationsreaktion durch Zugabe von Ammoniumperoxodisulfat (APS) 
(Roth, Karlsruhe DE) gestartet. Nach Befüllen des Glasplattenzwischenraums bis zur markierten Höhe wurde das Trenngel mit 100 \% Ethanol überschichtet, um Luftblasen und dadurch entstehende Unebenheiten an der Oberfläche des Trenngels zu verhindern. Nach etwa 10 min war die Polymerisation des Trenngels abgeschlossen, und das verbleibende Ethanol konnte abgeschüttet werden. Anschließend wurde die Polymerisationsreaktion des Sammelgels ebenfalls durch Zugabe von APS gestartet. Nach maximaler Befüllung des Glasplattenzwischenraums wurde zügig ein Kamm in das polymerisierende Sammelgel eingebracht, wodurch Taschen zur Befüllung der Gele mit den vorbereiteten Proben geschaffen wurden. Nach etwa 15 min war die Polymerisation des Sammelgels beendet, sodass der Kamm, die Klammern sowie die Dichtungen entfernt und die polymerisierten SDS-Gele innerhalb der Glasplatten in einer feuchten Kammer bei etwa $4^{\circ} \mathrm{C}$ für maximal 10 Tage eingelagert werden konnten.

Die Elektrophorese wurde in einem Nachbau einer Biometra-Elektrophoresekammer durchgeführt. Hierzu wurden zunächst das obere sowie untere Becken zur Hälfte mit Laufpuffer gefüllt, die vorbereiteten SDS-Gele innerhalb der Glasplatten in das untere Becken gestellt und mithilfe von Klammern an der Kammer befestigt. Anschließend konnten die beiden Becken vollständig mit Laufpuffer befüllt werden, sodass eine elektrisch leitfähige Strecke zwischen dem oberen und unteren Becken über das SDSGel erzeugt wurde. Die Zusammensetzung des Laufpuffers ist in Tabelle 2.13 aufgelistet.

\begin{tabular}{|c|c|c|}
\hline \multirow[t]{4}{*}{ Laufpuffer $5 x$} & $30,3 \mathrm{~g}$ & TRIS $(0,25 \mathrm{M})$ \\
\hline & $142,6 \mathrm{~g}$ & Glycin $(1,9 \mathrm{M})$ \\
\hline & $0,5 \%$ & SDS (50 ml $10 \%$ SDS) \\
\hline & & mit Aqua dest. auf $1000 \mathrm{ml}$ auffüllen \\
\hline
\end{tabular}

Tabelle 2.13: SDS-Laufpuffer 5x - Zusammensetzung

Die quantitative Bestimmung der molekularen Massen wurde durch Zugabe einer Proteinleiter $(4 \mu \mathrm{l}$ Fermentas \#SM061) ermöglicht. Nun wurden die vorbereiteten Proteinproben im warmen Zustand auf das Gel aufgetragen. Dabei wurden $30 \mu \mathrm{l}$ pro Tasche pipettiert, was einer Proteinmenge aus 300.000 Zellen entsprach. Durch Anlegen eines konstanten Stroms mit $10 \mathrm{~mA}$ wurden die Proteinanteile beim Durchlaufen des Sammelgels räumlich konzentriert. Bei Übertritt der Proteine zum Trenngel wurde die Stromstärke auf $20 \mathrm{~mA}$ erhöht. Die Elektrophorese wurde unter 
optischer Kontrolle bei Erreichen des unteren Endes des SDS-Gels beendet und die Glasplatten mit dem dazwischen befindlichen SDS-Gel aus der Kammer zur Vorbereitung des Immunoblots entfernt.

\subsubsection{Immunoblot}

Der Immunoblot beschreibt im Rahmen der vorliegenden Arbeit die Übertragung von Proteinen des SDS-Gels auf eine adsorbierende PVDF-Membran mithilfe der Elektrophorese. Die somit transferierten Proteine können daraufhin mithilfe einer Antikörperreaktion nachgewiesen werden, womit die Bezeichnung „Immunoblot" ihre Begründung findet.

Zur Übertragung der Proteine auf die Transfermembran wurde diese für $15 \mathrm{~s}$ in Methanol aktiviert und zusammen mit sechs Streifen Whatman Pappe und zwei Schwämmen für $20 \mathrm{~min}$ in kaltem Transferpuffer (etwa $4^{\circ} \mathrm{C}$ ) inkubiert. Die Blot-Kassette (PeqLab Biotechnologie $\mathrm{GmbH}$, Erlangen, DE) wurde in folgender Reihe von Annode zu Kathode bestückt: Schwamm - drei Lagen Pappe - Transfermembran - SDS-Gel - drei Lagen Pappe - Schwamm. Anschließend wurde die Blot-Kassette mithilfe von Gummibändern fixiert und in eine mit kaltem Transferpuffer (ca. $4^{\circ} \mathrm{C}$ ) befüllte Blot-Kammer gestellt.

Eine Wasserkühlung ermöglichte eine näherungsweise konstante Temperatur des Transferpuffers. Der Immnunoblot wurde bei Einsatz von zwei Blot-Kassetten mit einer konstanten Stromstärke von $350 \mathrm{~mA}$ für $2 \mathrm{~h}$ durchgeführt. Tabelle 2.14 stellt die Zusammensetzung des verwendeten Transferpuffers dar.

\begin{tabular}{|c|c|c|}
\hline \multirow[t]{4}{*}{ Transferpuffer } & $6,05 \mathrm{~g}$ & TRIS (25 mM) \\
\hline & $28,8 \mathrm{~g}$ & Glycin (192 mM) \\
\hline & $400 \mathrm{ml}$ & Methanol (20\%) \\
\hline & & mit Aqua dest. auf $2 \mathrm{I}$ auffüllen, $\mathrm{pH}=8,3$ \\
\hline
\end{tabular}

Tabelle 2.14: Transferpuffer - Zusammensetzung 


\subsubsection{Coomassie-Färbung}

Nach erfolgtem Transfer der Proteine wurde die Transfermembran für etwa 5 min in einer Färbelösung (Coomassie-Brillant-Blau-Färbung, Roth, Karlsruhe, DE) geschwenkt und anschließend in eine Entfärbelösung gelegt, bis der Hintergrund entfärbt war und sich die Proteinbanden gut sichtbar darstellten. Nach einem Waschschritt in TBS-T (zweimal $5 \mathrm{~min}$ ) konnte die eingefärbte Transfermembran eingescannt und für den spezifischen Proteinnachweis vorbereitet werden. Die Zusammensetzung der hier verwendeten Lösungen ist in Tabelle 2.15 aufgelistet.

\begin{tabular}{|c|c|c|}
\hline Färbelösung & $\begin{array}{r}0,1 \mathrm{~g} \\
50 \mathrm{ml} \\
7 \mathrm{ml}\end{array}$ & $\begin{array}{l}\text { Brillant-Blau R } 250(0,1 \%) \\
\text { Methanol }(50 \%) \\
\text { Essigsäure }(7 \%) \\
\text { mit Aqua dest. auf } 100 \mathrm{ml} \text { auffüllen }\end{array}$ \\
\hline Entfärbelösung & $\begin{array}{r}50 \mathrm{ml} \\
7 \mathrm{ml}\end{array}$ & $\begin{array}{l}\text { Methanol }(50 \%) \\
\text { Essigsäure }(7 \%) \\
\text { mit Aqua dest. auf } 100 \mathrm{ml} \text { auffüllen }\end{array}$ \\
\hline TBS-T & $\begin{array}{r}200 \mathrm{mM} \\
1,5 \mathrm{M} \\
0,5 \%\end{array}$ & $\begin{array}{l}\text { TRIS-HCl } \\
\mathrm{NaCl} \\
\text { Tween } 20\end{array}$ \\
\hline
\end{tabular}

\subsubsection{Spezifischer Proteinnachweis}

Der spezifische Proteinnachweis wurde mithilfe einer Antikörperreaktion realisiert. Hierzu wurden die freien Antikörperbindungsstellen auf der Transfermembran zunächst mit einer Blocklösung (5\%, gelöst in TBS-T, nonfat dried milk powder, AppliChem $\mathrm{GmbH}$, Darmstadt, DE) für 30 min geblockt, um unspezifische Bindungen des primären Antikörpers zu verhindern. Im Anschluss wurde die Transfermembran mit dem in Blocklösung verdünnten primären Antikörper bei $4^{\circ} \mathrm{C}$ für etwa $16 \mathrm{~h}$ (über Nacht) inkubiert. Hiernach wurde die Transfermembran mit $5 \times 5$ min mit TBS-T gewaschen und mit dem in Blocklösung verdünnten sekundären Antikörper für 60 min inkubiert. Die dabei verwendeten Antikörper sind Enzymgekoppelt (horseraddish peroxidase) und in Abhängigkeit vom gewählten primären Antikörper gegen Kaninchen- oder Maus-Antikörper gerichtet. Eine Liste der verwendeten primären und sekundären Antikörper sowie deren Verdünnung ist Tabelle $2.17 \mathrm{zu}$ entnehmen. Es 
folgte ein weiterer Waschschritt für $5 \times 5$ min mit TBS-T. Anschließend wurde die Transfermembran mit einem Substrat (Amersham-ECL-Prime-Western-BlottingDetection-Reagent), das durch die katalysierte Reaktion des gekoppelten Enzyms umgesetzt wurde, für 5 min inkubiert. Die dabei ablaufende chemische LumineszenzReaktion wurde durch Auflegen eines Films sowie anschließender Entwicklung und Fixierung (Kodak, Rochester, USA) nachgewiesen. Die hierbei eingehaltenen Zeiten bezüglich der Dauer des Filmauflegens und der Entwicklung wurden empirisch wiederholt angepasst, sodass eine optimale Belichtung erreicht werden konnte. Die Fixierung wurde nach Wässern des Films für 5 min ausgeführt.

\subsubsection{Quantitative Auswertung des Western Blots}

Zur quantitativen Auswertung des Western Blots wurden die fixierten Filme gewässert, getrocknet und mit $1200 \mathrm{dpi}$ eingescannt. Mithilfe des Bildverarbeitungsprogramms ImageJ (Schneider et al. 2012) wurden die Graustufen der Proteinbanden ermittelt, über die horizontale Ausrichtung des Films integriert und über die vertikale Länge der betrachteten Blot-Lane dargestellt. Unter Berücksichtigung des Hintergrundrauschens als Offset, wurden die so ermittelten, aufsummierten Grauwerte über die vertikale Länge der Blot-Lane integriert, womit ein nominelles Maß für die Intensität der chemischen Lumineszenz und damit für die detektierte Proteinmenge errechnet werden konnte. Zur Normalisierung der Ergebnisse wurde das Housekeeping-Protein $\alpha$-Tubulin in allen betrachteten Zelllinie bestimmt. $\alpha$-Tubulin ist Teil des Zytoskeletts (Nogales et al. 1998) und liegt näherungsweise in den verwendeten Zellen in konstanter Konzentration vor. Der Quotient aus den normalisierten Ergebnissen von Probe und Kontrolle ermöglicht somit die Angabe des relativen Proteingehalts.

\subsubsection{Strippen der Transfermembran}

Durch das Strippen einer Transfermembran können bereits gekoppelte Antikörper getrennt und ein weiterer spezifischer Proteinnachweis geführt werden. Hierfür wurde die PVDF-Membran in Stripping-Puffer gelegt und in einem Wasserbad für $15 \mathrm{~min}$ bei $65^{\circ} \mathrm{C}$ inkubiert. Während dieser Inkubation wurde das Wasserbad regelmäßig geschwenkt. Anschließend wurde die PVDF-Membran $5 \times 5$ min mit TBS-T gewaschen und erneut dem Prozess des spezifischen Proteinnachweises (Kapitel 2.3.5) 
zugeführt. Alternativ wurde die Transfermembran zur Lagerung in $100 \%$ Methanol für $15 \mathrm{~s}$ gelegt, für etwa $15 \mathrm{~min}$ auf Filterpapier getrocknet und bei $-20^{\circ} \mathrm{C}$ eingefroren. Die Zusammensetzung des Stripping-Puffers ist in Tabelle 2.16 dargestellt

\begin{tabular}{|c|c|c|}
\hline \multirow[t]{3}{*}{ Stripping-Puffer } & $62,5 \mathrm{mM}$ & TRIS-HCI \\
\hline & $2 \%$ & SDS \\
\hline & $150 \mathrm{mM}$ & $\beta$-Mercaptoethanol \\
\hline
\end{tabular}

Tabelle 2.16: Stripping-Puffer - Zusammensetzung

\subsubsection{Verwendete Antikörper}

Tabelle 2.17 listet die im Rahmen der Western Blots eingesetzten Antikörper auf.

\begin{tabular}{|c|c|c|c|}
\hline \multicolumn{4}{|c|}{ primäre Antikörper } \\
\hline Name & Anbieter / Produkt & Spezies & Verdünnung \\
\hline SMURF1 & $\begin{array}{l}\text { Abnova } \\
\text { M01, clone 1D7 }\end{array}$ & $\begin{array}{l}\text { Maus } \\
\text { lgG, monoklonal }\end{array}$ & $1: 500$ \\
\hline SMURF2 & $\begin{array}{l}\text { Santa Cruz } \\
\text { sc393848 }\end{array}$ & $\begin{array}{l}\text { Maus } \\
\text { IgG, monoklonal }\end{array}$ & $1: 500$ \\
\hline SMAD1 & $\begin{array}{l}\text { Santa Cruz } \\
\text { sc7965 }\end{array}$ & $\begin{array}{l}\text { Maus } \\
\text { IgG, monoklonal }\end{array}$ & $1: 250$ \\
\hline SMAD2/3 & $\begin{array}{l}\text { Santa Cruz } \\
\text { sc133098 }\end{array}$ & $\begin{array}{l}\text { Maus } \\
\text { IgG, monoklonal }\end{array}$ & $1: 500$ \\
\hline SOX9 & $\begin{array}{l}\text { Acris } \\
\text { AP06583PU-N }\end{array}$ & $\begin{array}{l}\text { Kaninchen } \\
\text { synthetisch, polyklonal }\end{array}$ & $1: 1000$ \\
\hline RUNX2 & $\begin{array}{l}\text { Santa Cruz } \\
\text { sc390715 }\end{array}$ & $\begin{array}{l}\text { Maus } \\
\text { lgG, monoklonal }\end{array}$ & $1: 1000$ \\
\hline a-Tubulin & $\begin{array}{l}\text { Sigma Aldrich } \\
\text { T6199 }\end{array}$ & $\begin{array}{l}\text { Maus } \\
\text { IgG, monoklonal }\end{array}$ & $1: 2000$ \\
\hline DDK & $\begin{array}{l}\text { Origene } \\
\text { TA50011-100 }\end{array}$ & $\begin{array}{l}\text { Maus } \\
\text { lgG, monoklonal }\end{array}$ & $1: 1000$ \\
\hline \multicolumn{4}{|c|}{ sekundäre Antikörper, gekoppelt mit Peroxidase } \\
\hline Name & Anbieter / Produkt & Spezies & Verdünnung \\
\hline Anti-Maus & $\begin{array}{l}\text { Sigma Aldrich } \\
\text { A9917 }\end{array}$ & $\begin{array}{l}\text { Ziege } \\
\text { lgG, polyklonal }\end{array}$ & $1: 40.000$ \\
\hline Anti-Kaninchen & $\begin{array}{l}\text { Sigma Aldrich } \\
\text { A0545 }\end{array}$ & $\begin{array}{l}\text { Ziege } \\
\text { lgG, polyklonal }\end{array}$ & 1:100.000 \\
\hline
\end{tabular}

Tabelle 2.17: Liste der verwendeten Antikörper im Western Blot 


\subsection{Transienter Knockdown von SMURF1 und SMURF2}

Um die Rolle von SMURF1 und SMURF2 in den betrachteten Signalwegen der isolierten CPCht untersuchen zu können, wurde sowohl ein Knockdown als auch eine Überexpression von SMURF1 sowie SMURF2 realisiert und die Auswirkungen auf ausgewählte Proteine innerhalb der betrachteten Signalwege betrachtet. Ein Knockdown bedeutet eine Suppression der Transkription eines proteinspezifischen, translatierten DNA-Abschnitts und somit eine spezifische Suppression der Genexpression.

Der im Folgenden beschriebene Knockdown wurde mithilfe einer von außen in die Zelle eingebrachten small-interfering RNA (siRNA) realisiert. Hierbei handelt es sich um eine RNA, die spezifisch mRNA bindet und diese durch Aktivierung der Ribonuklease-Funktion des RNA-induced silencing complex (RISC) abbaut. Somit kann durch Einsatz einer siRNA sowohl das mRNA-Level eines spezifischen Gens als auch dessen Transkriptionsniveau moduliert werden. Die beschriebene Methode wird als transienter Knockdown bezeichnet, da die verwendete siRNA einen zeitlich begrenzter Knockdown bedingt, welcher durch den Abbau der transfizierten siRNA im Rahmen zellinterner Stoffwechselprozesse zu begründen ist. Die Transfektion der siRNA wurde mittels Nukleofektion umgesetzt. Dabei handelt es sich um eine spezielle Form der Elektroporation, bei der die Zellmembran durch Anlegen einer Spannung permeabilisiert wird und durch Zugabe herstellerspezifischer Reagenzien siRNA in die Zelle gelangt. Bei Anwendung der beschriebenen Methode wird von einer Transfektionseffizienz von etwa $60 \%$ ausgegangen (Cell-Line-Nucleofector, Amaxa Biosystems).

\subsubsection{Auswahl geeigneter siRNA}

Zur Ermittlung geeigneter siRNA zum Knockdown von SMURF1 sowie SMURF2 wurde zunächst eine Auswahl potentiell geeigneter siRNA bei den in Tabelle 2.18 gelisteten Anbietern angefordert. Nach erfolgter Transfektion wurde eine qRT-PCR durchgeführt, um die siRNA zu ermitteln, die den nominell größten Knockdown des mRNA-Levels von SMURF1 und SMURF2 ermöglicht. Zudem erfolgte ein Nachweis 
des Knockdowns auf Proteinebene mittels Western Blot. Tabelle 2.18 stellt die ausgewählte siRNA und deren Zielsequenzen dar.

\begin{tabular}{|llll|}
\hline Name & Anbieter & Produkt & Zielsequenz 5‘ $3^{‘}$ \\
SMURF1 & OriGene & Catalog No. & GCAAUGGUGAAA- \\
27mer siRNA duplex & Technologies & SR311389BL & GGAUAACCUCGAT \\
SMURF2 & Qiagen & Catalog No. & CCCUAUGAAAGC- \\
FlexiTube siRNA & SI00134295 & UAUGAATT \\
\hline
\end{tabular}

Tabelle 2.18: Verwendete siRNA

\subsubsection{Transfektion der siRNA}

Zur Transfektion wurde das Human-MSC-NucleofectorTM-Kit (Cat. No. VPE-1001, Lonza) verwendet. Zunächst wurden zuvor geerntete Zellpellets mit jeweils $5 \cdot 10^{5}$ Zellen in $100 \mu \mathrm{l}$ einer Nucleofector-Supplement-Lösung (90 $\mu \mathrm{l}$ Nucleofector Solution $+20 \mu \mathrm{l}$ Supplement pro Zellpellet) resuspendiert. Hierzu wurden jeweils 0,2 nmol siRNA in $10 \mu \mathrm{l}$ RNAse-freiem Wasser verdünnt hinzugegeben. Die damit erzeugte Lösung wurde in eine Nucleofector-Küvette überführt und die Transfektion im Necleofector nach Herstellerangaben (Programm U-023) ausgeführt. Zur mikroskopischen Kontrolle der Nukleofektion wurde eine Probe anstelle der siRNA mit $4 \mu$ grünfluoreszierendem Protein versetzt. Anschließend wurden $500 \mu \mathrm{l} \mathrm{DMEM}+{ }_{+}+$in die Küvette gegeben und der gesamte Inhalt der Küvette in eine Kammer einer 6-WellPlatte mit 1,4 ml vorgelegtem DMEM+/+ überführt. Nach 24 h erfolgte ein Wechsel des Kulturmediums. Nach $48 \mathrm{~h}$ wurden die Zellen geerntet, deren Lebendzellzahl bestimmt und die gewonnenen Zellpellets bei $-80^{\circ} \mathrm{C}$ eingelagert.

\section{5 Überexpression von SMURF1 und SMURF2}

Durch Überexpression von SMURF1 sowie SMURF2 wurde deren intrazelluläre Proteinkonzentration in CPCht artifiziell erhöht. Hierdurch konnten Wechselwirkungen zwischen SMURF1 sowie SMURF2 und weiteren Proteinen der betrachteten Signalwege untersucht werden. Zudem fand somit ein zur Knockdown-Methode inverses Experiment Berücksichtigung, womit die Datenbasis zur Beurteilung der Untersuchungsergebnisse erweitert werden konnte und eine fundiertere Beurteilung ermöglicht wurde. 
In der vorliegenden Arbeit wurden Plasmide als Vektoren zur Überexpression von SMURF1 und SMURF2 verwendet. Vektoren beinhalten DNA, die von eukaryotischen Zellen intrazellulär translatiert wird, womit eine Überexpression der hierdurch codierten Proteine möglich ist. Hierfür wurden die gewählten Plasmide durch chemische Transfektion in das Zellinnere eingebracht. Die beschriebene Methode wird als transiente Überexpression bezeichnet, da DNA nicht in das zelleigene Erbgut eingebaut, sondern mithilfe eines Vektors von außen in die Zelle eingebracht wird. Dabei handelt es sich um eine zeitlich begrenzte Überexpression, da die transfizierte DNA im Rahmen zellinterner Stoffwechselprozesse abgebaut wird.

Abbildung 2.2 zeigt den schematischen Aufbau der verwendeten Plasmide pSMURF1Myc-DDK (RC222902, OriGene) und pSMURF2-Myc-DDK (RC210866, OriGene).
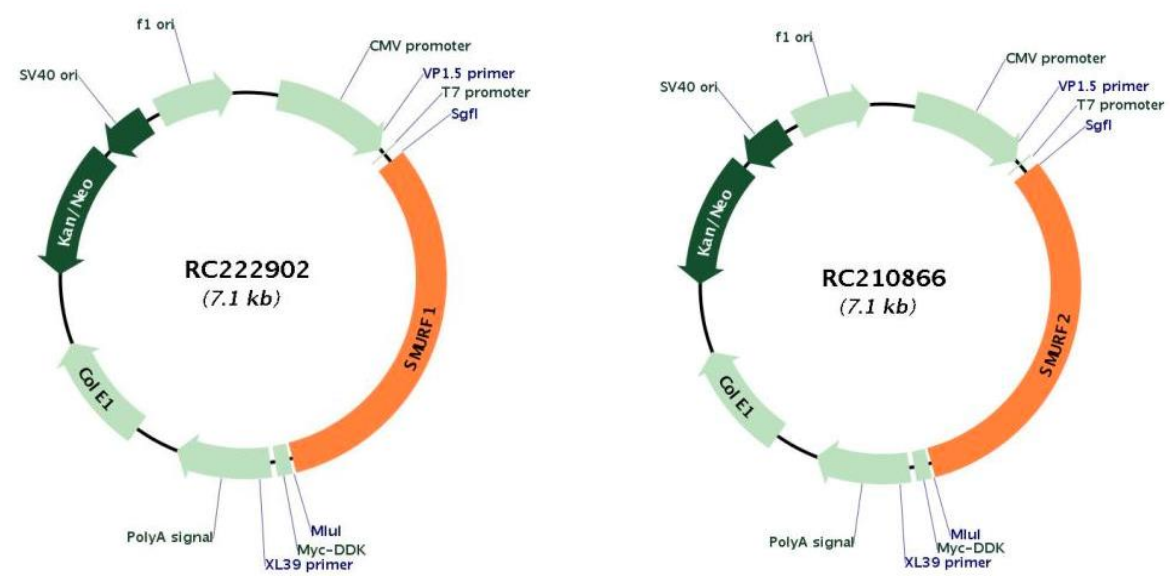

Abbildung 2.2: Aufbau der Plasmide zur Überexpression von SMURF1 und SMURF2; Produktbeschreibung, OriGene

Es wird ersichtlich, dass der prinzipielle Aufbau der beiden Plasmide identisch ist. Sie beinhalten die Gensequenz für SMURF1 bzw. SMURF2 sowie eine Promoterregion, die für den Start der Genexpression notwendig ist. Eine weitere wichtige Komponente ist ein Resistenzgen gegen Kanamycin, ein Antibiotikum der Gruppe der Aminoglykoside, das zur Selektion von Plasmid-produzierenden Escherichia coli (E. coli) eingesetzt wird und somit die Ausbeute der Produktion des Plasmids erhöht. Weiterhin ist ein Myc-DDK-Tag Teil des Plasmids, welcher zur Expression zweier Polypeptide innerhalb der transfizierten Zellen führt. In der vorliegenden Arbeit wurde der Nachweis des DDK-Tags mithilfe des Western Blots zum Nachweis der Transfektion sowie Translation von SMURF1/2 verwendet. 


\subsubsection{Vervielfältigung der Plasmide}

Um eine ausreichende Menge der ausgewählten Plasmide zur Verfügung zu stellen, wurden die angeforderten Plasmide zunächst in DH5a-Escherichia coli (NEB 5-alpha Competent E. coli High Efficiency $\mathrm{C} 2987 \mathrm{H}$, BioLabs) vervielfältigt. Hierfür wurden E. coli in LB-Bakteriennährmedium gemeinsam mit den Plasmiden in Schikanekolben überführt und Kanamycin $(50 \mathrm{mg} / \mathrm{ml}$, Verdünnung 1:1000) zur Selektion der plasmidproduzierenden E. coli hinzugegeben. Es folgte eine Inkubation über Nacht bei $37^{\circ} \mathrm{C}$ auf einem Schüttler. Im Anschluss wurden die Bakterien in sterile Dosen überführt und darauffolgend für $15 \mathrm{~min}$ bei $6000 \mathrm{~g}$ und $4{ }^{\circ} \mathrm{C}$ abzentrifugiert. Der Überstand wurde anschließend abgeschüttet.

\subsubsection{Isolierung der Plasmid-DNA aus DH5a-Escherichia coli}

Aus dem gewonnenen Bakterienzellpellet konnte nun mithilfe des EndoFree Plasmid Maxi Kits (No. 12362, Qiagen, NE) die vervielfältigte Plasmid-DNA isoliert werden.

Hierfür wurde das Bakterienzellpellet in $10 \mathrm{ml}$ Puffer P1 resuspendiert. Nach der Zugabe von $10 \mathrm{ml}$ Puffer P2 folgte eine Inkubation für $5 \mathrm{~min}$. Anschließend wurden $10 \mathrm{ml}$ Puffer P3 hinzugegeben und die gesamte Lösung durch Schwenken gemischt, bis ein Farbumschlag der Lösung beobachtet werden konnte. Darauffolgend wurde die Lösung auf eine Qiafilter-Catridge-Säule überführt und für 10 min inkubiert. Mithilfe eines Stempels, der in die Säule eingesetzt wurde, wurde die Lösung filtriert, das Filtrat mit 2,5 ml ER-Puffer versetzt und $30 \mathrm{~min}$ auf Eis inkubiert. Zur Vorbereitung des Quiagen-tip-500 wurde dieses mit $10 \mathrm{ml}$ QBT-Puffer equilibriert. Anschließend wurde das auf Eis inkubierte Filtrat auf das Qiagen-tip-500 aufgetragen. Nach Durchlaufen des Quiagen-tip-500 wurde dieses zweimal mit $30 \mathrm{ml}$ QC-Puffer gewaschen und der Durchfluss verworfen. Im Anschluss wurde die Plasmid-DNA mit $15 \mathrm{ml}$ QN-Puffer in ein Reagenzglas eluiert und mit $10,5 \mathrm{ml}$ Isopropanol versetzt. Es folgte eine Zentrifugation für $30 \mathrm{~min}$ bei $4^{\circ} \mathrm{C}$ mit $15.000 \mathrm{~g}$, wonach der Überstand verworfen wurde und das gewonnene Pellet für $15 \mathrm{~min}$ an der Luft trocknete. Abschließend wurde das Pellet, welches nun die Plasmid-DNA enthielt, in $100 \mu \mathrm{l}$ RNAse-freiem Wasser resuspendiert. Die Bestimmung der DNA-Konzentration der somit isolierten Plasmide erfolgte mithilfe des UV/VIS Nanodrop 1000 Spectrometers. Die Plasmide wurden bei $-20^{\circ} \mathrm{C}$ gelagert. 
Zur Kontrolle der klonierten Plasmid-DNA wurden diese von der Firma Seqlab, Göttingen sequenziert und die ermittelten Sequenzen mithilfe von BLAST eindeutig der DNA von SMURF1 sowie SMURF2 zugeordnet.

\subsubsection{Restriktionsverdau der klonierten Plasmid-DNA}

Zur Prüfung der klonierten Plasmid-DNA (Plasmid-SMURF1-Klon und PlasmidSMURF2-Klon) wurde diese zusätzlich zur genannten Sequenzkontrolle mithilfe des Restriktionsverdaus mit der vom Hersteller zugesendeten originalen Plasmid-DNA (Plasmid-SMURF1-orig und Plasmid-SMURF2-orig) verglichen. Bei diesem Verfahren werden Restriktionsenzyme eingesetzt, die an definierten Stellen der Plasmid-DNA schneiden und somit DNA-Abschnitte erzeugen, deren Basenpaaranzahl mit einer Gelelektrophorese bestimmt werden kann. Im Rahmen der vorliegenden Arbeit wurde das Restriktionsenzym vom Typ 2 mit der Bezeichnung BamH1 (ThermoFisher Scientific) eingesetzt. Typ 2 bedeutet, dass dieses Restriktionsenzym an einer definierten Erkennungssequenz schneidet. Für BamH1 ist in den beiden gelieferten PlasmidDNA zur Überexpression von SMURF1/2 die passende Erkennungssequenz (GGATCC) an jeweils zwei Stellen vorgesehen. Als Resultat werden demnach jeweils zwei DNA-Abschnitte mit unterschiedlicher Länge erwartet, wobei sich diese zwischen Plasmid-SMURF1-orig und Plasmid-SMURF2-orig unterscheiden. Kein Unterschied sollte zwischen der originalen und klonierten Form eines Plasmids zu finden sein.

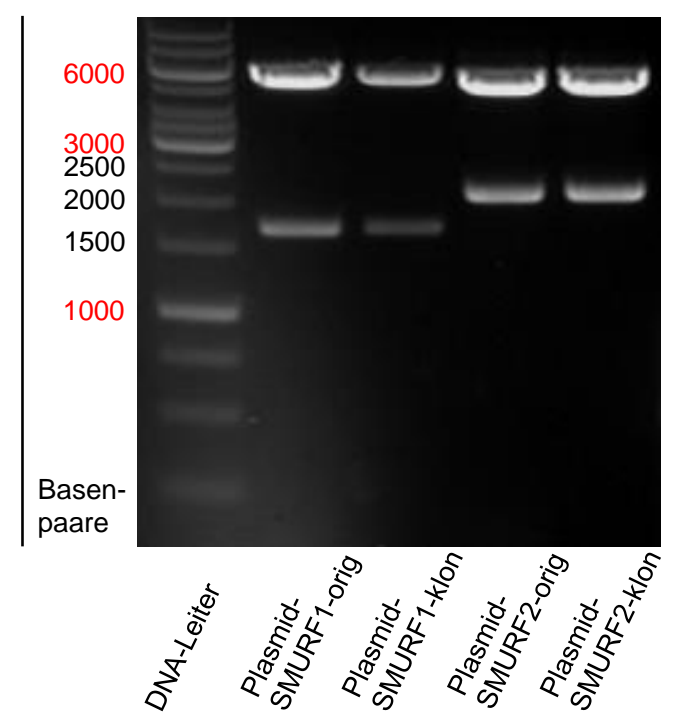

Abbildung 2.3: Gelelektrophorese-Agarose-Gel, Roti-GelStain,

Restriktionsverdau Plasmid-DNA Plasmid-SMURF1/2-orig/klon 
Abbildung 2.3 zeigt das Ergebnis der Gelelektrophorese in einem Agarose-Gel (500 mg Agarose in $50 \mathrm{ml}$ 1x TRIS-Acetat-EDTA-Puffer). Zur Sichtbarmachung der DNA-Abschnitte wurde ein Fluoreszenz-Färbereagenz (4 $\mu$ l Roti-GelStain, Carl Roth) verwendet. Zur Bestimmung der Basenpaaranzahl wurde eine DNA-Leiter (ThermoFisher Scientific GeneRuler 1 kb DNA Ladder) eingesetzt.

Die Fluoreszenz der DNA-Banden zeigt, dass sich die DNA-Abschnitte der originalen sowie klonierten Plasmid-DNA nicht unterscheiden. Die jeweilige Basenpaaranzahl der DNA-Abschnitte wurde mithilfe der Herstellerangaben auf Plausibilität geprüft und entspricht den Erwartungswerten. Bei Berücksichtigung dieser Ergebnisse zusammen mit der Sequenzkontrolle ist davon auszugehen, dass die beschriebene Klonierung der Plasmid-DNA in E. coli zu keiner relevanten Änderung der Basenabfolge führt.

\subsubsection{Transfektion der Plasmid-DNA}

Die Transfektion der Plasmid-DNA wurde an CPCht auf Zellkulturplatten durchgeführt. Hierbei handelte es sich um eine chemische Transfektion, da die Plasmid - DNA mithilfe eines chemischen Reagenz in die Zielzelle eingebracht wird. Die Zellen wurden hierfür, wie in Kapitel 2.1.4 beschrieben, aus den Zellkulturflaschen geerntet und zu je $5 \cdot 10^{4}$ Zellen auf Zellkulturplatten in DMEM+/+ ausgesät. Bei einer mikroskopisch beobachteten Konfluenz von etwa $60 \%$ wurden die Plasmide zur Überexpression von SMURF1 sowie SMURF2 transfiziert.

Pro Zellkulturplatte wurde ein Eppendorf-Cup mit $300 \mu$ LMEM, 4 ng Plasmid-DNA sowie $25 \mu \mathrm{l}$ Polyfect-Transfection-Reagent (Qiagen, NE) vorbereitet. Anschließend wurden die Lösungen im Vortexmischer für $10 \mathrm{~s}$ durchmischt und 10 min inkubiert. Während dieser Zeit wurde das Kulturmedium aus den Zellkulturplatten gesaugt und diese zweifach mit PBS gewaschen. Nach erfolgter Inkubation wurde $1 \mathrm{ml}$ DMEM+/+ in die Eppendorf-Cups pipettiert und deren Inhalt auf die vorbereiteten Zellkulturplatten gegeben. Abschließend wurde $7 \mathrm{ml} \mathrm{DMEM+/+} \mathrm{zu} \mathrm{jeder} \mathrm{Zellkulturplatte} \mathrm{hinzugegeben}$ und die Inkubation im Brutschrank gestartet. Nach $24 \mathrm{~h}$ wurde das Kulturmedium gewechselt. Nach $48 \mathrm{~h}$ wurden die Zellen geerntet, deren Lebendzellzahl bestimmt und die gewonnenen Zellpellets bei $-80^{\circ} \mathrm{C}$ eingelagert. 


\section{Ergebnisse}

\subsection{Nachweis von SMURF1 und SMURF2}

Vor Untersuchung der Funktionen von SMURF1/2 im Rahmen der chondrogenen Differenzierung von CPCs erfolgte deren Nachweis mithilfe immunhistologischer und immunzytologischer Methoden sowie deren Nachweis auf Proteinebene mithilfe des Western Blots.

\subsubsection{Immunhistologischer Nachweis in Kniegelenkknorpel}

Zum Nachweis von SMURF1/2 in humanem osteoarthrotischem Knorpel des Kniegelenks wurden immunhistochemische Färbungen des osteoarthrotischen Resektionsmaterials, das im Rahmen von Kniearthroplastiken entsteht, angefertigt, siehe Abbildung 3.1.
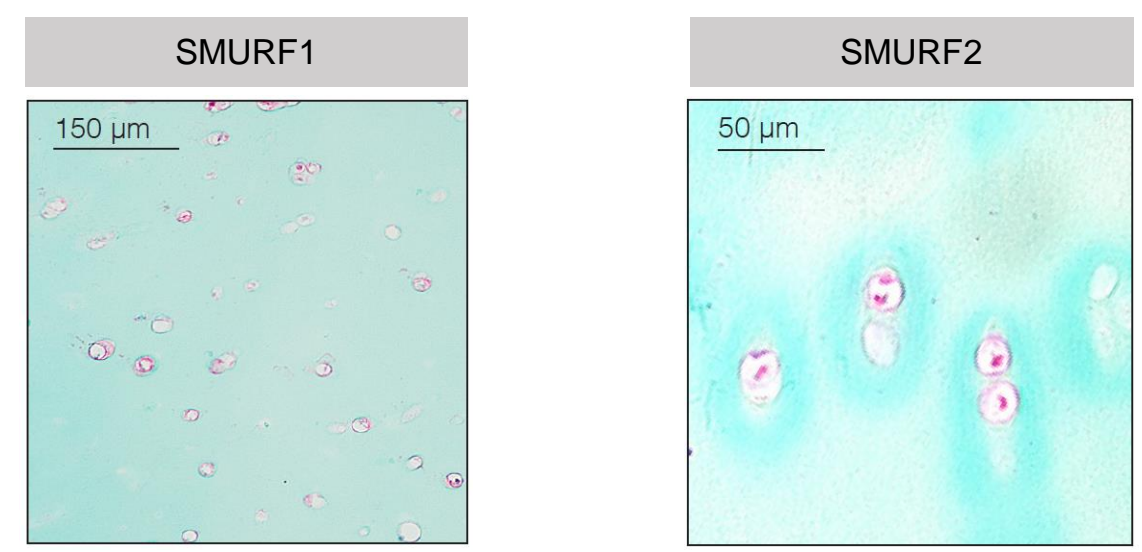

Abbildung 3.1: Immunhistologischer Nachweis von SMURF1 sowie SMURF2 in osteoarthrotischem Kniegelenkknorpel; Die hier gezeigten Abbildungen wurden mir freundlicherweise von Frau Katharina Kröber, einer Mitdoktorandin, überlassen.

Die immunhistochemische Reaktion weist SMURF1 sowie SMURF2 in osteoarthrotischem Kniegelenkknorpel nach. Die Immunreaktion beschränkt sich auf das Zytoplasma. 


\subsubsection{Immunzytologischer Nachweis in CPCht}

Der immunzytologische Nachweis mittels Antikörperreaktion diente der Lokalisation von SMURF1/2 im Zytoplasma von CPCht.

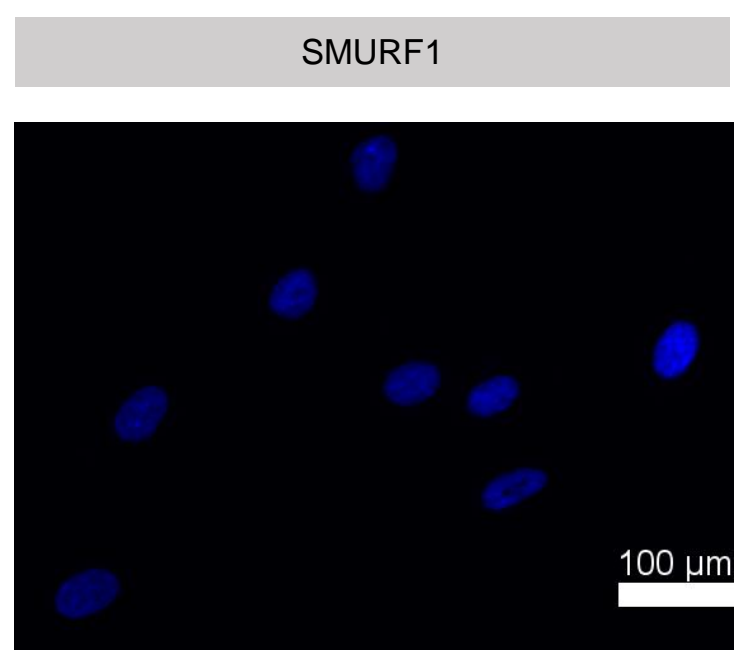

Kanal 1 - DAPI

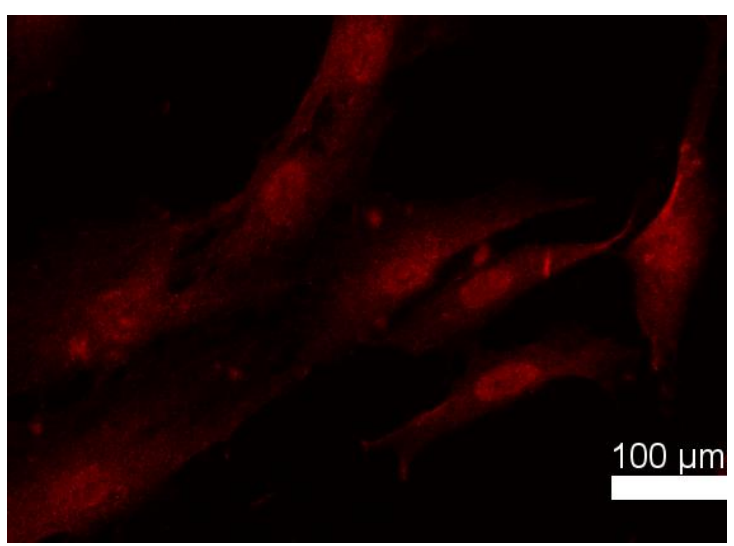

Kanal 2 - SMURF1

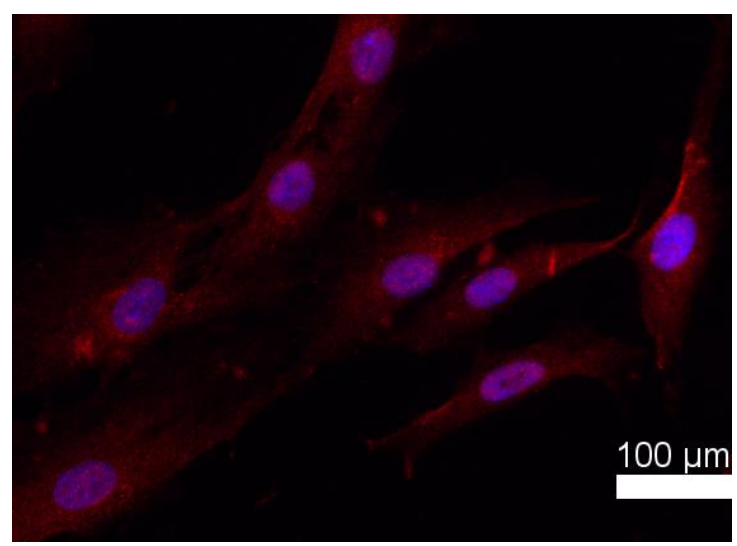

überlagert

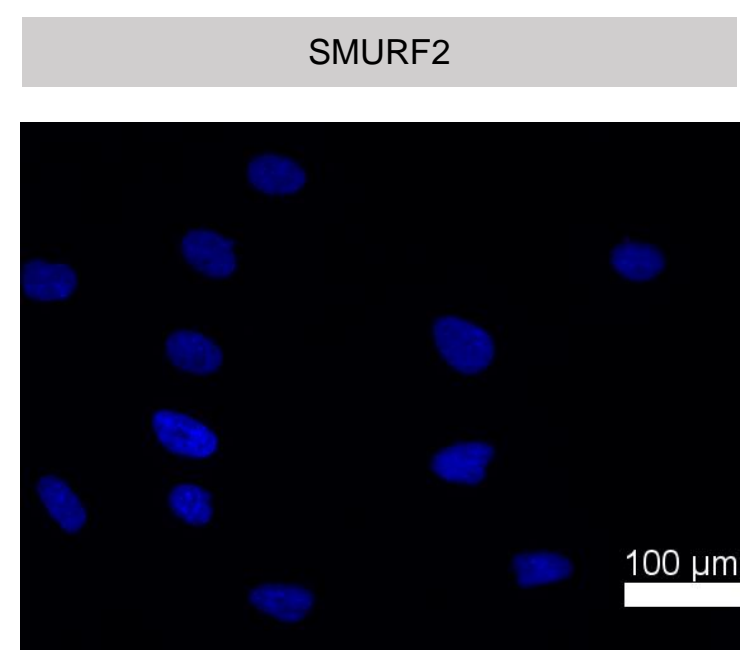

Kanal 1 - DAPI

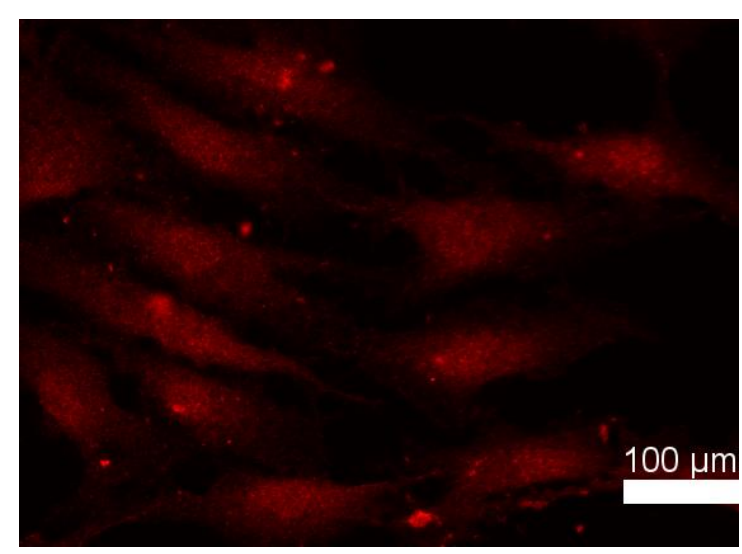

Kanal 2 - SMURF2

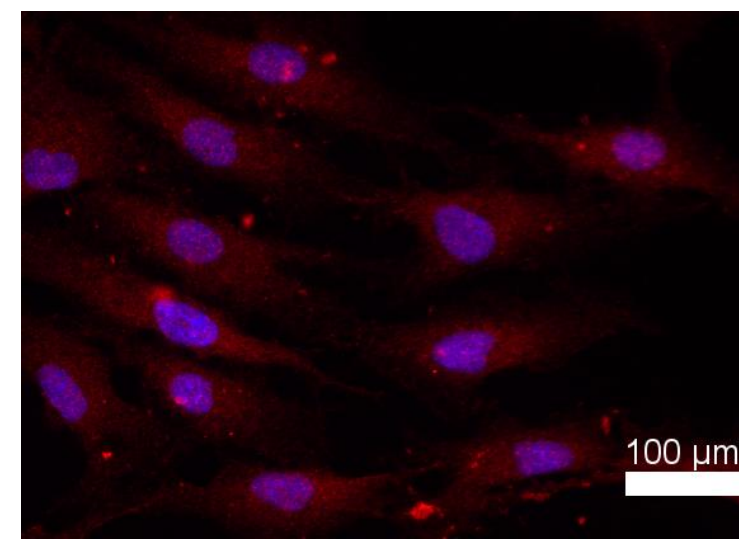

überlagert

Abbildung 3.2: Immunzytologischer Nachweis von SMURF1/2 in CPCht. 
Die Fluoreszenzverteilung in Abbildung 3.2 zeigt eine auf den Zellkern fokussierte Konzentrationsverteilung für SMURF1 und SMURF2 innerhalb einzelner CPCht. Weiterhin können SMURF1/2 im Zytoplasma nachgewiesen werden. Hier ist eine diffuse Verteilung zu beobachten.

Zum Ausschluss von unspezifischen Bindungen durch den sekundären Antikörper wurde eine Kontrollaufnahme für den sekundären Maus- sowie Kaninchen-Antikörper erstellt. Diese ist in Abbildung 3.3 dargestellt. Die eingesetzten sekundären Antikörper zeigen kein Fluoreszenzsignal in Kanal 2, womit von einer spezifischen Bindung des sekundären Antikörpers an den primären Antikörper ausgegangen werden kann.

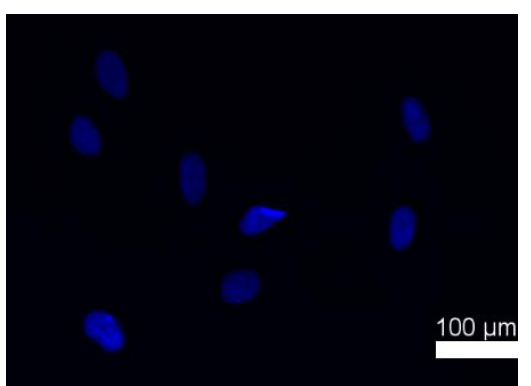

Maus - Kanal 1 - DAPI

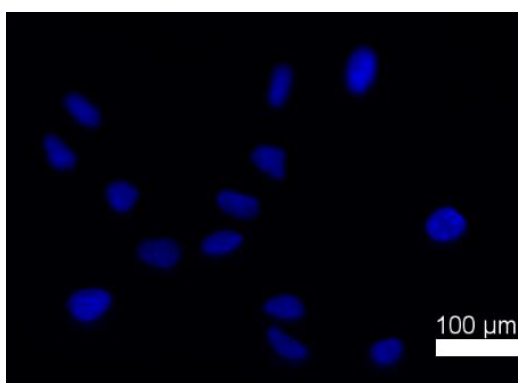

Kaninchen - Kanal 1 - DAPI

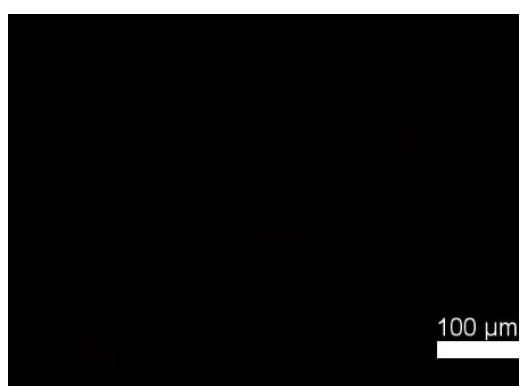

Maus - Kanal 2

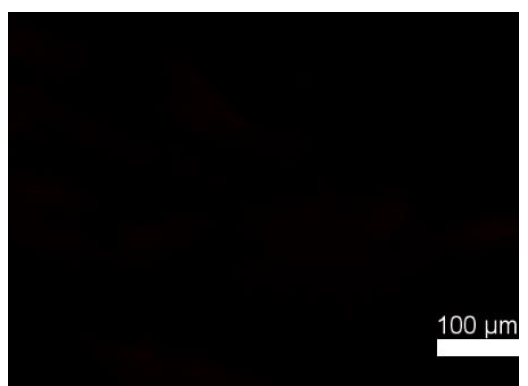

Kaninchen - Kanal 2

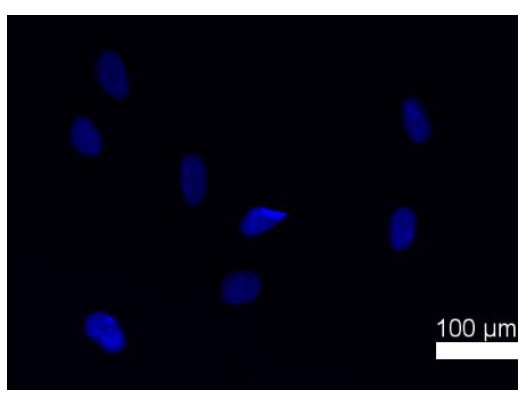

Maus - überlagert

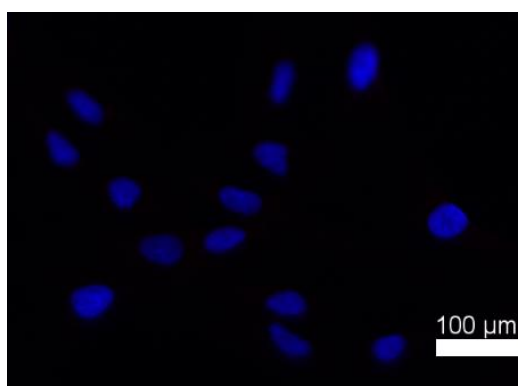

Kaninchen - überlagert

Abbildung 3.3: Immunzytologie - Kontrolle sekundärer Maus- und Kaninchen-Antikörper.

\subsubsection{Proteinnachweis in CPCht und primären CPCs}

SMURF1/2 wurden mithilfe des Western Blots in CPCht sowie in primären CPCs nachgewiesen. Zudem wurde dabei eine geeignete Verdünnung für die eingesetzten primären Antikörper ermittelt. Die Ergebnisse für SMURF1 und SMURF2 sind in Abbildung 3.4 dargestellt. Zur Ermittlung der molekularen Masse sind jeweils die Referenzwerte der Proteinleiter angegeben. Die Unterschiede in den relativen Abständen der einzelnen Niveaus, welche die Referenz der Proteinleiter markieren, ist durch Abweichungen in den Laufzeiten der einzelnen SDS-Gele zu erklären. 


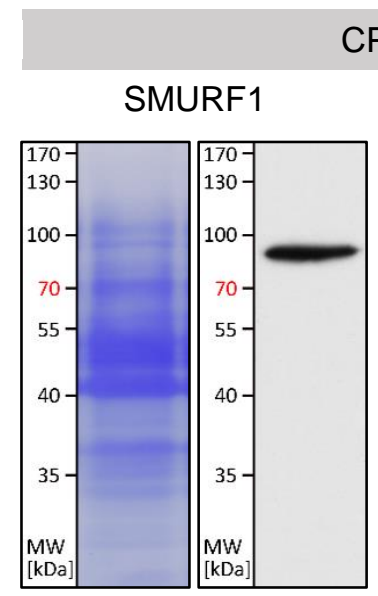

CPCht

SMURF2

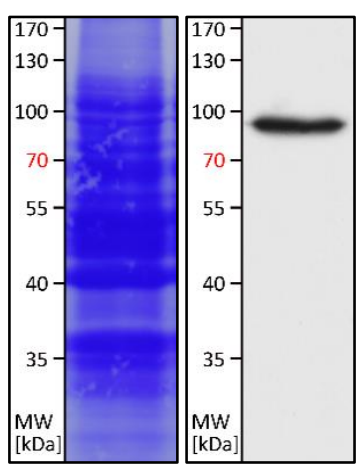

primäre CPCs

SMURF1

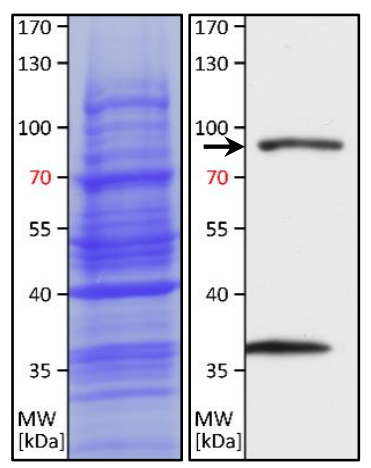

SMURF2

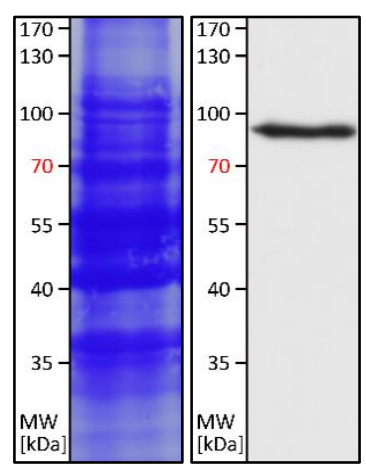

Abbildung 3.4: Nachweis von SMURF1/2 in CPCht und primären CPCs im Western Blot; links CoomassieFärbung, rechts Proteinnachweis im Western Blot; Antikörper-Verdünnung: siehe Tabelle 2.17.

Es zeigt sich, dass SMURF1/2 in primären CPCs sowie in der immortalisierten Zelllinie CPCht auf Proteineben mithilfe des Western Blots nachweisbar sind. Die Höhen der Proteinbanden stimmen mit den Molekülmassen von SMURF1/2 überein (86 kDa). Zudem zeigt sich eine zweite Bande für SMURF1 in primären CPCs bei etwa $36 \mathrm{kDa}$. Diese Reaktion kann durch Abbauprodukte von SMURF1 hervorgerufen sein, welche die identischen Zielstrukturen der primären Antikörper beinhalten.

\subsection{Nachweis von SOX9, RUNX2, SMAD1 und SMAD2/3}

SOX9, RUNX2 sowie SMAD1 und SMAD2/3 wurden im Rahmen dieser Arbeit als Mitspieler der durch SMURF1/2 beeinflussten Signalkaskaden untersucht. Hierfür wurden diese in CPCht mithilfe des Western Blots nachgewiesen und eine geeignete Antikörper-Verdünnung ermittelt, siehe Abbildung 3.5.

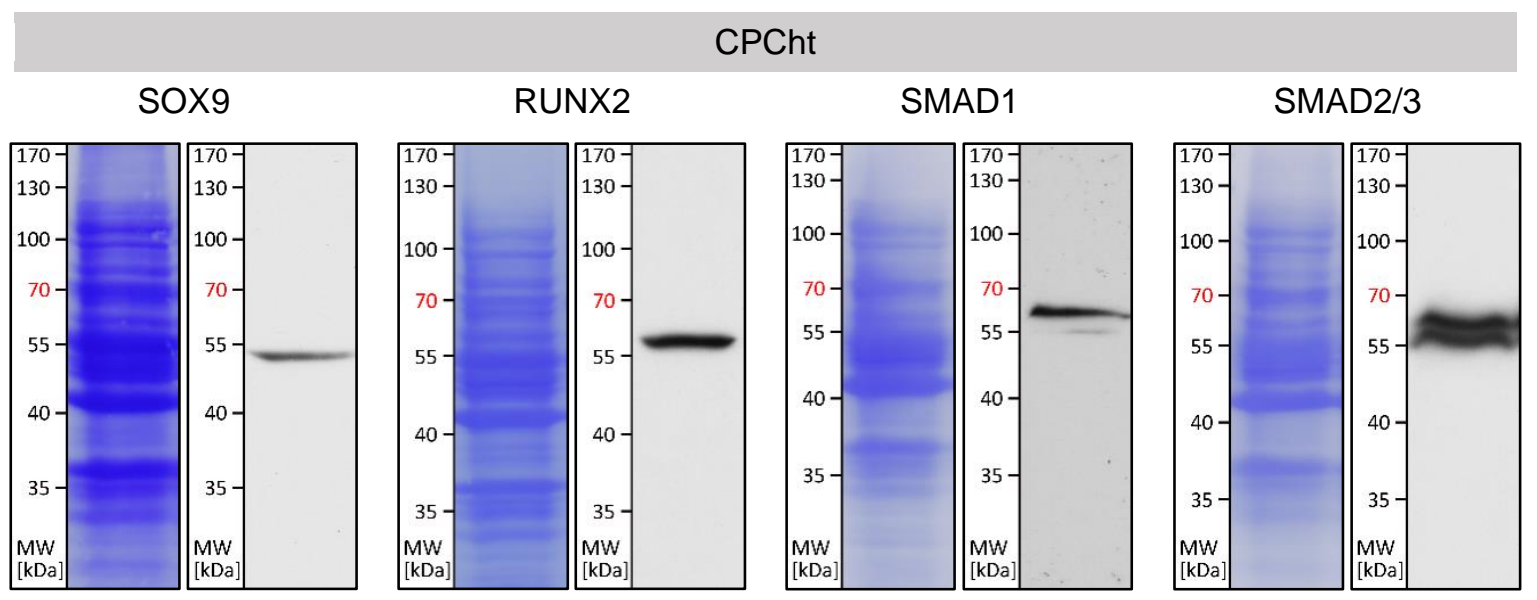

Abbildung 3.5: Nachweis von SOX9, RUNX2, SMAD1 sowie SMAD2/3 in CPCht im Western Blot; links Coomassie-Färbung, rechts Proteinnachweis im Western Blot; Antikörper-Verdünnung: siehe Tabelle 2.17. 


\subsection{Knockdown von SMURF1 und SMURF2 in CPCht}

Der Knockdown von SMURF1 und SMURF2 in CPCht wurde zunächst mithilfe des Western Blots nachgewiesen. Daraufhin wurden die Auswirkungen des Knockdowns von SMURF1/2 auf die betrachteten Proteine SOX9, RUNX2 sowie SMAD1 und SMAD2/3 auf Proteinebene untersucht.

In den gezeigten Western Blots wurden jeweils eine Kontrolle sowie die transfizierten Zellen parallel betrachtet. Um eine Aussage über den relativen Proteingehalt der Zelllinie zu ermöglichen, wurde zudem a-Tubulin als Housekeeping Protein im Western Blot quantitativ bestimmt. Die dargestellten Coomassie-Färbungen sowie Western Blots zeigen exemplarisch das Ergebnis der jeweiligen Untersuchung, die jeweils dreimal durchgeführt wurden $(n=3)$. Das Signifikanzniveau wurde mit $p=0,05$ festgelegt.

\subsubsection{Nachweis des Knockdowns im Western Blot}

Zum Nachweis des Knockdowns von SMURF1/2 in CPCht wurde der relative Proteingehalt von SMURF1/2 in siRNA-Knockdown-Zellen (CPCht-SMURF1 und CPCht-SMURF2) sowie in der Kontrolle (CPCht) quantitativ bestimmt. Abbildung 3.6 und Abbildung 3.7 zeigen exemplarisch die Coomassie-Färbung der Membran, die repräsentativen Ergebnisse der Western Blots sowie deren quantitative Auswertung. 

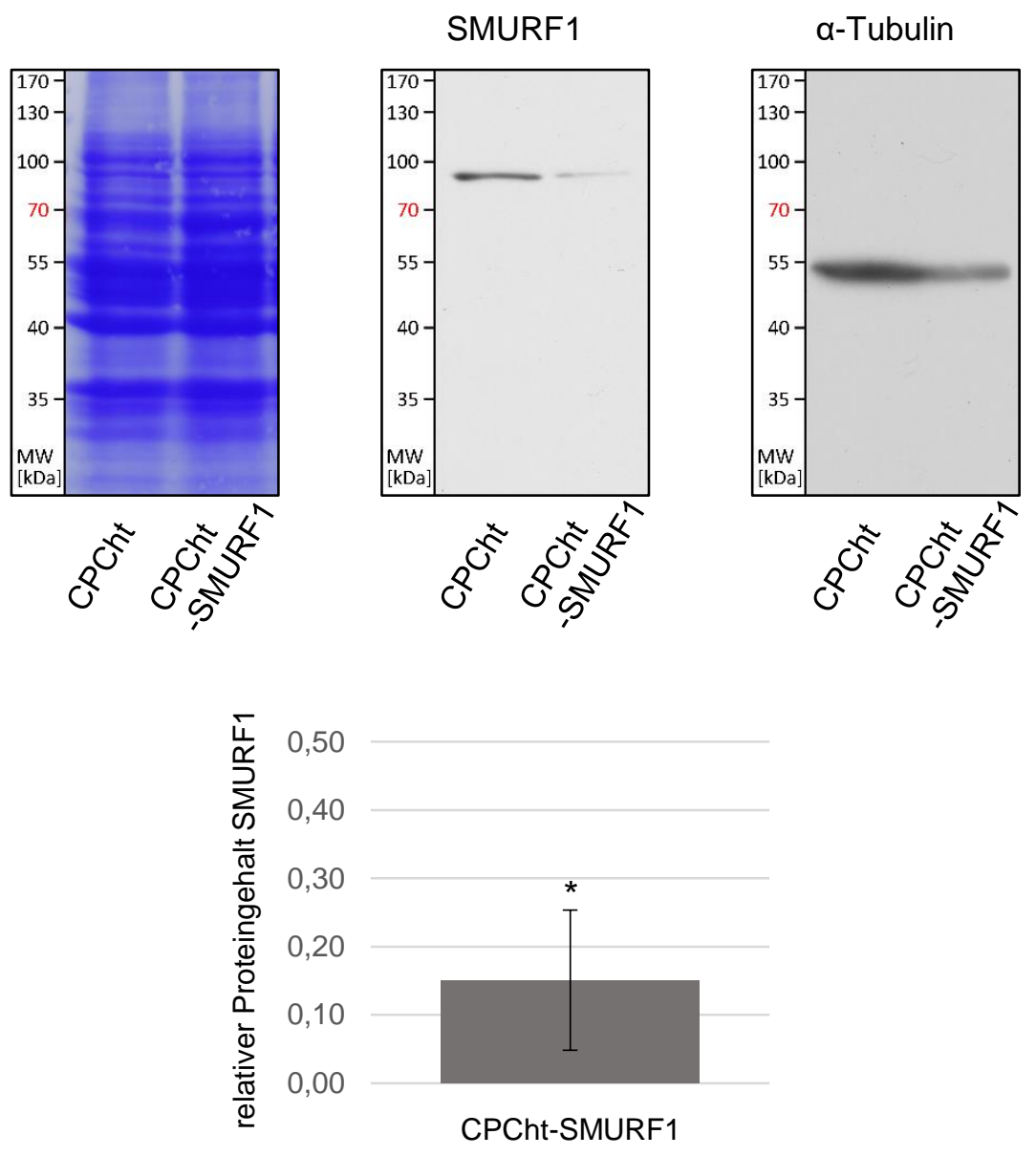

Abbildung 3.6: Nachweis des Knockdowns von SMURF1 in CPCht im Western Blot; links: Coomassie-Färbung; linke Bande zeigt Kontrolle (CPCht), rechte Bande zeigt transfizierte Zellen (CPCht-SMURF1); statistische Auswertung des relativen Proteingehalts mit $\mathrm{n}=3$; Fehlerbalken zeigt Standardabweichung; ${ }^{*}=$ signifikant $(p=0,05)$.

Der Knockdown von SMURF1 in CPCht kann nach quantitativer Auswertung des Western Blots bestätigt werden. Im Mittel wird ein signifikanter Knockdown von $0,15 \pm 0,10(p=0,03)$ erreicht, womit eine mittlere Reduktion der Proteinexpression von SMURF1 um $85 \%$ beschrieben ist. 

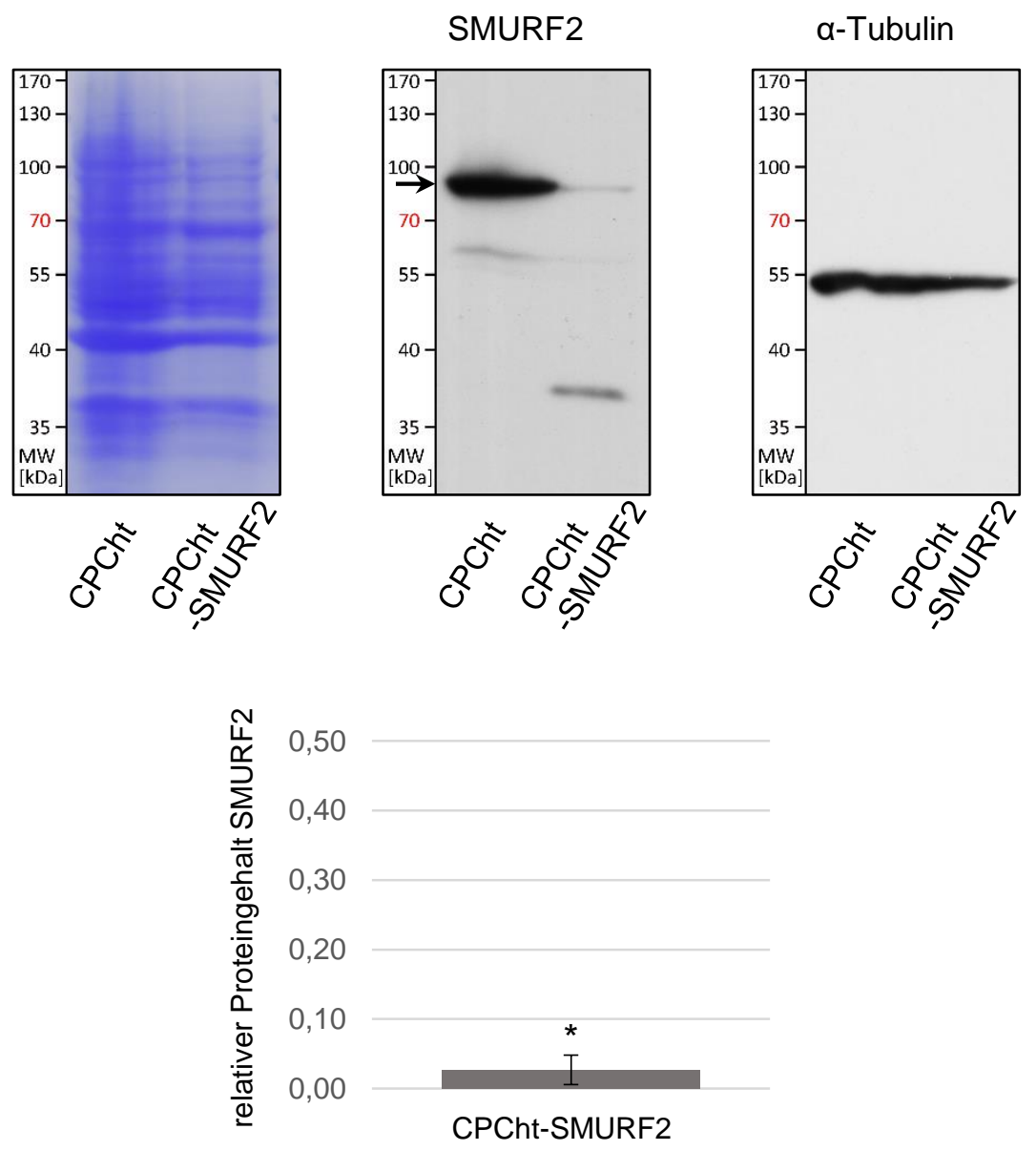

Abbildung 3.7: Nachweis des Knockdowns von SMURF2 in CPCht im Western Blot; links: Coomassie-Färbung; linke Bande zeigt Kontrolle (CPCht), rechte Bande zeigt transfizierte Zellen (CPCht-SMURF2); statistische Auswertung des relativen Proteingehalts mit $n=3$, Fehlerbalken zeigt Standardabweichung; * = signifikant $(p=0,05)$.

Der Knockdown von SMURF2 in CPCht kann nach quantitativer Auswertung des Western Blots bestätigt werden. Im Mittel wird ein signifikanter Knockdown von $0,03 \pm 0,02(p=0,005)$ erreicht, womit eine mittlere Reduktion der Proteinexpression von SMURF2 um 97\% beschrieben ist. Zusätzliche Reaktionen, die der Blot für SMURF2 in CPCht sowie CPCht-SMURF2 im Bereich von $60 \mathrm{kDa}$ sowie $36 \mathrm{kDa}$ zeigt, können durch Abbauprodukte von SMURF2 hervorgerufen sein. 


\subsubsection{Auswirkungen des Knockdowns von SMURF1}

Nach der Bestätigung des Knockdows von SMURF1 in CPCht auf Proteinebene wurden dessen Auswirkungen auf die Proteine SOX9, RUNX2, SMAD1 und SMAD2/3 betrachtet. Hierfür wurden Western Blots zur Bestimmung dieser Proteine in CPCht sowie transfizierten CPCht-SMURF1 angefertigt und quantitativ ausgewertet, siehe Abbildung 3.8 und Abbildung 3.9.
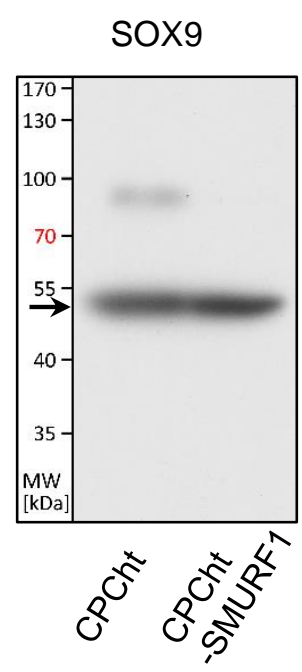

SMAD1
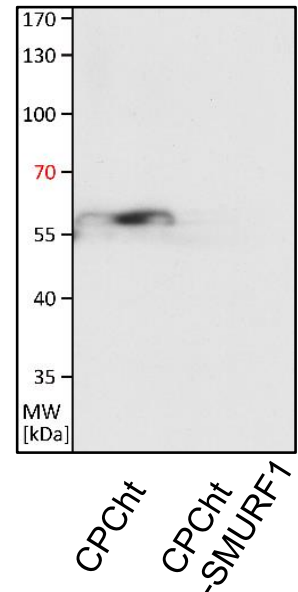

$\alpha$-Tubulin
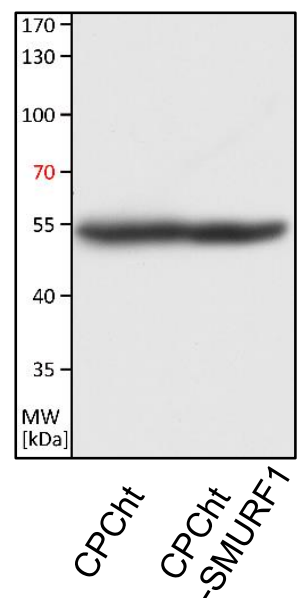

a-Tubulin

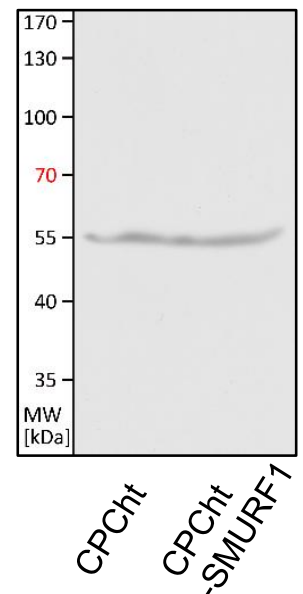

RUNX2
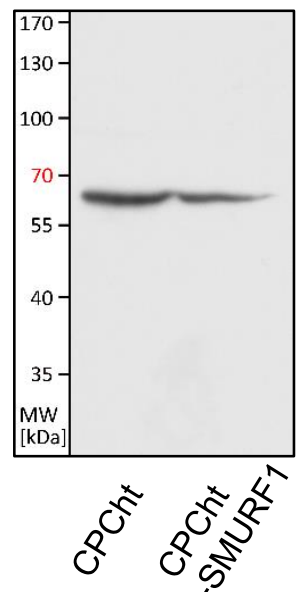

SMAD2/3

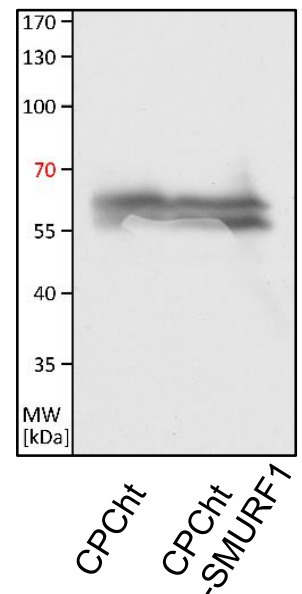

$\alpha-T u b u l i n$
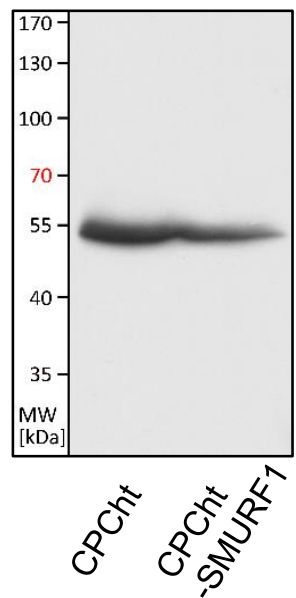

a-Tubulin

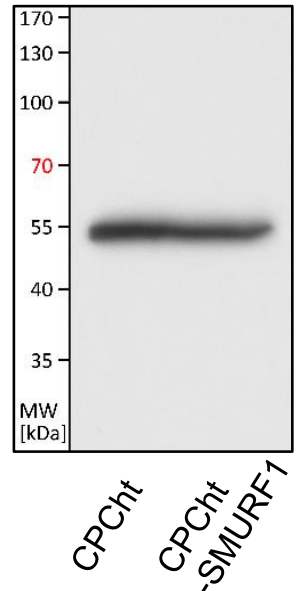

Abbildung 3.8: Auswirkungen des Knockdowns von SMURF1 auf SOX9, RUNX2, SMAD1 und SMAD2/3 in CPCht; linke Bande zeigt Kontrolle (CPCht), rechte Bande zeigt transfizierte Zellen (CPCht-SMURF1). 


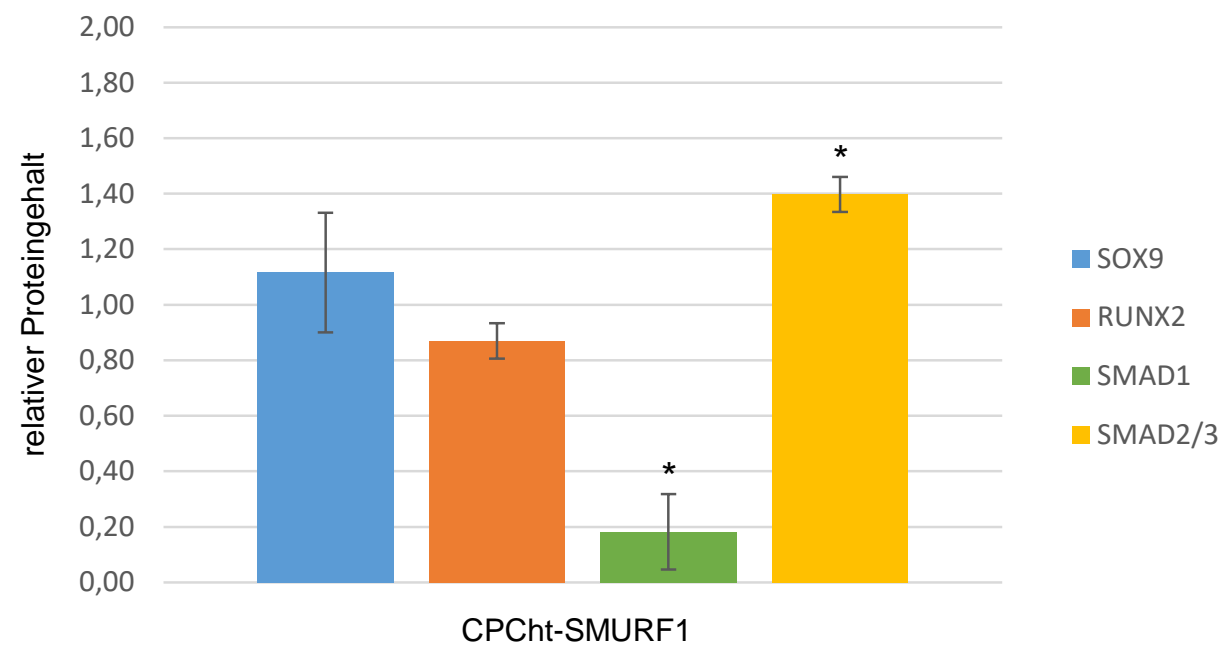

Abbildung 3.9: Auswirkungen des Knockdowns von SMURF1 auf SOX9, RUNX2, SMAD1 und SMAD2/3 in CPCht; statistische Auswertung des relativen Proteingehalts mit $n=3$, Fehlerbalken zeigt Standardabweichung; * = signifikant $(p=0,05)$.

Die Ergebnisse zeigen, dass keine signifikante Änderung des relativen Proteingehalts von SOX9 in CPCht bei Knockdown von SMURF1 nachzuweisen ist. Der relative Proteingehalt von SOX9 beträgt 1,12 $\pm 0,22$. Die Reaktion im Bereich von $90 \mathrm{kDa}$ kann durch ein unvollständiges Strippen der Transfermembran bei zuvor eingesetztem Antikörper für SMURF1 zu erklären sein. RUNX2 sinkt auf einen relativen Proteingehalt von $0,87 \pm 0,06$ ohne Signifikanz $(p=0,11)$. Zudem ist eine Änderung des relativen Proteingehalts der betrachteten SMADs in CPCht-SMURF1 zu beobachten. Der relative Proteingehalt von SMAD1 sinkt signifikant auf 0,18 $\pm 0,14$ $(p=0,005)$. Der relative Proteingehalt von SMAD2/3 steigt signifikant auf 1,40 $\pm 0,06$ $(p=0,04)$. 


\subsubsection{Auswirkungen des Knockdowns von SMURF2}

Nach Bestätigung des Knockdows von SMURF2 in CPCht, konnte dessen Auswirkungen auf die Proteinkonzentrationen von SOX9 und RUNX2 im Western Blot qualitativ beurteilt sowie quantitativ ausgewertet werden, siehe Abbildung 3.10.
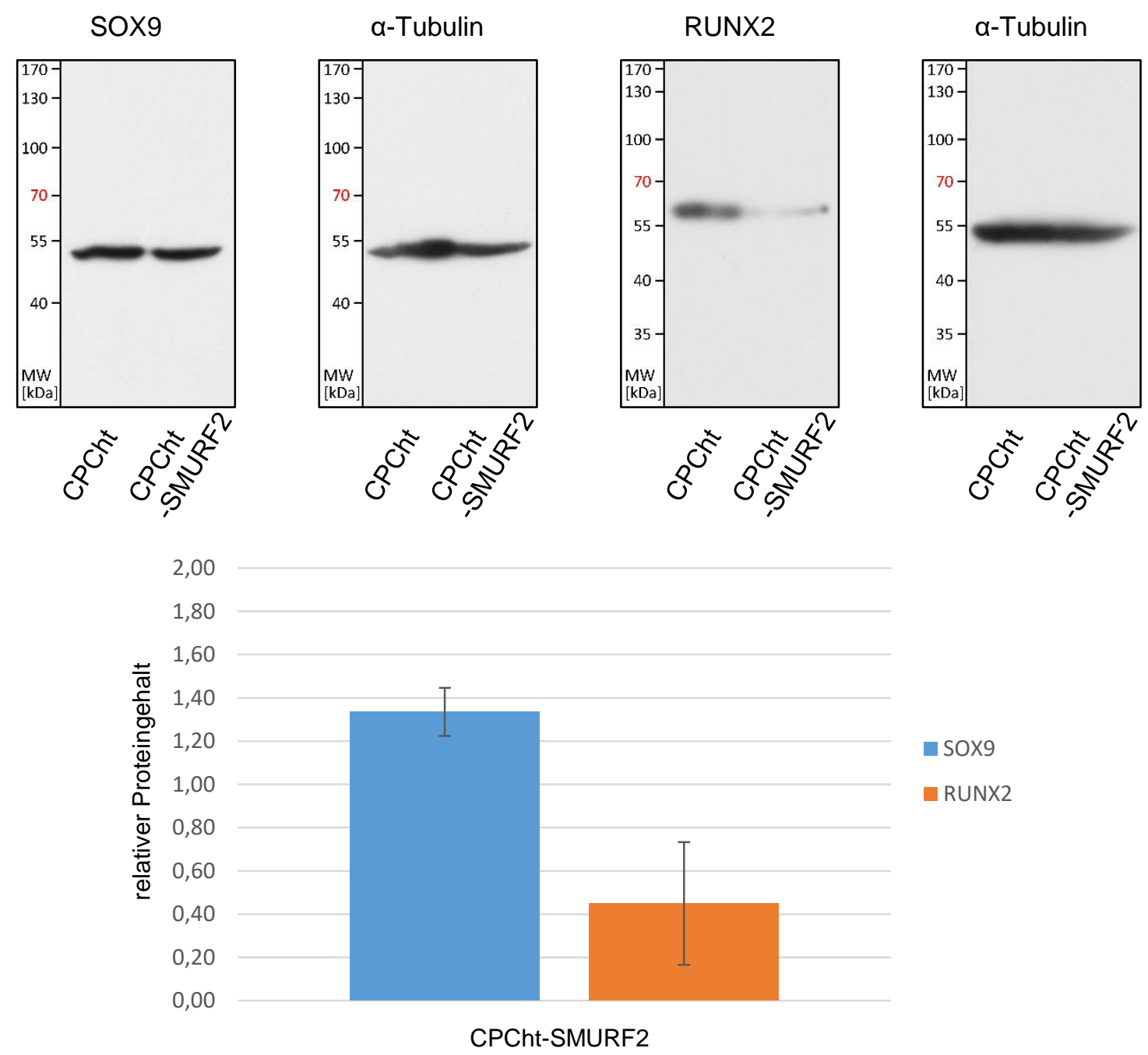

Abbildung 3.10: Auswirkungen des Knockdowns von SMURF2 auf SOX9 und RUNX2 in CPCht; linke Bande zeigt Kontrolle (CPCht), rechte Bande zeigt transfizierte Zellen (CPCht-SMURF2); statistische Auswertung des relativen Proteingehalts mit $n=3$, Fehlerbalken zeigt Standardabweichung; * $=$ signifikant $(p=0,05)$.

Der relative Proteingehalt von SOX9 erhöht sich mit Mittel auf $1,33 \pm 0,11$ ohne Signifikanz $(p=0,07)$. Die qualitative Betrachtung des Western Blots zeigt eine Verringerung des relativen Proteingehalts von RUNX2 bei Knockdown von SMURF2. Der quantitativ bestimmte relative Proteingehalt von $0,45 \pm 0,28$ in CPCht-SMURF2 für RUNX2 bestätigt diese Bewertung, zeigt jedoch keine statistische Signifikanz $(p=0,11)$. 


\section{4 Überexpression von SMURF1 und SMURF2 in CPCht}

Die Überexpression von SMURF1/2 in CPCht wurde zunächst mithilfe des Western Blots nachgewiesen. Darauffolgend wurden die Auswirkungen der Überexpression von SMURF1/2 auf die Proteine SOX9, RUNX2 sowie SMAD1 und SMAD2/3 auf Proteinebene untersucht.

In den gezeigten Western Blots wurden jeweils eine Kontrolle sowie die transfizierten Zellen parallel betrachtet. Um eine Aussage über den relativen Proteingehalt der jeweils betrachteten Zellen zu ermöglichen, wurde zudem das Housekeeping Protein a-Tubulin im Western Blot dargestellt und quantitativ bestimmt. Weiterhin wurde der DDK-Tag als Indikator für eine gelungene Transfektion nachgewiesen. Die dargestellten Coomassie-Färbungen sowie Western Blots zeigen exemplarisch das Ergebnis der jeweiligen Untersuchung, die jeweils dreimal durchgeführt wurden $(n=3)$. Das Signifikanzniveau wurde mit $p=0,05$ festgelegt.

\subsubsection{Nachweis der Überexpression im Western Blot}

Zum Nachweis der Überexpression von SMURF1/2 in CPCht wurde der relative Proteingehalt von SMURF1/2 in transfizierten Zellen (CPCht+SMURF1 und CPCht+SMURF2) sowie in einer Kontrolle (CPCht) quantitativ bestimmt. Abbildung 3.11 und Abbildung 3.12 zeigen exemplarisch die Coomassie-Färbung der Membran, die repräsentativen Ergebnisse der Western Blots sowie deren quantitative Auswertung. 
SMURF1

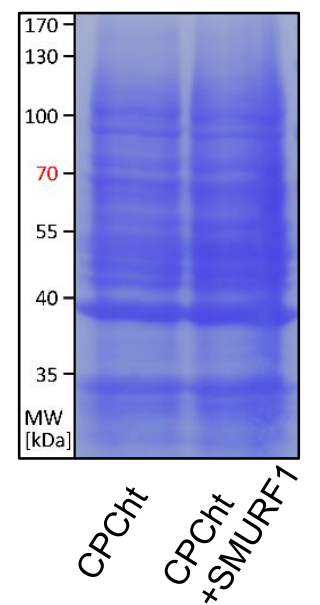

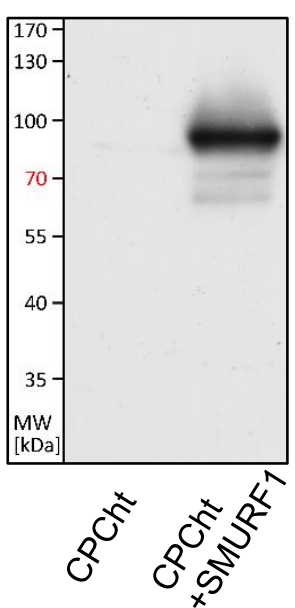

DDK

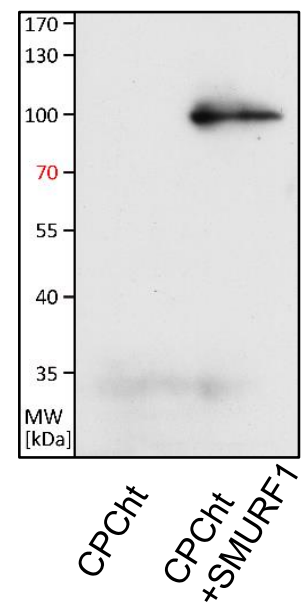

a-Tubulin

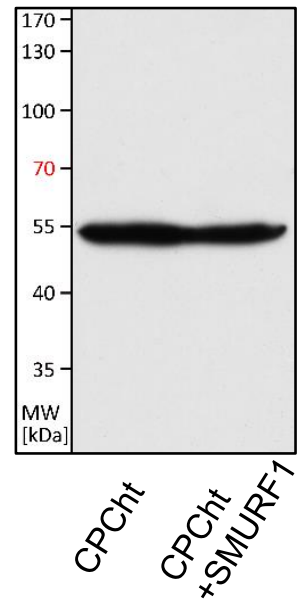

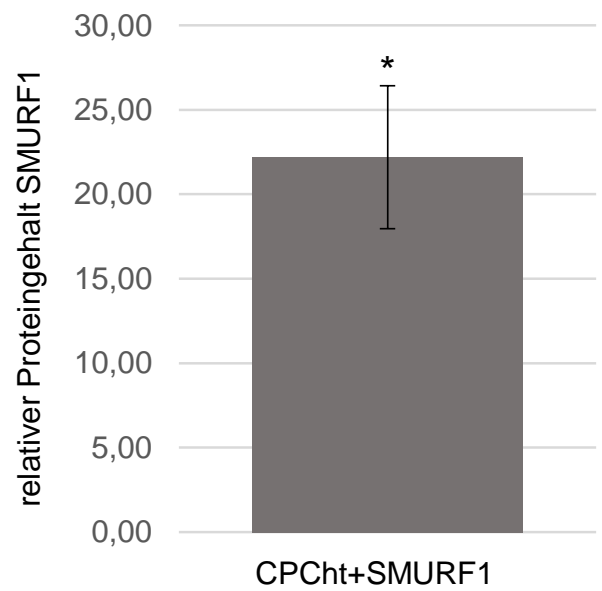

Abbildung 3.11: Nachweis der Überexpression von SMURF1 in CPCht im Western Blot; links: CoomassieFärbung; linke Bande zeigt Kontrolle (CPCht), rechte Bande zeigt transfizierte Zellen (CPCht+SMURF1); statistische Auswertung des relativen Proteingehalts mit $n=3$; Fehlerbalken zeigt Standardabweichung; ${ }^{*}=$ signifikant $(p=0,05)$.

Die Überexpression von SMURF1 in CPCht kann nach quantitativer Auswertung des Western Blots bestätigt werden. Es wird eine signifikante Überexpression mit einem relativen Proteingehalt von $22,20 \pm 4,23(p=0,04)$ erreicht. 
SMURF2

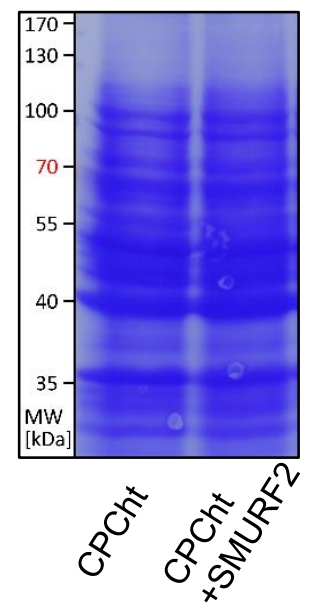

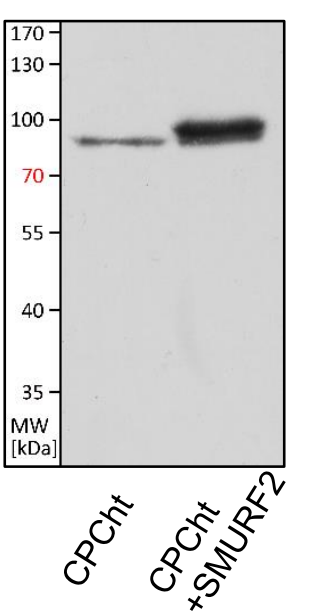

DDK

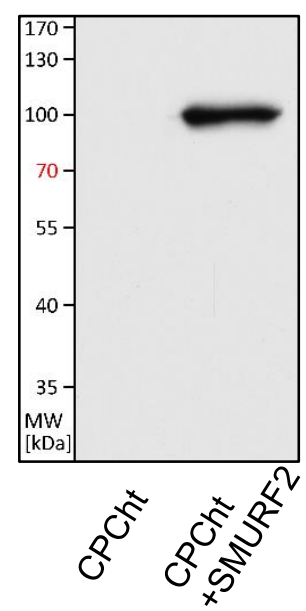

a-Tubulin

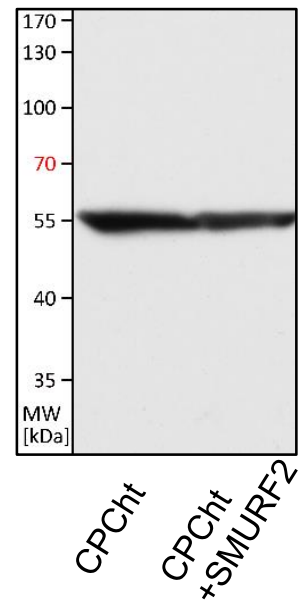

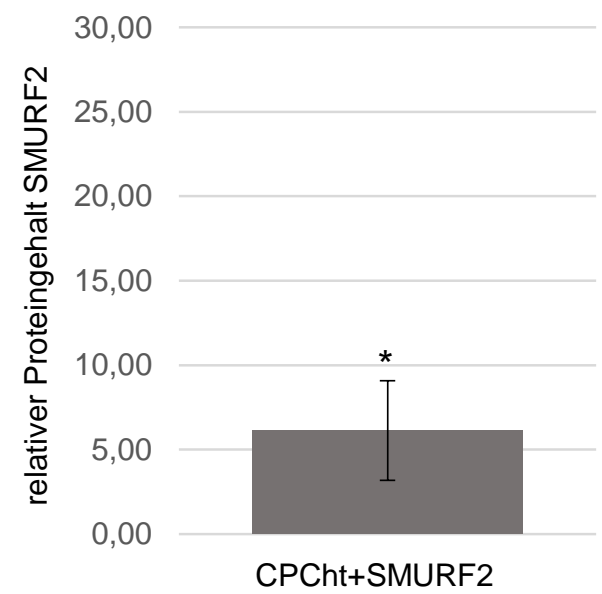

Abbildung 3.12: Nachweis der Überexpression von SMURF2 in CPCht im Western Blot; links: CoomassieFärbung; linke Bande zeigt Kontrolle (CPCht), rechte Bande zeigt transfizierte Zellen (CPCht+SMURF2); statistische Auswertung des relativen Proteingehalts mit $n=3$; Fehlerbalken zeigt Standardabweichung; ${ }^{*}=$ signifikant $(p=0,05)$.

Die Überexpression von SMURF2 in CPCht kann nach quantitativer Auswertung des Western Blots bestätigt werden. Es wird eine signifikante Überexpression von $6,12 \pm 2,94(p=0,047)$ erreicht. 


\subsubsection{Auswirkungen der Überexpression von SMURF1 auf Proteinebene}

Nach der Bestätigung der Überexpression von SMURF1 in CPCht wurden dessen Auswirkungen auf die Proteine SOX9, RUNX2, SMAD1 und SMAD2/3 betrachtet. Hierfür wurden Western Blots zur Bestimmung dieser Proteine in CPCht sowie in transfizierten CPCht+SMURF1 angefertigt und quantitativ ausgewertet, siehe Abbildung 3.13 und Abbildung 3.14.
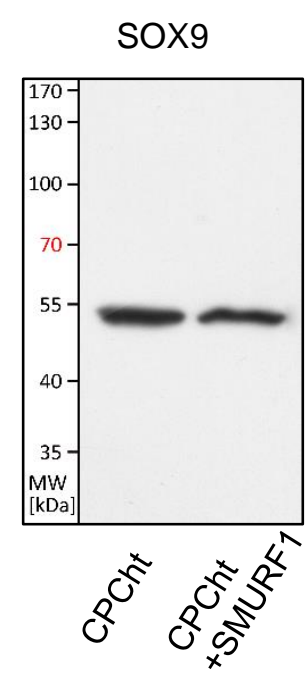

SMAD1
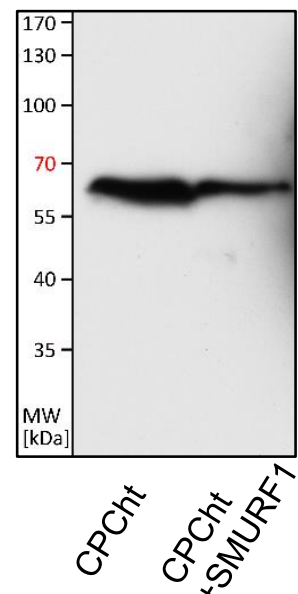

$\alpha-T u b u l i n$

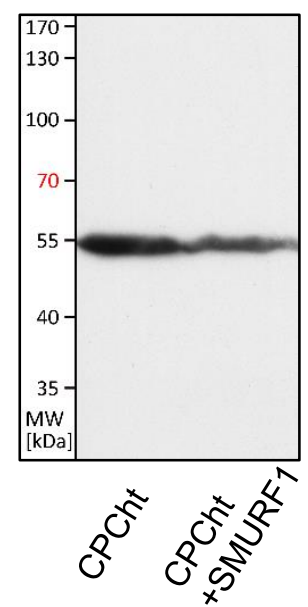

$\alpha-T u b u l i n$

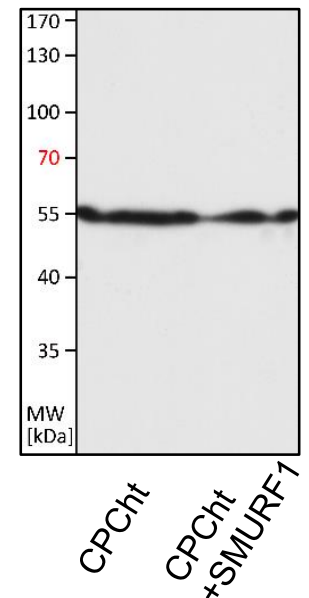

RUNX2

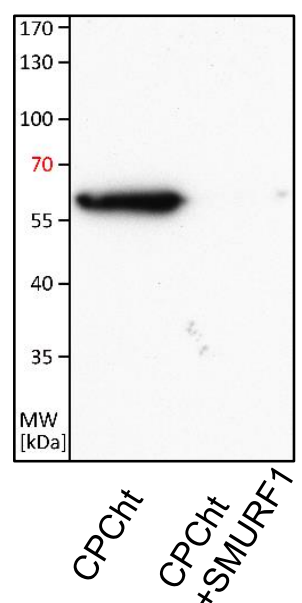

SMAD2/3

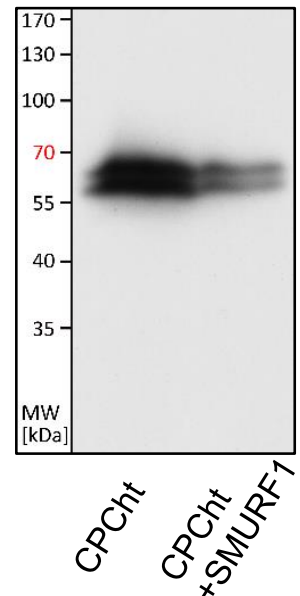

a-Tubulin

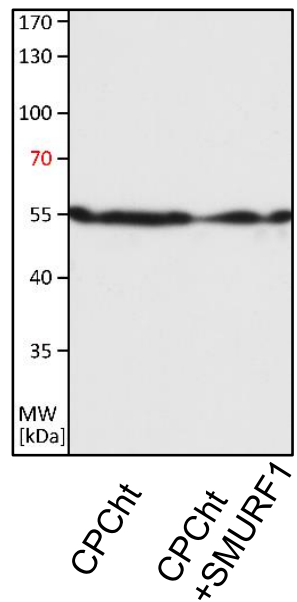

a-Tubulin

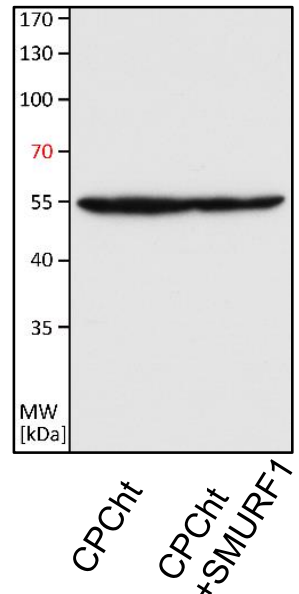

Abbildung 3.13: Auswirkungen der Überexpression von SMURF1 auf SOX9, RUNX2, SMAD1 und SMAD2/3 in CPCht; linke Bande zeigt Kontrolle (CPCht), rechte Bande zeigt transfizierte Zellen (CPCht+SMURF1). 


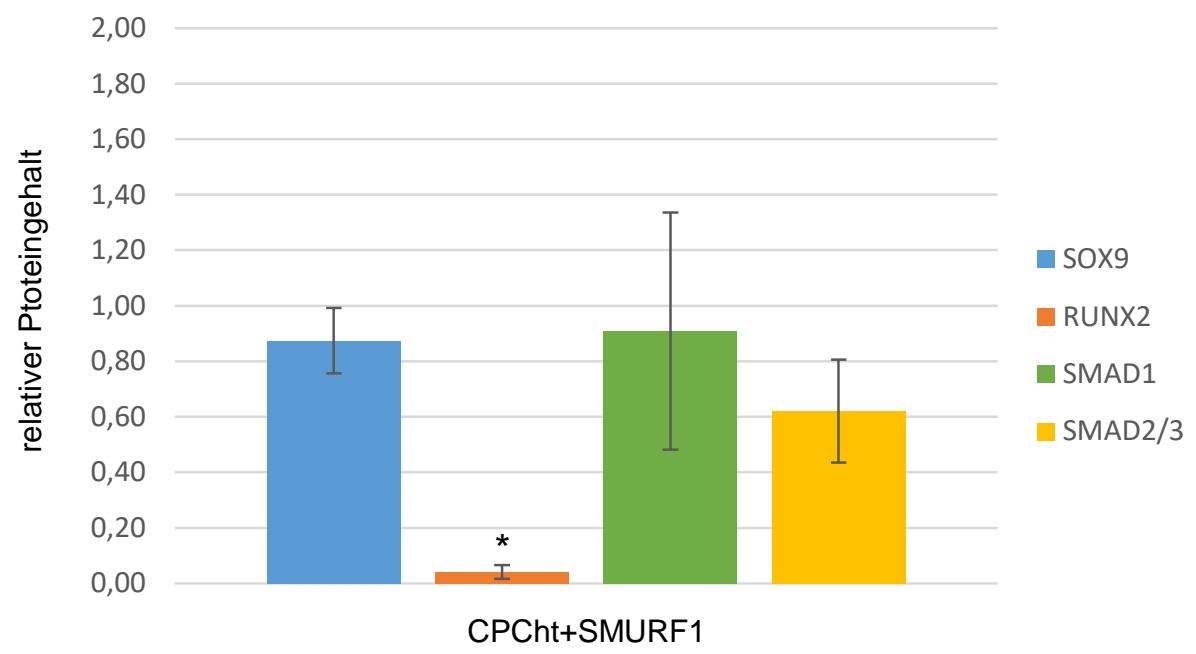

Abbildung 3.14: Auswirkungen der Überexpression von SMURF1 auf SOX9, RUNX2, SMAD1 und SMAD2/3 in CPCht; statistische Auswertung des relativen Proteingehalts mit $n=3$, Fehlerbalken zeigt Standardabweichung; * = signifikant $(p=0,05)$.

Die Ergebnisse zeigen, dass keine signifikante Änderung des relativen Proteingehalts von SOX9 sowie SMAD1 in CPCht bei Überexpression von SMURF1 nachzuweisen ist. SMAD1 wird statistisch mit einem relativen Proteingehalt von $0,91 \pm 0,43$ und SOX9 mit 0,87 $\pm 0,12(p=0,10)$ bestimmt. Eine Änderung des relativen Proteingehalts von RUNX2 kann statistisch signifikant nachgewiesen werden. Der relative Proteingehalt von RUNX2 sinkt auf 0,04 $\pm 0,03(p=0,006)$. Für SMAD2/3 zeigt die qualitative Betrachtung des Western Blots eine Verringerung des relativen Proteingehalts bei Überexpression von SMURF1. Der quantitativ bestimmte relative Proteingehalt von $0,62 \pm 0,18$ bestätigt diese Bewertung, zeigt jedoch keine statistische Signifikanz $(p=0,11)$. 


\subsubsection{Auswirkungen der Überexpression von SMURF2 auf Proteinebene}

Nach Bestätigung der Überexpression von SMURF2 in CPCht konnte dessen Auswirkungen auf die Proteine SOX9 und RUNX2 im Western Blot betrachtet und quantitativ ausgewertet werden, siehe Abbildung 3.15.
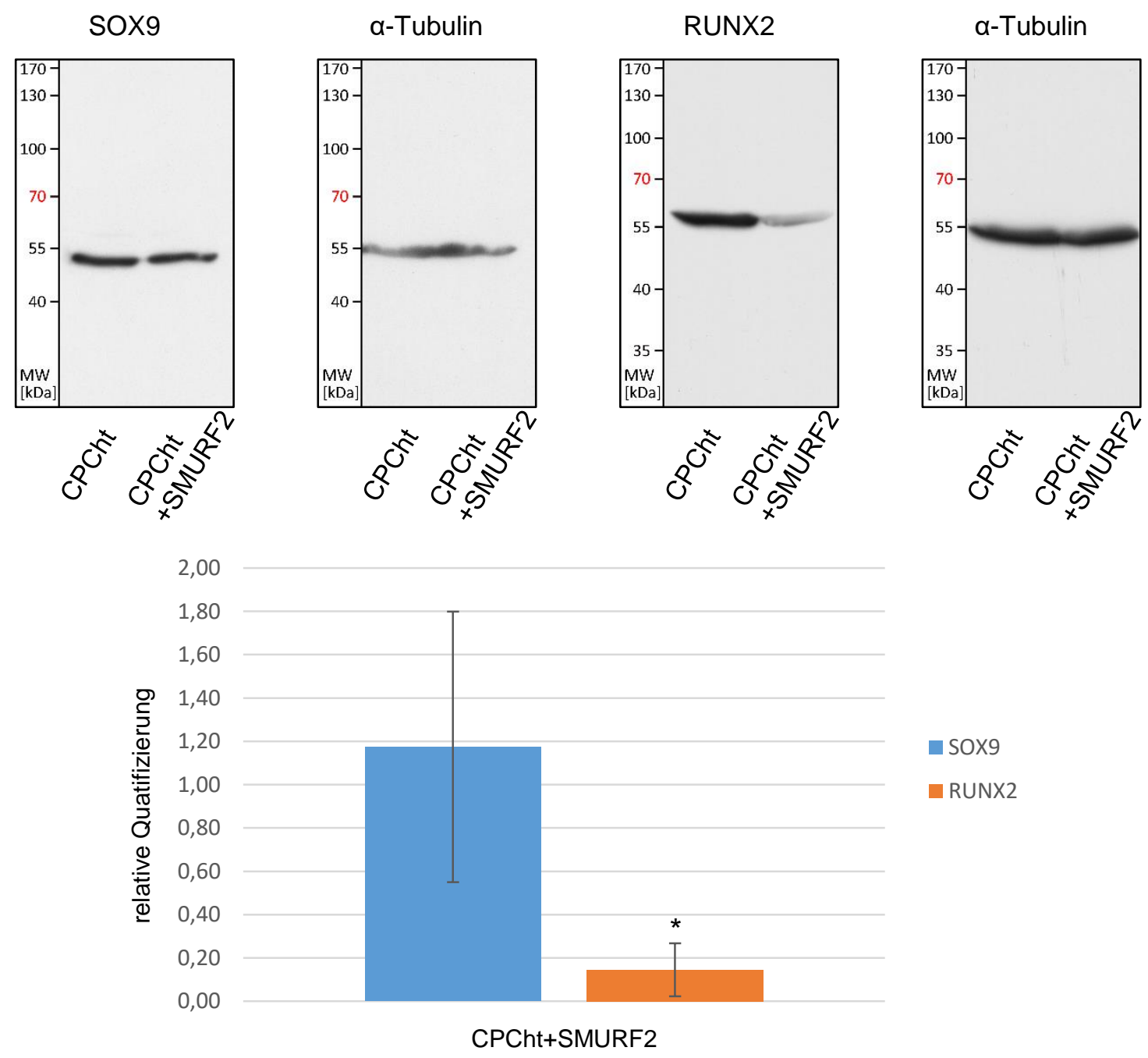

Abbildung 3.15: Auswirkungen der Überexpression von SMURF2 auf SOX9 und RUNX2 in CPCht; linke Bande zeigt Kontrolle (CPCht), rechte Bande zeigt transfizierte Zellen (CPCht+SMURF2); unten: statistische Auswertung des relativen Proteingehalts mit $n=3$, Fehlerbalken zeigt Standardabweichung; ${ }^{*}=$ signifikant $(p=0,05)$.

Der relative Proteingehalt von SOX9 zeigt keine signifikante Änderung in CPCht+SMURF2 und beträgt 1,17 $\pm 0,62$. Die qualitative Betrachtung des Western Blots für RUNX2 zeigt eine Verringerung des relativen Proteingehalts bei Überexpression von SMURF2. Die quantitative Auswertung liefert einen signifikanten Knockdown für RUNX2 von 0,14 $\pm 0,12(p=0,03)$. 


\section{Diskussion}

\subsection{Nachweis und Lokalisation von SMURF1/2}

Im Rahmen der vorliegenden Arbeit konnten SMURF1/2 immunhistochemisch in osteoarthrotischem Kniegelenkknorpel sowie erstmals immunzytologisch in CPCht und auf Proteinebene in CPCs sowie CPCht mithilfe des Western Blots nachgewiesen werden. Immunhistochemisch war kein direkter Vergleich zwischen krankem und gesundem humanen Knorpelgewebe bezüglich der Expression von SMURF1/2 möglich, da keine gesunden Knorpelpräparate zur Verfügung standen. In CPCht sowie in primären CPCs konnten SMURF1 sowie SMURF2 mit dieser Arbeit erstmals nachgewiesen werden. Der immunzytologische Nachweis konzentriert sich auf den Zellkern. Zudem ist ein diffuses Vorkommen von SMURF1/2 im Zytoplasma nachweisbar.

Ebisawa et al. (2001) zeigten in HEK-Zellen (human embryonic kidney-Zellen), dass SMURF1 durch SMAD7 aus dem Zellkern zur Zellmembran rekrutiert wird, womit ein Abbau von Typ 1 TGF- $\beta$-Rezeptoren assoziiert ist. Wu et al. (2008) wiesen SMURF2 in krankem Gelenkknorpel mit immunhistochemischen Verfahren intrazellulär nach und beschrieben eine vermehrte Expression von SMURF2 bei graduell zunehmender $O A$ im menschlichen Kniegelenk. Im gesunden Kniegelenkknorpel konnte immunhistochemisch kein SMURF2 nachgewiesen werden. Die hierfür benötigten gesunden Knorpelgewebsproben wurden im Rahmen von Teilamputationen der unteren Extremitäten nach Traumata gewonnen (Wu et al. 2008).

Die bisher in der Literatur beschriebenen Lokalisationen von SMURF1 sowie SMURF2 können demnach mit den Ergebnissen der immunhistologischen sowie immunzytologischen Nachweise bestätigt werden. Der erfolgreiche Nachweis auf Proteinebene bestätigt zudem das Vorhandensein von SMURF1/2 innerhalb von CPCs in humanem osteoarthrotischem Kniegelenkknorpel. 


\subsection{Auswirkungen des Knockdowns und der Überexpression von SMURF1 auf SMAD1 und SMAD2/3}

Der Knockdown von SMURF1/2 in CPCht wurde mithilfe der Transfektion von siRNA realisiert, womit sowohl das mRNA-Level als auch das Transkriptionsniveau von SMURF1/2 moduliert wurde. Der relative Proteingehalt von SMURF1 in CPChtSMURF1 beträgt $0,15 \pm 0,10$. Dies entspricht einem mittleren Knockdown von SMURF1 von $85 \%$. Bei Betrachtung des Proteinlevels der SMADs in CPCht-SMURF1 zeigt sich ein signifikanter Abfall des relativen Proteingehalts von SMAD1 mit $0,18 \pm 0,14$ sowie ein statistisch signifikanter Anstieg von SMAD2/3 auf 1,40 $\pm 0,06$.

Zhang et al. (2016) zeigten in Myoblasten der Maus (C2C12 - Zellen), dass es beim Einsatz von Verbindungen kleiner Moleküle (small molecule compounds), welche die HECT-Domäne blockieren, zu einer verringerten Ubiquitinierung von SMAD1 durch SMURF1 kommt. Daraus folgt, dass eine Einschränkung der Ubiquitinierungsfunktion von SMURF1 zu einem vermehrten Vorkommen von SMAD1 führt. Fukunaga et al. (2008) konnten hingegen keine Änderung des Proteinlevels von SMAD1 bei siRNAKnockdown von SMURF1 in Brustkrebszellen nachweisen. Die in der vorliegenden Arbeit beobachtete verminderte Expression von SMAD1 in CPCht-SMURF1 kann darauf zurückzuführen sein, dass SMAD1 als Target der Antikörperreaktion gewählt wurde und nicht das phosphorylierte und somit aktivierte SMAD1 (p-SMAD1). Dieser phosphorylierte Zustand ist Voraussetzung für eine Interaktion mit SMAD4 und damit für das Fortlaufen der Signaltransduktion (Qin et al. 2001). SMURF1 wurde ursprünglich mit dem Abbau von SMAD1 sowie SMAD5, welche Mediatoren des TGF$\beta$ - sowie BMP-Signalwegs sind, assoziiert (Massagué 1998; Zhu et al. 1999). Daraus kann näherungsweise geschlossen werden, dass ein Knockdown von SMURF1 zu einem verringerten Abbau von SMAD1 führt. Die in der vorliegenden Arbeit gegensätzliche Beobachtung kann darauf zurückzuführen sein, dass SMAD1 aufgrund der verstärkten Aktivierung des BMP-Signalweges vermehrt phosphoryliert wird, woraufhin das Proteinlevel steigt.

SMAD2/3 ist Teil des TGF- $\beta$-Signalwegs. Zhu et al. (1999) zeigten in Embryos von Xenopus Laevis (Krallenfrosch), dass ein erhöhtes Proteinlevel von SMURF1 zu einer verringerten Expression von SMAD2 führt. Damit kann vermutet werden, dass ein Knockdown von SMURF1 einen gegenteiligen Effekt bedingt. Hingegen stellten Ying 
et al. (2003) fest, dass SMURF1 keinen Einfluss auf das Proteinlevel von SMAD2/3 in C2C12-Zellen ausübt. SMURF1 ist gemeinsam mit I-SMADs am proteasomalen Abbau von Typ 1-TGF- $\beta$-Rezeptoren beteiligt (Ebisawa et al. 2001; Murakami et al. 2003). Der beobachtete Anstieg von SMAD2/3 in CPCht-SMURF1 kann auf den daraus resultierenden verringerten Abbau von Typ 1-TGF- $\beta$-Rezeptoren zurückzuführen sein. Hierdurch würde die Signaltransduktion auf SMAD2/3 verstärkt und das Proteinlevel von SMAD2/3 erhöht. Asano et al. (2004) zeigten hingegen, dass eine Überexpression von SMURF1 gemeinsam mit einem erhöhten Proteinlevel von SMAD7 in Fibroblasten bei Patienten mit Sklerodermie nicht zu einem vermehrten Abbau von Typ 1-TGF- $\beta$-Rezeptoren führt. Eine gegensätzliche Relation zwischen SMAD2/3 und SMAD1/5 beschrieben Li et al. (2006) in Chondrozyten der Maus. In SMAD3-Knockout-Mäusen wurde eine Erhöhung der Proteinlevel von SMAD1 sowie SMAD5 nachgewiesen, wobei keine Erhöhung von SMAD2 zu verzeichnen war (Li et al. 2006). Dieser inverse Zusammenhang zwischen SMAD1 sowie SMAD2/3 konnte in den hier durchgeführten Untersuchungen an CPCht ebenfalls gezeigt werden.

Die Überexpression erfolgte mithilfe einer chemischen Transfektion von Plasmiden, die als Vektoren zur Überexpression von SMURF1/2 eingesetzt wurden. In CPCht+SMURF1 wird eine signifikante Überexpression mit einem relativen Proteingehalt von $22,20 \pm 4,23$ erreicht. Zu erwarten ist eine im Vergleich zum siRNAKnockdown von SMURF1 inverse Auswirkung auf die untersuchten SMADs. Es zeigte sich für SMAD1 ein relativer Proteingehalt von 0,91 $\pm 0,43$ und damit keine signifikante Änderung. Für SMAD2/3 zeigt sich qualitativ ein Abfall des relativen Proteingehalts, womit ein inverses Verhalten im Vergleich zum Knockdown von SMURF1 gezeigt wird. Die quantitativ statistische Auswertung ergibt einen relativen Proteingehalt von $0,62 \pm 0,18$ ohne statistische Signifikanz $(p=0,11)$.

Ein Komplex aus SMURF1 und SMAD6 sowie eine Verbindung aus SMURF1 und SMAD7 werden mit dem Abbau von Typ 1-TGF- $\beta$-Rezeptoren in COS-Zellen (Fibroblasten aus Nierengewebe der grünen Meereskatze, Klon 7) assoziiert (Murakami et al. 2003). Bei Überexpression von SMURF1 kann demnach ein vermehrter Abbau dieses Rezeptors erwartet werden. Fisher et al. (2016) fanden eine Verminderung des Proteinlevels von SMAD3 bei verminderter Expression von Typ 2-TGF- $\beta$-Rezeptoren. Da Typ 1- sowie Typ 2-TGF- $\beta$-Rezeptoren funktionell miteinander gekoppelt sind (Miyazono et al. 2010), könnte das verminderte Vorkommen von SMAD2/3 in 
CPCht+SMURF1 erklärt werden, wobei zu beachten ist, dass mit einem $p$-Wert von 0,11 keine statistische Signifikanz vorliegt. Weiterhin zeigten Zhu et al. (1999), dass ein erhöhtes Proteinlevel von SMURF1 zu einer verringerten Expression von SMAD2 führt. Hingegen konnten Ying et al. (2003) keine Assoziation zwischen einer Überexpression von SMURF1 und einer Änderung des Proteinlevels von SMAD2/3 nachweisen.

\subsection{Auswirkungen des Knockdowns und der Überexpression von SMURF1 auf SOX9 und RUNX2}

Als Folge des Knockdowns von SMURF1 in CPCht ist keine signifikante Änderung des relativen Proteingehalts von SOX9 nachzuweisen. Der relative Proteingehalt von SOX9 in CPCht-SMURF1 beträgt 1,12 $\pm 0,22$. Der relative Proteingehalt von RUNX2 hingegen sinkt auf $0,87 \pm 0,06$ ohne Signifikanz $(p=0,11)$.

Zhao et al. (2003) untersuchten Osteoblastenvorläuferzellen einer transgenen Maus (2T3-Zellen) und beschrieben einen proteasomalen Abbau von RUNX2 durch SMURF1. Lee et al. (2014) wiesen eine erhöhte Expression von RUNX2 bei Knockdown von SMURF1 in C2C12-Zellen nach. Die in der vorliegenden Arbeit beobachtete Verminderung der Expression von RUNX2 in CPCht-SMURF1 zeigt einen gegenteiligen Effekt. Zu beachten ist, dass der beschriebene Abfall von RUNX2 mit einem relativen Proteinlevel von $0,87 \pm 0,06$ keine Signifikanz aufweist $(p=0,11)$ und damit in seiner Bedeutung kritisch zu bewerten ist. Weiterhin kann dieser Abfall im Zusammenhang mit dem signifikanten Abfall von SMAD1 gesehen werden, dessen Bedeutung in Kapitel 4.2 bereits diskutiert wurde. Yang et al. (2016) zeigten in humanen Zellen des Chondrosarkoms, dass ein Knockdown von p-SMAD1/5 zu einer verringerten Expression von RUNX2 führt. Dieser Zusammenhang wird durch die Ergebnisse der vorliegenden Arbeit bestätigt. Muhammad et al. (2014) untersuchten die Auswirkungen eines siRNA-Knockdowns von RUNX2 in MPCs. Hierbei fanden sie ein erhöhtes Proteinlevel von SMAD2/3 sowie p-SMAD2 (Muhammad et al. 2014). Sadatsuki et al. (2017) beschrieben keine Änderung des mRNA-Levels von RUNX2 bei einem verminderten mRNA-Level von SOX9 in MSCs der Synovia eines Mausmodells. Fan et al. (2016) zeigten, dass eine erhöhte Expression von SOX9 in MSCs der Synovia zu keiner Änderung der Genexpression von RUNX2 führt. Koelling 
et al. (2009) fanden, dass ein Knockdown von RUNX2 das Proteinlevel von SOX9 in CPCs erhöht. Weiterhin wiesen Cheng und Genever (2010) einen konzentrationsabhängigen gegenseitigen inhibitorischen Effekt zwischen SOX9 und RUNX2 in HEK Zellen nach. SOX9 führt RUNX2 dabei einem vermehrten lysosomalen Abbau zu. Umgekehrt scheint RUNX2 die Ubiquitinierung von SOX9 zu verstärken (Cheng und Genever 2010). Eine Erhöhung des Proteinlevels von SOX9 bei nicht signifikant verminderter Expression von RUNX2 nach siRNA-Knockdown von SMURF1 kann mit den Ergebnissen dieser Arbeit nicht bestätigt werden.

Die Expression von SOX9 und RUNX2 wurde zudem in CPCht+SMURF1 untersucht. Die Überexpression von SMURF1 führt zu einem signifikant verminderten Nachweis von RUNX2. Die Bestimmung des relativen Proteingehalts von RUNX2 ergibt dabei $0,04 \pm 0,03$. Der relative Proteingehalt von SOX 9 erfährt keine signifikante Änderung und beträgt $0,87 \pm 0,12$.

Kaneki et al. (2006) zeigten eine verminderte Expression von RUNX2 bei vermehrter Expression von SMURF1 im Knochen eines transgenen Mausmodells. Guo et al. (2008) bestätigten diese Beschreibung in 2T3-Zellen. Weiterhin stellten Shen et al. (2006) fest, dass SMAD6 RUNX2 bindet und somit den durch SMURF1 induzierten proteasomalen Abbau von RUNX2 verstärkt. Im Rahmen der vorliegenden Arbeit konnte dieser Zusammenhang ebenfalls bestätigt werden. Im Vergleich zur Untersuchung des siRNA-Knockdowns von SMURF1 ist keine signifikant inverse Auswirkung auf die untersuchten Transkriptionsfaktoren RUNX2 sowie SOX9 zu beobachten, wobei im Mittel SOX9 in CPCht-SMURF1 vermehrt exprimiert wird sowie in CPCht+SMURF1 der relative Proteingehalt verringert ist. Zhou et al. (2016) zeigten, dass die Stimulation von MSCs mit BMP2, ein Aktivator des BMP-Signalweges, zu einer vermehrten Expression von SOX9 sowie RUNX2 führt. Die von Koelling et al. (2009) beschriebene Erhöhung der Expression von SOX9 bei Knockdown von RUNX2 in CPCs kann in CPCht+SMURF1 nicht bestätigt werden. Hierbei ist zu diskutieren, ob eine Verlängerung der Inkubationszeit durch die Anwendung einer stabilen Transfektion zu einem verstärkten Knockdown von RUNX2 und damit zu einem erhöhen Proteinlevel von SOX9 führen würde. Weiterhin zeigten Muhammad et al. (2014), dass eine Verminderung der Expression von SMAD2 mit einem verminderten Proteinlevel von SOX9 in MPCs einhergeht. Die verminderte Expression von SMAD2 wurde hierbei durch Gabe von BMP2 erreicht (Muhammad et al. 2014). Mit einem 
relativen Proteinlevel von SMAD2/3 von 0,62 $\pm 0,18$ in CPCht+SMURF1 und einer Verminderung der Expression von SOX9 auf 0,87 $\pm 0,12$ kann diese Beschreibung bestätigt werden, zeigt jedoch statistisch keine Signifikanz. Einen direkten signifikanten Einfluss des Proteinlevels von SMURF1 auf die Expression von SOX9 ist bislang in der Literatur nicht beschrieben. Die hier gezeigten Ergebnisse deuten ebenfalls nicht auf einen direkten Abbau von SOX9 durch SMURF1 hin.

\subsection{Auswirkungen des Knockdowns und der Überexpression von SMURF2 auf SOX9 und RUNX2}

Analog zu SMURF1 wurde mithilfe der Transfektion von siRNA ein Knockdown von SMURF2 in CPCht durchgeführt und die Auswirkungen auf den relativen Proteingehalt von SOX9 sowie RUNX2 untersucht. Dabei wird ein relativer Proteingehalt für SMURF2 in CPCht-SMURF2 von 0,03 $\pm 0,02$ erreicht. Dies entspricht einem mittleren Knockdown von SMURF2 von $97 \%$. Bei Betrachtung des Proteinlevels von SOX9 in CPCht-SMURF2 zeigt sich ein Anstieg des relativen Proteingehalts auf 1,33 $\pm 0,11$ ohne Signifikanz $(p=0,07)$. Der relative Proteingehalt von RUNX2 sinkt in CPChtSMURF2 auf $0,45 \pm 0,28$ ohne Signifikanz $(p=0,11)$.

Entgegen den hier dargestellten Ergebnissen wiesen Kaneki et al. (2006) eine erhöhte Expression von RUNX2 bei siRNA-Knockdown von SMURF2 im Knochen eines transgenen Mausmodells nach. Khedgikar et al. (2013) beschrieben einen verminderten Abbau von RUNX2 in Osteoblasten bei siRNA-Knockdown von SMURF2. Muhammad et al. (2014) zeigten, dass eine Überexpression von SMAD2 zu einer Reduktion der Expression von RUNX2 in MPCs führt. Da SMURF2 den proteasomalen Abbau von SMAD2 bedingt (Nakano et al. 2009), kann vermutet werden, dass der Knockdown von SMURF2 zu einer erhöhten Expression von SMAD2 und damit zu einem verringerten Proteinlevel von RUNX2 führt. Fukunaga et al. (2008) wiesen eine vermehrte Expression von SMURF1 bei Knockdown von SMURF2 in Brustkrebszellen nach. Zudem wurde dargestellt, dass SMURF1 zu einem vermehrten proteasomalen Abbau von RUNX2 beiträgt (siehe Kapitel 4.3). Daraus kann geschlossen werden, dass die beobachtete verminderte Expression von RUNX2 in CPCht-SMURF2 indirekt über einen verminderten inhibitorischen Effekt auf SMURF1 vermittelt wird. Zudem wiesen Huang et al. (2016) ein erhöhtes mRNA-Level von SOX9 in einem SMURF2- 
Knockout-Mausmodell nach. Die Erhöhung des Proteinlevels von SOX9 in CPChtSMURF2 ist statistisch nicht signifikant, bestätigt jedoch die Beschreibung von Koelling et al. (2009) bezüglich der verstärkten Expression von SOX9 bei vermindertem Proteinlevel von RUNX2 in CPCs. Zu beachten ist, dass die im Rahmen dieser Arbeit erarbeiteten Ergebnisse des relativen Proteingehalts für SOX9 und RUNX2 in CPChtSMURF2 keine Signifikanz aufweisen, womit deren Bedeutung sowie die hier dargestellten möglichen Wechselwirkungen mit weiteren Signalkaskaden kritisch zu bewerten ist.

Die Überexpression von SMURF2 in CPCht kann nach quantitativer Auswertung des Western Blots bestätigt werden. Es wird eine Überexpression von 6,12 $\pm 2,94$ nachgewiesen, womit im Mittel die sechsfache Expression von SMURF2 in CPCht+SMURF2 erreicht wird. Der relative Proteingehalt von SOX9 in CPCht+SMURF2 zeigt mit 1,17 $\pm 0,62$ keine signifikante Änderung und zudem eine große Streuung der einzelnen Messwerte. RUNX2 wird signifikant $(p=0,03)$ vermindert exprimiert. Der relative Proteingehalt für RUNX2 in CPCht+SMURF2 beträgt $0,14 \pm 0,12$.

Kavsak et al. (2000) zeigten in COS-Zellen (Klon 1), dass SMAD7 SMURF2 aus dem Zellkern zur Zellmembran rekrutiert. Die Ubiquitinierung von Typ 1-TGF- $\beta$-Rezeptoren führte dort zu deren proteasomalen Abbau. Hieraus kann eine verminderte Aktivität des BMP-Signalwegs resultieren, die eine Verringerung der Expression von RUNX2 zur Folge hat (Yamaguchi et al. 2000). Für eine funktionelle Kopplung von SMURF2 und SMAD7 bezüglich ihrer Wechselwirkung mit RUNX2 spricht weiterhin, dass Vishal et al. (2017) eine erhöhte Expression von RUNX2 nach siRNA-Knockdown von SMAD7 in humanen osteoblastenähnlichen Zellen nachwiesen. Bizet et al (2012) untersuchten TGF- $\beta$-Co-Rezeptoren in humanen Keratinozyten. Hierbei fanden sie, dass CD109 den Abbau der membranständigen Typ 1-TGF- $\beta$-Rezeptoren durch den bereits beschriebenen SMAD7-SMURF2-Komplex fördert (Bizet et al. 2012). Weiterhin beschrieben Choi et al. (2014) in C2C12-Zellen sowie HEK-Zellen, dass die Stabilität von RUNX2 durch Phosphorylierung und damit die Inaktivierung von SMURF2 erhöht wird. Zudem zeigten Kaneki et al. (2006), dass die Expression von RUNX2 bei Induktion von SMURF2 durch TNF im Knochen eines transgenen Mausmodells vermindert wird. SOX9 wurde bisher in der Literatur nicht als Ziel der Ubiquitinierung durch SMURF2 beschrieben. Die Ergebnisse dieser Arbeit können diesen Anhalt 
bezüglich SOX9 in CPCht+SMURF2 nicht bestätigen, da die erhobene Standardabweichung eine Bewertung der Auswirkung der Überexpression von SMURF2 nicht ermöglicht. Zu diskutieren ist die im Vergleich zur Überexpression von SMURF1 $(22,20 \pm 4,23)$ weniger starke Überexpression von SMURF2 (6,12 $\pm 2,94)$. Die schwächere Überexpression von SMURF2 könnte zu einem weniger starken Effekt auf die untersuchten Proteine SOX9 und RUNX2 geführt haben, wordurch zudem die große Streuung in der statistischen Betrachtung von SOX9 erklärt werden könnte. Weiterhin könnten autoinhibitorische Mechanismen Einfluss auf die beobachteten Effekte bei Überexpression sowie Knockdown von SMURF2 genommen haben. So zeigten Wiesner et al. (2007), dass SMURF2 einer Autoinhibition durch Wechselwirkungen zwischen der C2- und HECT-Domäne unterliegt. SMAD7 löst diese Autoinhibition durch Bindung an SMURF2 auf und stabilisiert SMURF2 hierdurch (Wiesner et al. 2007). Dieser Mechanismus könnte ebenfalls eine mögliche Ursache für eine im Vergleich zu SMURF1 schwächere Überexpression von SMURF2 darstellen.

\subsection{SMURF1 und SMURF2 in der Differenzierung von CPCs}

CPCs sind fibroblastenartige Chondrozyten, die in osteoarthrotischem hyalinen Knorpel nachweisbar sind. CPCs besitzen Stammzelleigenschaften sowie das Potential zur Regeneration von Knorpelgewebe. Die Differenzierung der CPCs in Chondrozyten ist abhängig von den Transkriptionsfaktoren SOX9 und RUNX2, die als übergeordnete Regulatoren der Genexpression bei der chondrogenen Differenzierung beschrieben werden (Koelling et al. 2009; Schminke und Miosge 2014). Weiterhin wurden SOX9 sowie RUNX2 als wichtige Mitspieler in der osteochondrogenen Differenzierung von MSCs identifiziert (Lefebvre und Smits 2005). Lefebvre et al. (1997) zeigten, dass SOX9 die Expression von Kollagen II über eine Bindung an einen Enhancer steigert. RUNX2 wurde als spezifischer Transkriptionsfaktor für die Osteogenese von MSCs des Knochenmarks erkannt (Xu et al. 2015). Koelling et al. (2009) zeigten, dass durch einen Knockdown von RUNX2 in CPCs deren chondrogenes Potential in vitro erhöht wird. Dabei kam es zu einer erhöhten Expression von SOX9 sowie zu einem vermehrten Nachweis von Kollagen II. 
Im Rahmen dieser Arbeit konnte gezeigt werden, dass sowohl SMURF1 als auch SMURF2 Einfluss auf die Expression von RUNX2 nehmen. Dabei wird eine signifikant verminderte Expression von RUNX2 in CPCht+SMURF1 sowie CPCht+SMURF2 erreicht. Die zudem beobachtete verminderte Expression von RUNX2 bei siRNAKnockdown von SMURF1 sowie SMURF2 weisen keine Signifikanz auf und wurden bereits diskutiert (siehe Kapitel 4.2 und Kapitel 4.3). Eine signifikante Korrelation zwischen dem relativen Proteingehalt von SMURF1/2 und dem Transkriptionsfaktor SOX9 konnte nicht gezeigt werden, wobei mit Ausnahme des relativen Proteingehalts von SOX9 in CPCht+SMURF1 in allen betrachteten Zelllinien ein inverses Verhalten von SOX9 zum relativen Proteingehalt von RUNX2 bei Betrachtung der Mittelwerte zu vermerken ist. Somit wird die gegenseitige Inhibition von RUNX2 und SOX9 auf Proteinebene, welche von Cheng und Genever (2010) in HEK-Zellen beschrieben wurde, bestätigt.

Die Ergebnisse zeigen, dass SMURF1 und SMURF2 das Proteinlevel von RUNX2 beeinflussen. Dabei führt die Überexpression von SMURF1 sowie SMURF2 zu einem verminderten Vorkommen von RUNX2 auf Proteinebene in CPCht. Es kann vermutet werden, dass RUNX2 hierbei durch SMURF1/2 verstärkt ubiquitiniert und somit dem proteasomalen Abbau zugeführt wird. Daraus kann geschlossen werden, dass die Expression von SMURF1/2 in der chondrogenen Differenzierung von CPCs eine Rolle spielt und deren Überexpression das chondrogene Potential von CPCs stärken könnte.

Eine Dysregulation von Chondrozyten steht in direkter Verbindung mit Knorpeldegeneration im Rahmen einer OA (Shen et al. 2014). TGF- $\beta$ ist dabei in allen Stadien der Chondrogenese sowie an der Homöostase der Chondroyzten beteiligt (van der Kraan et al. 2012). Weiterhin nehmen BMPs Einfluss auf die Differenzierung von Chondrozyten (Green et al. 2015). SMADs sind intrazelluläre Mediatoren des TGF- $\beta$ sowie BMP-Signalwegs (Massagué 1998). Finnson et al. (2010) zeigten, dass eine vermehrte Phosphorylierung und damit Aktivierung von SMAD1/5 bei gleichzeitig verminderter Phosphorylierung von SMAD2/3 zu einer verringerten Produktion von Kollagen II sowie zu einer vermehrten Produktion von Kollagen I führt. Dies hat ein vermindertes chondrogenes Potential humaner Chondrozyten zur Folge.

Weiterhin konnte gezeigt werden, dass SMURF1 die Expression von SMAD1 sowie SMAD2/3 in CPCht beeinflusst. Daraus kann geschlossen werden, dass SMURF1 eine Rolle in der Differenzierung von Chondrozyten spielt. Die Ergebnisse zeigen, dass ein 
Knockdown von SMURF1 zu einer signifikant verminderten Expression von SMAD1 sowie zu einer signifikant vermehrten Expression von SMAD2/3 führt. Die Überexpression von SMURF1 führt zu einem inversen Effekt für SMAD2/3, wobei dieser statistisch nicht signifikant ist. Eine Beurteilung des Einflusses der Überexpression von SMURF1 auf das Proteinlevel von SMAD1 in CPCht ist mit den vorliegenden Ergebnissen nicht möglich.

Ein Knockdown von SMURF1 in CPCs könnte demnach zu einer vermehrten Expression von SMAD2/3 sowie zu einer verminderten Expression von SMAD1 führen, womit das chondrogene Potential und damit die Regenerationsfähigkeit des hyalinen Gelenkknorpels verbessert werden könnte. Diese mechanistische Überlegung steht allerdings im Widerspruch zu der zuvor formulierten Hypothese, dass die Überexpression von SMURF1 sowie SMURF2 zu einem erhöhten chondrogenen Potential beitragen könnte, da hierdurch RUNX2 vermindert sowie SOX9 vermehrt exprimiert würde. Ob die Verminderung von RUNX2 entweder durch direkte Wechselwirkung mit überexpremiertem SMURF1/2 oder durch einen Shift von SMAD1 zu SMAD2/3 in CPCs durch SMURF1-Knockdown zu einer vermehrten Produktion von Kollagen II und somit zur Steigerung des chondrogenen Potentials von CPCs führt, kann mit den vorliegenden Ergebnissen nicht abschließend beurteilt werden.

\subsection{Funktionen von SMURF1 und SMURF2 in OA}

OA ist eine degenerative Gelenkerkrankung, die alle Strukturen der Gelenke betrifft (Loeser et al. 2012). Dabei können auf zellulärer wie mikroskopischer Ebene pathologische Prozesse beobachtet werden, die einem konstanten Muster folgen (Goldring und Goldring 2010; Cucchiarini et al. 2016).

SOX9 und RUNX2 scheinen bei der Entstehung der OA eine relevante Rolle zu spielen (Schminke und Miosge 2014). So zeigten Wang et al. (2004), dass eine vermehrte Expression von RUNX2 zu einer erhöhten Aktivität von MMP-13 und damit vermutlich zu einer Progression der OA führt. Eine erhöhte Expression von SOX9 hingegen scheint die chondrogene Differenzierung von MSCs zu fördern und ist mit einer vermehrten Produktion von Kollagen II sowie Aggrecan assoziiert (Zhong et al. 2015). Zudem stellten Schminke und Miosge (2014) fest, dass der Knockdown von RUNX2 in CPCs zu einer verstärkten Expression von SOX9 sowie Kollagen II führte. Mehrere 
Untersuchungen weisen darauf hin, dass ein Shift von SOX9 zu RUNX2 die Entwicklung hypertropher Chondrozyten im hyalinen Knorpel begünstigt und somit die Progression der OA fördert (Zhong et al. 2015; Kerkhofs et al. 2016). Zhong et al. (2016) zeigten ebenfalls eine Korrelation zwischen einer verminderten Expression von SOX9, Aggrecan sowie Kollagen II und der Progression der OA mit einhergehender verstärkter Expression von RUNX2 und Kollagen X.

SMADs spielen als intrazelluläre Mediatoren der TGF- $\beta$ - sowie BMP-Signalkaskade (Shen et al. 2014) eine entscheidende Rolle in der Homöostase der Chondrozyten des hyalinen Knorpels sowie in der Entwicklung der OA (Finnson et al. 2010). So stellten Valdes et al. (2010) eine signifikante Korrelation zwischen einem EinzelnukleotidPolymorphismus (SNP) des SMAD3-Genabschnitts und Hüft- sowie Knieosteoarthrose fest und bestätigten damit die Ergebnisse des Mausmodells von Yang et al. (2001). Dieser zeigte, dass Mäuse mit einer Mutation im SMAD3-Genabschnitt OA entwickeln. Zudem scheinen SMAD-unabhängige TGF- $\beta$-Signalkaskaden ebenfalls Einfluss auf die Entwicklung einer OA zu nehmen. So zeigten Aref-Eshghi et al. (2015) für humanen osteoarthrotischen Knorpel, dass MMP13, eine Matrix-Metalloprotease, die mit einer irreversiblen Schädigung des Gelenkknorpels assoziiert wird (Loeser et al. 2012), unabhängig von SMAD3 vermehrt exprimiert wird. Weiterhin untersuchten Zhao et al. (2016) die Rolle von SMADs in der Entwicklung von OA bei Dunkin-HarleyHausmeerschweinchen und fanden einen Shift von SMAD2/3 zu SMAD1/5/8 bei Fortschreiten der OA. Die Überexpression von SMURF2 in transgenen Mäusen führte zur spontanen Entwicklung einer OA und zu einem verminderten Vorkommen von pSMAD3 (Wu et al. 2008). In einem Mausmodell mit einer SMURF2-Defizienz untersuchten Huang et al. (2016) die Entwicklung von OA in immortalisierten Chondrozyten und fanden eine vermehrte Expression von SOX9, Kollagen II und Aggrecan sowie ein erhöhtes Proteinlevel von SMURF1 bei Behandlung mit TGF- $\beta 3$. Histologisch konnte in dieser Untersuchung jedoch kein Unterschied zwischen SMURF2-defizienten Mäusen und der Kontrollgruppe bezüglich der Entwicklung einer OA festgestellt werden.

Die im Rahmen dieser Arbeit erfassten Ergebnisse bestätigen die Vermutung, dass SMADs sowie SOX9 und RUNX2 auf Proteinebene durch SMURF1/2 beeinflusst werden. Bei Zusammenschau der Ergebnisse kann die Hypothese aufgestellt werden, dass ein Knockdown von SMURF1 sowie eine Überexpression von SMURF2 das 
chondrogene Potential von CPCs in humanem hyalinen Gelenkknorpel stärken könnte, womit ein Ansatz zur Behandlung der OA entwickelt werden könnte. Der Knockdown von SMURF1 führt zu einer Erhöhung des chondrogenen Markers SOX9 sowie von SMAD2/3, dessen vermehrtes Vorkommen ebenfalls mit einer Verstärkung des chondrogenen Potentials von MPCs assoziiert wurde (Muhammad et al. 2014). Damit einhergehend wird eine Verringerung des osteogenen Markers RUNX2 sowie SMAD1 in CPCht-SMURF1 gezeigt. Deren vermehrtes Vorkommen wird mit der Progression der OA assoziiert (Zhao et al. 2016). Die Ergebnisse für SOX9 sowie RUNX2 in CPChtSMURF1 weisen jedoch keine Signifikanz auf, wodurch die Interpretation dieser Ergebnisse erschwert ist. Die Überexpression von SMURF2 führt zu einer signifikant verminderten Expression von RUNX2, jedoch zu keiner nachweisbaren Erhöhung des chondrogenen Potentials durch Erhöhung des Proteinlevels von SOX9.

Die inversen Modulationen von SMURF1/2, also die Überexpression von SMURF1 sowie der Knockdown von SMURF2, führen nicht zu inversen Ergebnisse bei Betrachtung der Proteinlevel von SOX9, RUNX2 und SMADs. Diese Abweichungen der Ergebnisse von den erwarteten Werten wurden bereits zuvor diskutiert. Hervorzuheben ist, dass sowohl eine Überexpression von SMURF1 als auch eine Überexpression von SMURF2 zu einem signifikant erhöhten Proteinlevel von RUNX2, einem Schlüsselfaktor der osteogenen Differenzierung (Xu et al. 2015), führen. Hierbei spielt wohl der direkte Abbau von RUNX2 durch SMURF1/2, der bereits von Zhao et al. (2003) sowie Kaneki et al. (2006) beschrieben wurde, eine entscheidende Rolle. Inwiefern dieser Abbau durch die Verminderung des osteogenen Potentials von CPCs zur Stärkung deren chondrogenen Potentials und damit zur Erhöhung der regenerativen Fähigkeiten des hyalinen Gelenkknorpels letztlich zur Behandlung der OA beitragen kann, bleibt in nachfolgenden Untersuchungen zu beantworten. 


\section{Zusammenfassung}

$O A$ ist eine degenerative Gelenkerkrankung, die sich durch einen zunehmenden Verlust des Gelenkknorpels auszeichnet. Dabei beschreibt OA nicht ausschließlich pathologische Veränderungen des Gelenkknorpels, sondern vielmehr eine Erkrankung des gesamten Gelenks. Im Jahr 2020 wird die OA voraussichtlich eine der vier Hauptursachen für krankheitsbedingte körperliche Beeinträchtigungen weltweit sein, womit die epidemiologische Bedeutung dieser Erkrankung unterstrichen wird.

Im Krankheitsverlauf führen körpereigene Reparaturmechanismen zu der Bildung eines fibrokartilaginären Ersatzgewebes, das jedoch weder in seiner molekularen Struktur noch in seinen mechanischen Eigenschaften ein adäquater Ersatz für hyalinen Gelenkknorpel darstellt. CPCs sind Teil dieses Umbauprozesses, besitzen Stammzelleigenschaften sowie die Fähigkeit, hyaline Matrixproteine zu bilden. Aufgrund dieses chondrogenen Regenerationspotentials könnten CPCs als Ansatzpunkt für eine regenerative Therapie der OA geeignet sein.

Im Rahmen der vorliegenden Arbeit konnten erstmals die intrazellulären Enzyme SMURF1 und SMURF2, die einen funktionellen Teil des UPS bilden, in primären CPCs auf Proteinebene nachgewiesen werden. Zudem konnten erstmals SMURF1/2 in CPCht immunzytologisch sowie auf mRNA- und Proteinebene nachgewiesen werden. Immunhistochemisch war ein Nachweis von SMURF1/2 in osteoarthrotischem Gewebe ebenfalls möglich. Es konnte gezeigt werden, dass SMADs als Mediatoren des TGF- $\beta$ - sowie BMP-Signalwegs sowie der Transkriptionsfaktor RUNX2, der als Schlüsselfaktor in der Entstehung einer $O A$ vermutet wird, durch SMURF1/2 beeinflusst werden. Ein Einfluss von SMURF1/2 auf das Proteinlevel von SOX9 zeigte sich statistisch nicht signifikant. Statistisch signifikant waren die Ergebnisse für SMAD1 und SMAD2/3 bei Knockdown von SMURF1 sowie die Ergebnisse für RUNX2 bei Überexpression von SMURF1 in CPCht. So wurde in CPCht-SMURF1 eine verminderte Expression von SMAD1 sowie ein erhöhte Expression von SMAD2/3 nachgewiesen. In CPCht+SMURF1 sowie CPCht+SMURF2 wurde jeweils eine verminderte Expression von RUNX2 gezeigt. 
SMURF1/2 greifen demnach an verschiedenen Punkten der untersuchten Signalkaskaden an. Es wird vermutet, dass diese Signalwege eine Rolle bei der Entstehung einer OA sowie bei der Regeneration des hyalinen Gelenkknorpels spielen. Ein Knockdown von SMURF1 in CPCs könnte durch einen Shift von SMAD1 zu SMAD2/3 das chondrogene Potential und damit die Regenerationsfähigkeit des hyalinen Gelenkknorpels steigern. Jedoch zeigt sich auch eine Verminderung des osteogenen Potentials bei Überexpression von SMURF1 sowie SMURF2 durch eine verminderte Expression von RUNX2, welche jedoch nicht mit einem gesteigerten chondrogenen Potential einhergeht. Welche der beiden beschriebenen Mechanismen zur Steigerung der Synthese von Kollagen II sowie Aggrecan, die in osteoarthrotischem Knorpelgewebe vermindert gebildet werden, beiträgt und somit in der Behandlung der OA einen pharmakologischen Angriffspunkt liefern könnte, bedarf weiterer Untersuchungen. 


\section{Literaturverzeichnis}

Altman R, Asch E, Bloch D, Bole G, Borenstein D, Brandt K, Christy W, Cooke TD, Greenwald R, Hochberg M (1986): Development of criteria for the classification and reporting of osteoarthritis. Classification of osteoarthritis of the knee. Diagnostic and Therapeutic Criteria Committee of the American Rheumatism Association. Arthritis Rheum 29, 1039-1049

Aref-Eshghi E, Liu M, Harper PE, Doré J, Martin G, Furey A, Green R, Rahman P, Zhai $G$ (2015): Overexpression of MMP13 in human osteoarthritic cartilage is associated with the SMAD-independent TGF- $\beta$ signalling pathway. Arthritis Res Ther $\underline{17}, 264$

Arora K, Warrior R (2001): A new Smurf in the village. Dev Cell 1 , 441-442

Asano Y, Ihn H, Yamane K, Kubo M, Tamaki K (2004): Impaired Smad7-Smurfmediated negative regulation of TGF-beta signaling in scleroderma fibroblasts. J Clin Invest $\underline{113}$, 253-264

Attisano L, Lee-Hoeflich ST (2001): The Smads. Genome Biol 2, reviews3010.1reviews 3010.8

Bizet AA, Tran-Khanh N, Saksena A, Liu K, Buschmann MD, Philip A (2012): CD109mediated degradation of TGF- $\beta$ receptors and inhibition of TGF- $\beta$ responses involve regulation of SMAD7 and Smurf2 localization and function. J Cell Biochem 113, 238-246

Blagojevic M, Jinks C, Jeffery A, Jordan KP (2010): Risk factors for onset of osteoarthritis of the knee in older adults: a systematic review and meta-analysis. Osteoarthr Cartil 18, 24-33

Buckwalter JA, Mankin HJ (1998): Articular cartilage: tissue design and chondrocytematrix interactions. Instr Course Lect $\underline{47}, 477-486$

Buckwalter JA, Mankin HJ, Grodzinsky AJ (2005): Articular cartilage and osteoarthritis. Instr Course Lect 54, 465-480

Burch ML, Zheng W, Little PJ (2011): Smad linker region phosphorylation in the regulation of extracellular matrix synthesis. Cell Mol Life Sci $\underline{68}, 97-107$

Cao Y, Zhang L (2013): A Smurf1 tale: function and regulation of an ubiquitin ligase in multiple cellular networks. Cell Mol Life Sci $\underline{70}, 2305-2317$

Cheng A, Genever PG (2010): SOX9 determines RUNX2 transactivity by directing intracellular degradation. J Bone Miner Res $\underline{25}$, 2680-2689 
Choi YH, Kim Y-J, Jeong HM, Jin Y-H, Yeo C-Y, Lee KY (2014): Akt enhances Runx2 protein stability by regulating Smurf2 function during osteoblast differentiation. FEBS J 281, 3656-3666

Chong PA, Lin H, Wrana JL, Forman-Kay JD (2010): Coupling of tandem Smad ubiquitination regulatory factor (Smurf) WW domains modulates target specificity. Proc Natl Acad Sci USA 107, 18404-18409

Cucchiarini M, Madry H, Guilak F, Saris DB, Stoddart MJ, Koon Wong M, Roughley P (2014): A vision on the future of articular cartilage repair. Eur Cell Mater 27, 1216

Cucchiarini M, de Girolamo L, Filardo G, Oliveira JM, Orth P, Pape D, Reboul P (2016): Basic science of osteoarthritis. J Exp Orthop $\underline{3}, 22$

David D, Nair SA, Pillai MR (2013): Smurf E3 ubiquitin ligases at the cross roads of oncogenesis and tumor suppression. Biochim et Biophys Acta (BBA) $\underline{1835}$, $119-128$

Derynck R, Zhang YE (2003): Smad-dependent and Smad-independent pathways in TGF- $\beta$ family signalling. Nature $\underline{425}, 577-584$

Eames BF, Sharpe PT, Helms JA (2004): Hierarchy revealed in the specification of three skeletal fates by Sox9 and Runx2. Dev Biol 274, 188-200

Ebisawa T, Fukuchi M, Murakami G, Chiba T, Tanaka K, Imamura T, Miyazono K (2001): Smurf1 Interacts with Transforming Growth Factor- $\beta$ Type I Receptor through Smad7 and Induces Receptor Degradation. J Biol Chem 276, 1247712480

Englund M, Guermazi A, Gale D, Hunter DJ, Aliabadi P, Clancy M, Felson DT (2008): Incidental meniscal findings on knee MRI in middle-aged and elderly persons. N Engl J Med 359, 1108-1115

Fan W, Li J, Wang Y, Pan J, Li S, Zhu L, Guo C, Yan Z (2016): CD105 promotes chondrogenesis of synovium-derived mesenchymal stem cells through Smad2 signaling. Biochem Biophys Res Commun 474, 338-344

Felson DT, Lawrence RC, Dieppe PA, Hirsch R, Helmick CG, Jordan JM, Kington RS, Lane NE, Nevitt MC, Zhang Y, et al. (2000): Osteoarthritis: new insights. Part 1: the disease and its risk factors. Ann Intern Med 133, 635-646

Finnson KW, Parker WL, Chi Y, Hoemann CD, Goldring MB, Antoniou J, Philip A (2010): Endoglin differentially regulates TGF- $\beta$-induced Smad2/3 and Smad1/5 signalling and its expression correlates with extracellular matrix production and cellular differentiation state in human chondrocytes. Osteoarthr Cartil 18, 15181527

Fisher GJ, Shao Y, He T, Qin Z, Perry D, Voorhees JJ, Quan T (2016): Reduction of fibroblast size/mechanical force down-regulates TGF- $\beta$ type II receptor: implications for human skin aging. Aging Cell $\underline{15}, 67$ 
Fukunaga E, Inoue Y, Komiya S, Horiguchi K, Goto K, Saitoh M, Miyazawa K, Koinuma D, Hanyu A, Imamura T (2008): Smurf2 Induces Ubiquitin-dependent Degradation of Smurf1 to Prevent Migration of Breast Cancer Cells. J Biol Chem 283, 35660-35667

Gari MA, AlKaff M, Alsehli HS, Dallol A, Gari A, Abu-Elmagd M, Kadam R, Abuzinadah MF, Gari M, Abuzenadah AM, et al. (2016): Identification of novel genetic variations affecting osteoarthritis patients. BMC Med Genet 17, 68

Goldring MB, Goldring SR (2010): Articular cartilage and subchondral bone in the pathogenesis of osteoarthritis. Ann N Y Acad Sci 1192, 230-237

Gong B, Radulovic M, Figueiredo-Pereira ME, Cardozo C (2016): The UbiquitinProteasome System: Potential Therapeutic Targets for Alzheimer's Disease and Spinal Cord Injury. Front Mol Neurosci $\underline{9}, 4$

Green JD, Tollemar V, Dougherty M, Yan Z, Yin L, Ye J, Collier Z, Mohammed MK, Haydon RC, Luu HH, et al. (2015): Multifaceted signaling regulators of chondrogenesis: Implications in cartilage regeneration and tissue engineering. Genes Dis 2, 307-327

Guilak F, Alexopoulos LG, Upton ML, Youn I, Choi JB, Cao L, Setton LA, Haider MA (2006): The pericellular matrix as a transducer of biomechanical and biochemical signals in articular cartilage. Ann N Y Acad Sci 1068, 498-512

Guo R, Yamashita M, Zhang Q, Zhou Q, Chen D, Reynolds DG, Awad HA, Yanoso L, Zhao L, Schwarz EM, et al. (2008): Ubiquitin ligase Smurf1 mediates tumor necrosis factor-induced systemic bone loss by promoting proteasomal degradation of bone morphogenetic signaling proteins. J Biol Chem $\underline{283}$, 23084-23092

Hardmeier R, Redl H, Marlovits S (2010): Effects of mechanical loading on collagen propeptides processing in cartilage repair. J Tissue Eng Regen Med 4, 1-11

He B, Wu JP, Kirk TB, Carrino JA, Xiang C, Xu J (2014): High-resolution measurements of the multilayer ultra-structure of articular cartilage and their translational potential. Arthritis Res Ther $\underline{16}, 205$

Heinegård D, Saxne T (2011): The role of the cartilage matrix in osteoarthritis. Nat Rev Rheumatol $\underline{7}, 50-56$

Hershko A, Ciechanover A (1998): The Ubiquitin System. Annu Rev Biochem 67, 425479

Hill CL, Seo GS, Gale D, Totterman S, Gale ME, Felson DT (2005): Cruciate ligament integrity in osteoarthritis of the knee. Arthritis Rheum $\underline{52}, 794-799$

Homrich M, Gotthard I, Wobst H, Diestel S (2015): Cell Adhesion Molecules and Ubiquitination-Functions and Significance. Biology (Basel) $\underline{5}, 1$ 
Houard X, Goldring MB, Berenbaum F (2013): Homeostatic mechanisms in articular cartilage and role of inflammation in osteoarthritis. Curr Rheumatol Rep 15, 375

Huang H, Veien ES, Zhang H, Ayers DC, Song J (2016): Skeletal Characterization of Smurf2-Deficient Mice and In Vitro Analysis of Smurf2-Deficient Chondrocytes. PLOS ONE 11, e0148088

Huang L, Chen $\mathrm{CH}$ (2009): Proteasome regulators: activators and inhibitors. Curr Med Chem 16, 931-939

Huber M, Trattnig S, Lintner F (2000): Anatomy, biochemistry, and physiology of articular cartilage. Invest Radiol $\underline{35}, 573-580$

Inoue Y, Imamura T (2008): Regulation of TGF-beta family signaling by E3 ubiquitin ligases. Cancer Sci $\underline{99}$, 2107-2112

Johnson VL, Hunter DJ (2014): The epidemiology of osteoarthritis. Best Pract Res Clin Rheumatol $\underline{28}, 5-15$

Johnstone B, Alini M, Cucchiarini M, Dodge GR, Eglin D, Guilak F, Madry H, Mata A, Mauck RL, Semino CE, Stoddart MJ (2013): Tissue engineering for articular cartilage repair-the state of the art. Eur Cell Mater 25, 248-267

Jordan KM, Arden NK, Doherty M, Bannwarth B, Bijlsma JWJ, Dieppe P, Gunther K, Hauselmann H, Herrero-Beaumont G, Kaklamanis P, et al. (2003): EULAR Recommendations 2003: an evidence based approach to the management of knee osteoarthritis: Report of a Task Force of the Standing Committee for International Clinical Studies Including Therapeutic Trials (ESCISIT). Ann Rheum Dis $\underline{62}, 1145-1155$

Kaneki H, Guo R, Chen D, Yao Z, Schwarz EM, Zhang YE, Boyce BF, Xing L (2006): Tumor Necrosis Factor Promotes Runx2 Degradation through Up-regulation of Smurf1 and Smurf2 in Osteoblasts. J Biol Chem 281, 4326-4333

Kavsak P, Rasmussen RK, Causing CG, Bonni S, Zhu H, Thomsen GH, Wrana JL (2000): Smad7 binds to Smurf2 to form an E3 ubiquitin ligase that targets the TGF beta receptor for degradation. Mol Cell $\underline{6}, 1365-1375$

Kawakami Y, Rodriguez-León J, Izpisúa Belmonte JC (2006): The role of TGFbetas and Sox9 during limb chondrogenesis. Curr Opin Cell Biol $\underline{18}$, 723-729

Kerkhofs J, Leijten J, Bolander J, Luyten FP, Post JN, Geris L (2016): A Qualitative Model of the Differentiation Network in Chondrocyte Maturation: A Holistic View of Chondrocyte Hypertrophy. PLoS ONE 11, e0162052

Khedgikar V, Kushwaha P, Gautam J, Verma A, Changkija B, Kumar A, Sharma S, Nagar GK, Singh D, Trivedi PK, et al. (2013): Withaferin A: a proteasomal inhibitor promotes healing after injury and exerts anabolic effect on osteoporotic bone. Cell Death Dis $\underline{4}$, e778 
Koelling S, Kruegel J, Irmer M, Path JR, Sadowski B, Miro X, Miosge N (2009): Migratory Chondrogenic Progenitor Cells from Repair Tissue during the Later Stages of Human Osteoarthritis. Cell Stem Cell 4, 324-335

van der Kraan PM, Blaney Davidson EN, Blom A, van den Berg WB (2009): TGF-beta signaling in chondrocyte terminal differentiation and osteoarthritis: Modulation and integration of signaling pathways through receptor-Smads. Osteoarthr Cartil 17, 1539-1545

van der Kraan PM, Goumans M-J, Blaney Davidson E, ten Dijke P (2012): Agedependent alteration of TGF- $\beta$ signalling in osteoarthritis. Cell Tissue Res $\underline{347}$, 257-265

Kreuz PC, Steinwachs MR, Erggelet C, Krause SJ, Konrad G, Uhl M, Südkamp N (2006): Results after microfracture of full-thickness chondral defects in different compartments in the knee. Osteoarthr Cartil $\underline{14}, 1119-1125$

Kuettner KE (1992): Biochemistry of articular cartilage in health and disease. Clin Biochem 25, 155-163

Laemmli UK (1970): Cleavage of structural proteins during the assembly of the head of bacteriophage T4. Nature 227, 680-685

Lahm A, Kasch R, Spank H, Erggelet C, Esser J, Merk H, Mrosek E (2014): Correlation between 3D microstructural and 2D histomorphometric properties of subchondral bone with healthy and degenerative cartilage of the knee joint. Histol Histopathol 29, 1477-1488

Lecker SH, Goldberg AL, Mitch WE (2006): Protein Degradation by the UbiquitinProteasome Pathway in Normal and Disease States. J Am Soc Nephrol 17, 1807-1819

Lee H-L, Park H-J, Kwon A, Baek K, Woo KM, Ryoo H-M, Kim G-S, Baek J-H (2014): Smurf1 plays a role in EGF inhibition of BMP2-induced osteogenic differentiation. Exp Cell Res $\underline{323}$, 276-287

Lefebvre V, Smits P (2005): Transcriptional control of chondrocyte fate and differentiation. Birth Defects Res C Embryo Today $\underline{75}$, 200-212

Lefebvre V, Huang W, Harley VR, Goodfellow PN, de Crombrugghe B (1997): SOX9 is a potent activator of the chondrocyte-specific enhancer of the pro alpha1(II) collagen gene. Mol Cell Biol 17, 2336-2346

Li T-F, Darowish M, Zuscik MJ, Chen D, Schwarz EM, Rosier RN, Drissi H, O'Keefe RJ (2006): Smad3-Deficient Chondrocytes Have Enhanced BMP Signaling and Accelerated Differentiation. J Bone Miner Res 21, 4-16

Loeser RF, Goldring SR, Scanzello CR, Goldring MB (2012): Osteoarthritis: A disease of the joint as an organ. Arthritis Rheum $\underline{64}, 1697-1707$ 
Lohmander LS, Roos EM (2007): Clinical update: treating osteoarthritis. Lancet $\underline{370}$, 2082-2084

Lu K, Li P, Zhang M, Xing G, Li X, Zhou W, Bartlam M, Zhang L, Rao Z, He F (2011): Pivotal role of the $\mathrm{C} 2$ domain of the Smurf1 ubiquitin ligase in substrate selection. J Biol Chem 286, 16861-16870

Madry $\mathrm{H}$, Cucchiarini $\mathrm{M}$ (2014): Tissue-engineering strategies to repair joint tissue in osteoarthritis: nonviral gene-transfer approaches. Curr Rheumatol Rep $\underline{16}, 450$

Madry H, van Dijk CN, Mueller-Gerbl M (2010): The basic science of the subchondral bone. Knee Surg Sports Traumatol Arthrosc 트, 419-433

Mancuso CA, Ranawat CS, Esdaile JM, Johanson NA, Charlson ME (1996): Indications for total hip and total knee arthroplasties. J Arthroplasty 11, 34-46

Massagué J (1998): TGF-beta signal transduction. Annu Rev Biochem $\underline{67}, 753-791$

McMahon LA, O’Brien FJ, Prendergast PJ (2008): Biomechanics and mechanobiology in osteochondral tissues. Regen Med $\underline{3}, 743-759$

Metzger MB, Hristova VA, Weissman AM (2012): HECT and RING finger families of E3 ubiquitin ligases at a glance. J Cell Sci $\underline{125}, 531-537$

Michael JW-P, Schlüter-Brust KU, Eysel P (2010): The Epidemiology, Etiology, Diagnosis, and Treatment of Osteoarthritis of the Knee. Dtsch Arztebl Int 107, 152

Miosge N, Hartmann M, Maelicke C, Herken R (2004): Expression of collagen type I and type II in consecutive stages of human osteoarthritis. Histochem Cell Biol $\underline{122}, 229-236$

Miyazono K, Kamiya Y, Morikawa M (2010): Bone morphogenetic protein receptors and signal transduction. J Biochem $\underline{147}, 35-51$

Muhammad H, Schminke B, Miosge N (2013): Current concepts in stem cell therapy for articular cartilage repair. Expert Opin Biol Ther 13, 541-548

Muhammad H, Schminke B, Bode C, Roth M, Albert J, von der Heyde S, Rosen V, Miosge N (2014): Human Migratory Meniscus Progenitor Cells Are Controlled via the TGF- $\beta$ Pathway. Stem Cell Reports $\underline{3}$, 789-803

Muller S, Breederveld RS, Tuinebreijer WE (2010): Results of osteochondral autologous transplantation in the knee. Open Orthop $\mathrm{J} \underline{4}, 111-114$

Mundlos S, Otto F, Mundlos C, Mulliken JB, Aylsworth AS, Albright S, Lindhout D, Cole WG, Henn W, Knoll JH, et al. (1997): Mutations involving the transcription factor CBFA1 cause cleidocranial dysplasia. Cell $\underline{89}, 773-779$ 
Murakami G, Watabe T, Takaoka K, Miyazono K, Imamura T (2003): Cooperative Inhibition of Bone Morphogenetic Protein Signaling by Smurf1 and Inhibitory Smads. Mol Biol Cell 14, 2809-2817

Nakano A, Koinuma D, Miyazawa K, Uchida T, Saitoh M, Kawabata M, Hanai J, Akiyama H, Abe M, Miyazono K, et al. (2009): Pin1 down-regulates transforming growth factor-beta (TGF-beta) signaling by inducing degradation of Smad proteins. J Biol Chem 284, 6109-6115

Nie J, Xie P, Liu L, Xing G, Chang Z, Yin Y, Tian C, He F, Zhang L (2010): Smad Ubiquitylation Regulatory Factor $1 / 2$ (Smurf1/2) Promotes p53 Degradation by Stabilizing the E3 Ligase MDM2. J Biol Chem 285, 22818-22830

Nogales E, Wolf SG, Downing KH (1998): Structure of the $\alpha \beta$ tubulin dimer by electron crystallography. Nature $\underline{391}, 199-203$

Oegema TR, Carpenter RJ, Hofmeister F, Thompson RC (1997): The interaction of the zone of calcified cartilage and subchondral bone in osteoarthritis. Microsc Res Tech $\underline{37}, 324-332$

Orvedahl A, Sumpter R, Xiao G, Ng A, Zou Z, Tang Y, Narimatsu M, Gilpin C, Sun Q, Roth $M$, et al. (2011): Image-based genome-wide siRNA screen identifies selective autophagy factors. Nature $\underline{480}, 113-117$

Otto F, Thornell AP, Crompton T, Denzel A, Gilmour KC, Rosewell IR, Stamp GW, Beddington RS, Mundlos S, Olsen BR, et al. (1997): Cbfa1, a candidate gene for cleidocranial dysplasia syndrome, is essential for osteoblast differentiation and bone development. Cell $\underline{89}, 765-771$

Pauli C, Grogan SP, Patil S, Otsuki S, Hasegawa A, Koziol J, Lotz MK, D'Lima DD (2011): Macroscopic and histopathologic analysis of human knee menisci in aging and osteoarthritis. Osteoarthr Cartil 19, 1132-1141

Perera JR, Gikas PD, Bentley G (2012): The present state of treatments for articular cartilage defects in the knee. Ann R Coll Surg Engl 94, 381-387

Peterson L, Brittberg M, Kiviranta I, Akerlund EL, Lindahl A (2002): Autologous chondrocyte transplantation. Biomechanics and long-term durability. Am J Sports Med $\underline{30}, 2-12$

Pfaffl MW (2001): A new mathematical model for relative quantification in real-time RTPCR. Nucleic Acids Res $\underline{29}$, e45

Pombo-Suarez M, Calaza M, Gomez-Reino JJ, Gonzalez A (2008): Reference genes for normalization of gene expression studies in human osteoarthritic articular cartilage. BMC Mol Biol $\underline{9}, 17$

Poole CA, Flint MH, Beaumont BW (1987): Chondrons in cartilage: ultrastructural analysis of the pericellular microenvironment in adult human articular cartilages. J Orthop Res $\underline{5}, 509-522$ 
Pritzker KPH, Gay S, Jimenez SA, Ostergaard K, Pelletier J-P, Revell PA, Salter D, van den Berg WB (2006): Osteoarthritis cartilage histopathology: grading and staging. Osteoarthr Cartil 14, 13-29

Qin BY, Chacko BM, Lam SS, de Caestecker MP, Correia JJ, Lin K (2001): Structural Basis of Smad1 Activation by Receptor Kinase Phosphorylation. Mol Cell $\underline{8}$, 1303-1312

Rabenberg M: Arthrose. Gesundheitsberichterstattung des Bundes. (Heft 54); Berlin 2013

Sadatsuki R, Kaneko H, Kinoshita M, Futami I, Nonaka R, Culley KL, Otero M, Hada S, Goldring MB, Yamada Y, et al. (2017): Perlecan is required for the chondrogenic differentiation of synovial mesenchymal cells through regulation of Sox9 gene expression. J Orthop Res $\underline{35}$, 837-846

Schminke B, Miosge N (2014): Cartilage Repair In Vivo: The Role of Migratory Progenitor Cells. Curr Rheumatol Rep $\underline{16}, 1-8$

Schneider CA, Rasband WS, Eliceiri KW (2012): NIH Image to ImageJ: 25 years of image analysis. Nat Methods $\underline{9}, 671-675$

Shen J, Li S, Chen D (2014): TGF- $\beta$ signaling and the development of osteoarthritis. Bone Res $\underline{2}, 14002$

Shen R, Chen M, Wang Y-J, Kaneki H, Xing L, O'keefe RJ, Chen D (2006): Smad6 interacts with Runx2 and mediates Smad ubiquitin regulatory factor 1 -induced Runx2 degradation. J Biol Chem 281, 3569-3576

Sophia Fox AJ, Bedi A, Rodeo SA (2009): The basic science of articular cartilage: structure, composition, and function. Sports Health 1, 461-468

Spahn G (2007): Knorpelschaden und Gonarthrose, Teil IV. Aktuelle Traumatol $\underline{37}$, 16-30

Suresh B, Lee J, Kim K-S, Ramakrishna S (2016): The Importance of Ubiquitination and Deubiquitination in Cellular Reprogramming. Stem Cells Int 2016, 6705927

Suzuki C, Murakami G, Fukuchi M, Shimanuki T, Shikauchi Y, Imamura T, Miyazono $\mathrm{K}$ (2002): Smurf1 regulates the inhibitory activity of Smad7 by targeting Smad7 to the plasma membrane. J Biol Chem 277, 39919-39925

Tesche F, Miosge N (2005): New aspects of the pathogenesis of osteoarthritis: the role of fibroblast-like chondrocytes in late stages of the disease. Histol Histopathol $\underline{20}, 329-337$

Tramutola A, Di Domenico F, Barone E, Perluigi M, Butterfield DA (2016): It Is All about (U)biquitin: Role of Altered Ubiquitin-Proteasome System and UCHL1 in Alzheimer Disease. Oxid Med Cell Longev 2016, 2756068 
Valdes AM, Spector TD, Tamm A, Kisand K, Doherty SA, Dennison EM, Mangino M, Tamm A, Kerna I, Hart DJ, et al. (2010): Genetic variation in the SMAD3 gene is associated with hip and knee osteoarthritis. Arthritis Rheum $\underline{62}, 2347-2352$

Vandesompele J, De Preter K, Pattyn F, Poppe B, Van Roy N, De Paepe A, Speleman F (2002): Accurate normalization of real-time quantitative RT-PCR data by geometric averaging of multiple internal control genes. Genome Biol $\underline{3}$, RESEARCH0034

Vishal M, Vimalraj S, Ajeetha R, Gokulnath M, Keerthana R, He Z, Partridge NC, Selvamurugan N (2017): MicroRNA-590-5p Stabilizes Runx2 by Targeting Smad7 During Osteoblast Differentiation. J Cell Physiol 232, 371-380

Vos T, Flaxman AD, Naghavi M, Lozano R, Michaud C, Ezzati M, Shibuya K, Salomon JA, Abdalla S, Aboyans V, et al. (2012): Years lived with disability (YLDs) for 1160 sequelae of 289 diseases and injuries 1990-2010: a systematic analysis for the Global Burden of Disease Study 2010. Lancet $\underline{380}$, 2163-2196

Wang X, Manner PA, Horner A, Shum L, Tuan RS, Nuckolls GH (2004): Regulation of MMP-13 expression by RUNX2 and FGF2 in osteoarthritic cartilage. Osteoarthr Cartil $\underline{12}$, 963-973

Wegner M (1999): From head to toes: the multiple facets of Sox proteins. Nucleic Acids Res 27, 1409-1420

Wiesner S, Ogunjimi AA, Wang H-R, Rotin D, Sicheri F, Wrana JL, Forman-Kay JD (2007): Autoinhibition of the HECT-type ubiquitin ligase Smurf2 through its C2 domain. Cell $\underline{130}, 651-662$

Wolff JH (1995): Julius Wolff und sein Gesetz der Transformation der Knochen. Orthopade 24, 378-386

Woolf AD, Pfleger B (2003): Burden of major musculoskeletal conditions. Bull World Health Organ $\underline{81}, 646-656$

Woolf AD, Erwin J, March L (2012): The need to address the burden of musculoskeletal conditions. Best Pract Res Clin Rheumatol 26, 183-224

Wrana JL, Attisano L (2000): The Smad pathway. Cytokine Growth Factor Rev 11, 513

Wu Q, Kim K-O, Sampson ER, Chen D, Awad H, O'Brien T, Puzas JE, Drissi H, Schwarz EM, O'Keefe RJ, et al. (2008): Induction of an Osteoarthritis-like Phenotype and Degradation of Phosphorylated Smad3 bySmurf2 in Transgenic Mice. Arthritis Rheum $\underline{58}, 3132-3144$

Wuelling M, Vortkamp A (2010): Transcriptional networks controlling chondrocyte proliferation and differentiation during endochondral ossification. Pediatr Nephrol 25, 625-631 
Wunderle VM, Critcher R, Hastie N, Goodfellow PN, Schedl A (1998): Deletion of longrange regulatory elements upstream of SOX9 causes campomelic dysplasia. Proc Natl Acad Sci USA $\underline{95}$, 10649-10654

Xu J, Li Z, Hou Y, Fang W (2015): Potential mechanisms underlying the Runx2 induced osteogenesis of bone marrow mesenchymal stem cells. Am J Transl Res $\underline{7}$, 2527-2535

Yamaguchi A, Komori T, Suda T (2000): Regulation of osteoblast differentiation mediated by bone morphogenetic proteins, hedgehogs, and Cbfa1. Endocr Rev $\underline{21}, 393-411$

Yang K, Tang X-D, Guo W, Xu X-L, Ren T-T, Ren C-M, Wang S-D, Bao X, Zhang F, Sun K-K (2016): BMPR2-pSMAD1/5 signaling pathway regulates RUNX2 expression and impacts the progression of dedifferentiated chondrosarcoma. Am J Cancer Res $\underline{6}, 1302-1316$

Yang X, Chen L, Xu X, Li C, Huang C, Deng CX (2001): TGF-beta/Smad3 signals repress chondrocyte hypertrophic differentiation and are required for maintaining articular cartilage. J Cell Biol 153, 35-46

Ying S-X, Hussain ZJ, Zhang YE (2003): Smurf1 Facilitates Myogenic Differentiation and Antagonizes the Bone Morphogenetic Protein-2-induced Osteoblast Conversion by Targeting Smad5 for Degradation. J Biol Chem 278, 3902939036

Zhang Y, Wang C, Cao Y, Gu Y, Zhang L, Zhang Y, Wang C, Cao Y, Gu Y, Zhang L (2016): Selective compounds enhance osteoblastic activity by targeting HECT domain of ubiquitin ligase Smurf1. Oncotarget $\underline{8}, 50521-50533$

Zhao M, Qiao M, Oyajobi BO, Mundy GR, Chen D (2003): E3 Ubiquitin Ligase Smurf1 Mediates Core-binding Factor a1/Runx2 Degradation and Plays A Specific Role in Osteoblast Differentiation. J Biol Chem 278, 27939-27944

Zhao W, Wang T, Luo Q, Chen Y, Leung VYL, Wen C, Shah MF, Pan H, Chiu K, Cao $X$, Lu WW (2016): Cartilage degeneration and excessive subchondral bone formation in spontaneous osteoarthritis involves altered TGF- $\beta$ signaling. $J$ Orthop Res $\underline{34}$, 763-770

Zhong L, Huang X, Karperien M, Post JN (2015): The Regulatory Role of Signaling Crosstalk in Hypertrophy of MSCs and Human Articular Chondrocytes. Int J Mol Sci $\underline{16}$, 19225-19247

Zhong L, Huang X, Karperien M, Post JN (2016): Correlation between Gene Expression and Osteoarthritis Progression in Human. Int J Mol Sci 17, 1126

Zhou N, Li Q, Lin X, Hu N, Liao J-Y, Lin L-B, Zhao C, Hu Z-M, Liang X, Xu W, et al. (2016): BMP2 induces chondrogenic differentiation, osteogenic differentiation and endochondral ossification in stem cells. Cell Tissue Res $\underline{366}, 101-111$ 
Zhu H, Kavsak P, Abdollah S, Wrana JL, Thomsen GH (1999): A SMAD ubiquitin ligase targets the BMP pathway and affects embryonic pattern formation. Nature $\underline{400}$, $687-693$ 


\section{Danksagung}

An dieser Stelle möchte ich meinen Dank an Herrn Prof. Dr. med. Nicolai Miosge für die herausragende und kontinuierliche Betreuung dieser Dissertation richten. Insbesondere für die freundliche Aufnahme in sein Team sowie für die Möglichkeit, einen Einblick in die experimentelle medizinische Forschung zu gewinnen.

Weiterhin bedanke ich mich herzlich bei Frau Christa Bode und Frau Andrea Bernhard für die geduldige, unermüdliche und lehrreiche Einarbeitung sowie Betreuung des praktischen Teils dieser Arbeit.

Für viele unterhaltsame Stunden im Labor und anregende Diskussionen bedanke ich mich bei meinen Kommilitoninnen und Kommilitonen Theresa, Katharina, Thomas, Philipp und Gökhan.

Für viele Stunden Korrekturlesen bedanke ich mich bei Katharina Schillo und Julian Dülk. 